\title{
GFPT2/GFAT2 and AMDHD2 act in tandem to control the hexosamine pathway.
}

Virginia Kroef ${ }^{1 *}$, Sabine Ruegenberg ${ }^{1,2 *}$, Moritz Horn ${ }^{1,3}$, Kira Allmeroth ${ }^{1}$, Lena Ebert $^{4,5,6}$, Seyma Bozkus ${ }^{2}$, Stephan Miethe ${ }^{1}$, Ulrich Elling ${ }^{7}$, Bernhard Schermer ${ }^{4,5,6}$, Ulrich Baumann ${ }^{2}$, Martin S. Denzel ${ }^{1,5,6}$

\author{
${ }^{1}$ Max Planck Institute for Biology of Ageing \\ D-50931 Cologne, Germany \\ ${ }^{2}$ Institute of Biochemistry \\ University of Cologne \\ D-50674 Cologne, Germany \\ ${ }^{3} \mathrm{JLP}$ Health $\mathrm{GmbH}$ \\ A-1130 Vienna, Austria and \\ Acus Laboratories $\mathrm{GmbH}$ \\ D-50931 Cologne, Germany
}

${ }^{4}$ Department II of Internal Medicine

University of Cologne

Faculty of Medicine and University Hospital Cologne

D-50931 Cologne, Germany

${ }^{5}$ Center for Molecular Medicine Cologne (CMMC)

Faculty of Medicine and University Hospital Cologne

University of Cologne

D-50931 Cologne, Germany

${ }^{6}$ CECAD - Cluster of Excellence

Faculty of Medicine and University Hospital Cologne

University of Cologne

D-50931 Cologne, Germany

${ }^{7}$ IMBA - Institute of Molecular Biotechnology of the Austrian Academy of Science

Vienna Biocenter

A-1030 Vienna, Austria

*These authors contributed equally

correspondence:

mdenzel@age.mpg.de 


\section{Abstract}

2 The hexosamine biosynthetic pathway (HBP) produces the essential metabolite

3 UDP-GlcNAc and plays a key role in metabolism, health, and aging. The HBP is 4 controlled by its rate-limiting enzyme glutamine fructose-6-phosphate

5 amidotransferase (GFPT/GFAT) that is directly inhibited by UDP-GIcNAc in a 6 feedback loop. HBP regulation by GFPT is well studied but other HBP 7 regulators have remained obscure. Elevated UDP-GlcNAc levels counteract the 8 glycosylation toxin tunicamycin (TM) and thus we screened for TM resistance in 9 haploid mouse embryonic stem cells (mESCs) using random chemical 10 mutagenesis to determine alternative HBP regulation. We identified the $11 \mathrm{~N}$-acetylglucosamine deacetylase AMDHD2 that catalyzes a reverse reaction in 12 the HBP and its loss strongly elevated UDP-GlcNAc. To better understand into the HBP. 
Introduction

25 The hexosamine biosynthetic pathway (HBP) is an anabolic branch of glycolysis consuming about $2-3 \%$ of cellular glucose ${ }^{1,2}$. It provides substrates for various posttranslational modification (PTM) reactions and has been strongly associated with stress resistance and longevity as well as cell growth and transformation ${ }^{3-5}$. Thus, the HBP plays an essential role for metabolic adaptations and cellular homeostasis ${ }^{6}$.

In the first and rate limiting step of the HBP, glutamine fructose-6-phosphate amidotransferase (GFPT) converts fructose-6-phosphate (Frc6P) and L-glutamine (L-Gln) to D-glucosamine-6-phosphate $(\mathrm{GlcN} 6 \mathrm{P})^{2}$. The two mammalian GFPT paralogs GFPT1 and GFPT2 show 75-80\% amino acid sequence identity ${ }^{7}$. While GFPT1 is ubiquitously expressed, GFPT2 is reported to be predominantly expressed in the nervous system. Notably, GlcN6P can be converted to Frc6P by glucosamine-6-phosphate deaminase 1 and 2 (GNPDA1/2), shunting metabolites back into glycolysis ${ }^{8}$. In the second step of the HBP, glucosamine-phosphate N-acetyltransferase (GNA1) acetylates GlcN6P to N-acetylglucosamine-6-phosphate (GlcNAc-6P) using acetyl-CoA as uridine 5'-diphosphate-N-acetyl-D-galactosamine (UDP-GalNAc) by the enzyme 
UDP-HexNAc ${ }^{14}$. The HBP is the only source for UDP-GIcNAc and relies on

50 substrates from carbon, nitrogen, fatty-acid, and energy metabolism. It is therefore optimally positioned as a metabolic sensor that can modulate downstream cellular signaling through UDP-GlcNAc dependent PTMs ${ }^{1}$.

UDP-GlcNAc is a precursor of several important biomolecules such as chitin, peptidoglycans, glycosaminoglycans, and for a number of dynamic glycosylation events. Mucin-type O-glycosylation plays an important role in the extracellular matrix ${ }^{15}$. N-linked-glycosylation orchestrates protein folding in the endoplasmic reticulum (ER) and is therefore crucial in protein homeostasis ${ }^{16}$. $\mathrm{N}$-glycans further contribute to the cell surface glycocalyx as structural components of proteins ${ }^{17}$. Finally, the addition of single GlcNAc moieties to Thr/Ser residues, termed O-GlcNAcylation, occurs dynamically on hundreds of proteins, thus modulating a variety of downstream pathways ${ }^{18}$. Surprisingly, this dynamic PTM is accomplished by a single protein, O-GlcNAc transferase $(\mathrm{OGT})$, and O-GlcNAcase (OGA) is the only known enzyme to remove O-GIcNAc modifications ${ }^{19,20}$. While it is known that these glycosylation reactions are limited by intracellular UDP-GIcNAc, how the HBP is regulated to adapt UDP-GlcNAc levels according to nutrient availability is poorly understood. Due to the diverse function of UDP-GIcNAc, alterations in its abundance can have detrimental effects resulting in pathological conditions like diabetes, cancer, cardiovascular diseases, and neurodegenerative diseases ${ }^{1,21-23}$.

In a previous chemical mutagenesis screen in Caenorhabditis elegans we isolated mutants resistant to the toxin tunicamycin (TM) as a proxy for enhanced protein quality control and found that TM resistant mutants were enriched for longevity ${ }^{3}$. TM is a competitive inhibitor of UDP- 
74 GlcNAc:dolichylphosphate GlcNAc-1-phosphotransferase (GPT), which catalyzes the first step of $\mathrm{N}$-glycan synthesis utilizing UDP-GlcNAc ${ }^{24}$. TM thus disrupts $\mathrm{N}$-glycosylation and leads to proteins misfolding and proteotoxic stress $^{16}$. We found that single amino acid substitutions in GFPT1 result in gainof-function due to loss of UDP-GlcNAc feedback inhibition, elevating cellular UDP-GIcNAc levels and thereby counteracting TM toxicity ${ }^{25}$. By introducing the same gain-of-function mutation in GFPT1 of mouse neuroblastoma Neuro2a (N2a) cells, we confirmed a conserved mechanism ${ }^{26}$, suggesting that screening for TM resistance might be a suitable unbiased means to analyze the HBP through genetic approaches in mammalian cells. Based on this knowledge, we aimed to identify novel regulators of the HBP in mammalian cells, which could serve as potential drug targets for future therapeutic interventions. In this study, we combined chemical mutagenesis with whole exome sequencing in haploid murine cells and identified the $\mathrm{N}$-acetylglucosamine-6phosphate deacetylase AMDHD2 (Amidohydrolase Domain Containing 2) as a novel regulator of the HBP. Through AMDHD2 deletion, we discovered a 90 configuration of the HBP that uses GFPT2 as the key enzyme. Functionally, 91 GFPT2 shows a lower sensitivity to UDP-GIcNAc feedback inhibition compared to GFPT1 therefore requiring AMDHD2 to balance HBP metabolic flux. 
Chemical mutagenesis screen for tunicamycin resistance in haploid mESCs identifies AMDHD2 toxicity, making TM resistance a proxy for HBP activity in genetic screens. To investigate $\mathrm{HBP}$ regulation in mammalian cells we therefore performed an unbiased TM resistance screen. The mutagen N-ethyl-N-nitrosourea (ENU) induces single nucleotide variants that enable a screen at amino acid resolution. Thus, we used ENU in haploid cells, which uniquely enable identification of recessive alleles ${ }^{27-29}$. In order to reach a high degree of saturation, 27 million AN3-12 mouse embryonic stem cells (mESCs) were used for mutagenesis. This was followed by TM selection using a WT lethal dose $(0.5 \mu \mathrm{g} / \mathrm{ml})$ for three weeks (Figure $1 \mathrm{~A}) .29$ resistant clones were randomly selected and picked to grow isogenic mutant lines. Whole exome sequencing was done with four clones, which showed strong TM resistance (Figure 1-figure supplement 1A). Two clones revealed independent missense mutations in the Amdhd2 coding sequence (Figure 1-figure supplement 1B). A second round of whole exome sequencing of the remaining 25 clones revealed in total 11 independent amino acid substitutions at 10 distinct positions in Amdhd2 (38\% of sequenced clones) (Figure 1B, Figure 1-figure supplement 1B). Surprisingly we did not identify any mutations in the HBP's rate limiting enzymes Gfpt1 or Gfpt2. In addition, we performed a random insertional mutagenesis screen using an enhanced gene trapping system, which was previously established in haploid mESCs (Figure 1-figure supplement $1 \mathrm{C})^{30}$. After selection for TM resistance and mapping of the insertion site by Sanger sequencing, we identified Amdhd2 
118 in 4 of the 20 analyzed clones (Figure 1C, Figure 1-figure supplement 1C).

119 Since disruption of the Amdhd2 locus by transgene insertion was sufficient to 120 mediate TM resistance, we concluded that the identified mutations are loss-of121 function mutations. To corroborate that Amdhd2 disruption leads to TM 122 resistance we generated Amdhd2 KO mutants in diploid WT AN3-12 cells using 123 CRISPR/Cas9. We generated and validated a specific AMDHD2 antibody, 124 which confirmed a successful KO of AMDHD2 (Figure 1D). To exclude off target effects, we generated three independent Amdhd2 KO lines using distinct guide combinations. All homozygous Amdhd2 KO cells showed significant TM resistance compared to WT cells, confirming AMDHD2 loss-of-function as causal for TM resistance (Figure 1E,F, Figure 1-figure supplement 1D).

Disruption of Amdhd2 mediates tunicamycin resistance via elevated HBP 130 flux

AMDHD2 is an amidohydrolase that plays a potential role in the HBP by catalyzing the deacetylation of GlcNAc-6P in the "reverse" direction of the pathway ${ }^{31}$. However, a role of AMDHD2 in modulating cellular UDP-GIcNAc levels has not been recognized before. We hypothesized that AMDHD2 loss-offunction might increase UDP-GIcNAc levels leading to TM resistance (Figure 2A). To test this, we measured UDP-GlcNAc levels via ionic chromatography/mass spectrometry (IC-MS) and found that TM resistant mutants identified in the insertional mutagenesis screen (clone 1-4) as well as the CRISPR/Cas9-generated AMDHD2 KO mutants showed a significant 140 increase in UDP-GlcNAc concentrations (Figure 2B, Figure 2-figure supplement 1). These data indicate that the TM resistance is mediated by elevated HBP product availability due to reduced catabolism of GlcNAc-6P. To 
143 further corroborate a causal role of AMDHD2 mutation in elevated UDP-GIcNAc 144 levels and the accompanying TM resistance, we performed rescue experiments 145 with N-terminally FLAG-HA-tagged human AMDHD2 (hAMDHD2). We compared the expression of WT hAMDHD2 and, based on information from the bacterial homolog $\mathrm{N}$-acetylglucosamine-6-phosphate deacetylase $(\mathrm{NagA})^{32}$, a

potential catalytically inactive mutant with a D294A substitution (hAMDHD2 D294A) in control WT and AMDHD2 KO mESCs (Figure 2-figure supplement 2A, B). Overexpression of WT or mutant hAMDHD2 did not affect UDP-GIcNAc levels or TM resistance in WT mESCs (Figure 2C, D). However, in AMDHD2 KO cells only re-expression of functional WT hAMDHD2 reduced UDP-GIcNAc levels, while overexpression of the inactive hAMDHD2 D294A mutant still resulted in significantly elevated UDP-GlcNAc levels compared to WT cells. This observation was functionally supported by TM resistance assays using the same cell lines; overexpression of mutant hAMDHD2 D294A in the AMDHD2 KO background had no effect, but expression of WT hAMDHD2 reduced TM resistance. Together, these data emphasize the relevance of functional AMDHD2 for HBP activity and they show that AMDHD2 deletion results in TM resistance via increased HBP activity.

To better understand the physiological consequences of HBP activation through AMDHD2 regulation, we disrupted the Amdhd2 locus to generate a $\mathrm{KO}$ mouse (Figure 2-figure supplement 2A-C). Although the Amdhd2 mutation distributed in Mendelian ratios in the offspring, no viable homozygous $A m d h d 2 \mathrm{KO}$ pups were weaned (Figure 2E), indicating a recessive mutation. Heterozygous animals however, did not show any macroscopic changes, although further analysis is still missing and alterations on a behavioral, anatomical, histological or 
molecular level cannot be excluded. Homozygous Amdhd2 KO embryos showed early embryonic lethality, indicating an essential function of AMDHD2 during development. Taken together, we identified AMDHD2 as novel regulator of the HBP important in mESCs and for embryonic development.

\section{Structural and biochemical characterization of human AMDHD2}

Until now, no structure of eukaryotic AMDHD2 was available and functional properties of human AMDHD2 remain largely unexplored. Therefore, we performed a structural and a biochemical characterization of human AMDHD2. Initial apo AMDHD2 crystals diffracted poorly and no structure could be solved.

Based on homology to bacterial NagA, human AMDHD2 is likely to bind a divalent cation in the active site, potentially stabilizing the protein and supporting co-crystallization. Consequently, we analyzed the stabilizing effect of several divalent cations. Addition of $\mathrm{CoCl}_{2}, \mathrm{NiCl}_{2}$, and $\mathrm{ZnCl}_{2}$ to the SEC buffer increased the thermal stability of AMDHD2 by $3-4^{\circ} \mathrm{C}$ (Figure $3 \mathrm{~A}$ ). Moreover, we tested the influence of $\mathrm{CoCl}_{2}, \mathrm{NiCl}_{2}$, and $\mathrm{ZnCl}_{2}$ on the deacetylase activity of AMDHD2. For that purpose, the metal co-factor of AMDHD2 was first removed by incubation with EDTA and then $\mathrm{CoCl}_{2}, \mathrm{NiCl}_{2}$, or $\mathrm{ZnCl}_{2}$ were added back. Addition of $\mathrm{MgCl}_{2}$ served as negative control, while an untreated AMDHD2 was used as positive control. Both $\mathrm{CoCl}_{2}$ and $\mathrm{ZnCl}_{2}$ restored and $\mathrm{ZnCl}_{2}$ even increased AMDHD2 activity (Figure 3B). Thus, $\mathrm{Co}^{2+}$ or $\mathrm{Zn}^{2+}$ might be the metal co-factor in human AMDHD2. We next tested co-crystallization of AMDHD2 with $\mathrm{ZnCl}_{2}$ or $\mathrm{CoCl}_{2}$. While no crystals formed in the presence of $\mathrm{CoCl}_{2}$, the cocrystallization with $\mathrm{ZnCl}_{2}$ yielded needle clusters in several conditions. Optimized crystals diffracted to a resolution limit of $1.84 \AA$ (AMDHD2 $+Z n)$ or $1.90 \AA$ (AMDHD2 + Zn + GlcN6P). The data collection and refinement statistics 
are summarized in Table 1. Human AMDHD2 is organized in two domains, a deacetylase domain responsible for the conversion of GlcNAc-6P into GlcN6P and a second small domain with unknown function (DUF) (Figure 3C, Figure 3figure supplement 1 ). Residues from both the $\mathrm{N}$-terminus and the C-terminus contribute to the DUF domain. The structure of AMDHD2 was almost completely modeled into the electron density map except for some $\mathrm{N}$-terminal (1-5) and C-terminal residues (407-409). In the asymmetric unit, AMDHD2 forms a dimer through direct interactions of the deacetylase domains with an interface of $1117 \AA^{2}$ and this dimeric assembly was judged as biological relevant by the EPPIC server ${ }^{33}$. Although the dimer is formed by a rather small interface, this conformation is supported by the crystallographic B-factors, which show low values at the interface, indicating a mutual stabilization (Figure 3figure supplement 2) and by dynamic light scattering (DLS) measurements, confirming the presence of AMDHD2 dimers in solution (Figure 3-figure supplement 3). A comparison between both monomers from the dimer in the crystal revealed no major structural differences between monomer $A$ and monomer B (Figure 3-figure supplement 4). The structure of the deacetylase domain showed a TIM (triosephosphate isomerase) barrel-like fold (Figure 3D). A typical TIM-barrel has eight alternating $\beta$-strands and $\alpha$-helices forming a barrel shape where the parallel $\beta$-sheet builds the core that is surrounded by 213 the $\alpha$-helices. In AMDHD2, the eight alternating $\beta$-strands/a-helices are 214 interrupted after eight $\beta$-strands and seven $\alpha$-helices by an insertion of three antiparallel $\beta$-strands $(\beta 15-\beta 17)$, which form an additional $\beta$-sheet close to the active site (Figure 3C, Figure 3-figure supplement 5). In monomer B, this

$217 \beta$-sheet shows the highest crystallographic B-factors within the structure 
218 (Figure 3-figure supplement 2), indicating high flexibility and suggesting a 219 functional role as a lid to the active site. The DUF-domain consists of two $220 \beta$-sheets, which are composed of three or six antiparallel $\beta$-strands each, and two small $\alpha$-helices (Figure 3D). Together, these $\beta$-sheets form a $\beta$-sandwich. A superposition of the Zn-bound and the GlcN6P- and Zn-bound structures of AMDHD2 indicated no structural changes by the binding of the product (Figure 3-figure supplement 6). Residues from both monomers contribute to GlcN6P-binding (Figure 3E, Figure 3-figure supplement 7A). The phosphate group of the sugar is interacting via hydrogen bonds with Asn235 and Ala236, as well as ionic interactions to His242* and Arg243* of the other monomer (Figure 3E, Figure 3-figure supplement 7A,B). To assess a functional role of the residues His242* and Arg243*, and especially of the dimeric state on catalytic activity of AMDHD2, we generated the double mutant H242A/R243A and the mutants I280E and I280R, whose side chains might disrupt dimerization (Figure 3F). Analytical size-exclusion chromatography measurements confirmed the presence of monomeric I280E $(45.7 \pm 0.1 \mathrm{kDa})$ and monomeric I280R $(44.4 \pm 0.5 \mathrm{kDa})$ compared to dimeric wildtype AMDHD2 $(89.2 \pm 0.9 \mathrm{kDa})$ (Figure $3 \mathrm{G}, \mathrm{H}$ ). In contrast, the H242A/R243A substitution did not clearly disrupt dimerization $(79.4 \pm 0.8 \mathrm{kDa}) \quad$ (Figure $3 \mathrm{G}, \mathrm{H})$. Strikingly, I280E, I280R, and H242A/R243A showed no catalytic activity, supporting that AMDHD2 must form a dimer to be active and that the residues His242* and Arg243* are indispensable for catalytic activity. GlcN6P binding to the active site is further mediated by hydrogen bonds between the hydroxyl groups of GlcN6P with 241 Ala154 and His272. The catalytic $\mathrm{Zn}$ ion is coordinated via electrostatic 242 interactions with Glu143, His211, His232, and two water molecules, which in 
243 turn are stabilized by interactions with GlcN6P and several amino acid side 244 chains including Asp294 that might, based on the homology to bacterial NagA, 245 act as the catalytic base ${ }^{32}$ (Figure 3E, Figure 3-figure supplement 7A,B). We confirmed the presence of a single $\mathrm{Zn}$ ion in the human AMDHD2 active site by measuring an anomalous signal at the $\mathrm{Zn}-\mathrm{K}$ edge (Figure 3J). Given the conservation of all functional residues (Figure 3-figure supplement 8), the human AMDHD2 reaction mechanism is likely to be very similar to the proposed mechanism for the enzyme from E. coli ${ }^{32}$. In addition to GlcNAc-6P, bacterial NagAs are reported to use N-acetylgalactosamine-6-phosphate (GalNAc-6P) and $\mathrm{N}$-acetylglucosamine-6-sulphate (GlcNAc-6S) as substrates, albeit with increased $\mathrm{K}_{\mathrm{m}}$ values ${ }^{32,34}$. The high structural conservation of the side chains interacting with the sugar's C4 for GalNAc-6P or the phosphate group prompted us to test whether human AMDHD2 can catalyze the deacetylation of GalNAc-6P and GlcNAc-6S as well. Of note, we did not observe activity towards these $\mathrm{N}$-acetyl amino sugars that might be of physiological relevance (Figure 3figure supplement 9). In summary, our data show that human AMDHD2 is an obligate dimeric protein with high specificity for GlcNAc-6P that carries a single catalytic $\mathrm{Zn}$ ion in the active center.

\section{Characterization of AMDHD2 loss-of-function mutants}

We next characterized the eleven AMDHD2 substitutions from our screen and the putative active site mutant D294A to understand how they might affect the function of AMDHD2. Many AMDHD2 variants were soluble upon bacterial expression, including F146L, A154P, T185A, S208T, and D294A (Figure 4A). 
268 chain $\mathrm{NH}$ group to the $3-\mathrm{OH}$ group of the sugar (Figure 3E, Figure 3-figure supplement 7A,B). In contrast, no soluble expression could be achieved for AMDHD2 G102D, G130R, G226E, and G265V (Figure 4A, Figure 4-figure supplement 1). The substitution of the small, flexible glycine by charged and/or bigger residues are likely to be incompatible with the proper tertiary structure and/or the folding process, thus resulting in insoluble AMDHD2 protein variants that remain in the pellet fraction after sample lysis (Figure 4-figure supplement 1). The effect of the L142F mutation was even more severe as the substitution of Leu142 by the bigger phenylalanine resulted in AMDHD2 fragmentation (Figure 4A). Also, the I38T and G265R substitutions reduced soluble expression, indicating disturbed protein folding. We next tested the consequences of the I38T, T185A, G265R, and D294A substitutions on AMDHD2 activity. AMDHD2 T185A showed reduced activity and no activity was detected for G265R and D294A, while the third substitution, I38T, remained active (Figure 4C). This result indicates a functional role of Asp294 in the catalytic mechanism, confirming our idea that this substitution inactivates AMDHD2 and justifying its use in the rescue experiments (Figure 2C,D). Asp294 is likely to act as catalytic base that activates the nucleophilic water molecule together with the metal ion, and later protonating the leaving group ${ }^{32}$. Moreover, the I38T substitution is the only identified mutation from the screen that is located in the DUF domain of AMDHD2. It reduced bacterial AMDHD2 expression yields, suggesting impaired protein folding. This is likely to result in a loss-of-function in vivo, while the purified and soluble protein is active. Taken together, the structural and biochemical characterization of AMDHD2 revealed 
292 that loss-of-function and subsequent HBP activation resulted from folding

293 defects in AMDHD2 or it was caused by a loss of catalytic activity. 

enzyme

Having established that a loss of AMDHD2 function results in HBP activation, we wondered about the role of the HBP's rate limiting enzyme GFPT1. Under normal conditions, GFPT1 is constantly feedback inhibited by UDP-GIcNAc, crucially limiting HBP activity $^{25}$. A gain-of-function substitution in GFPT1 (G451E), however, increased HBP flux in nematodes and in murine cells, demonstrating a high degree of conservation ${ }^{26}$. In AN3-12 cells, the G451E gain-of-function substitution, introduced into the genomic locus by CRISPR/Cas9, as well as a Gfpt1 KO did not affect UDP-GlcNAc levels (Figure 5-figure supplement 1). While Gfpt1 is widely expressed across cell types, it is known that in some tissues Gfpt2 is the predominantly expressed paralog $^{7}$. Since loss of GFPT1 did not affect HBP activity, we hypothesized that GFPT2 instead of GFPT1 might control metabolite entry into the HBP in AN3-12 mESCs. Indeed, Gfpt2 mRNA was abundantly expressed in AN3-12 cells, while expression levels of Gfpt1 were comparatively low (Figure 5A). Next, we performed WB analysis using pure purified human GFPT and compared those to the GFPT abundance in various cell lines. GFPT2 was found abundantly expressed, while GFPT1 was difficult to detect in AN3-12 mESCs (Figure 5B). E14 mESCs likewise showed predominant GFPT2 expression and low GFPT1 abundance. In contrast, mouse neuronal N2a cells as well as muscle precursor C2C12 myoblasts showed predominant GFPT1 expression and GFPT2 was virtually undetectable. These data suggest a HBP configuration characterized by a high GFPT2:GFPT1 ratio in mESCs. 
318 To further investigate the possibility of ESC-specific HBP regulation, we next checked AMDHD2 levels in mESCs and compared them to cells using GFPT1 as the predominant first HBP enzyme. Mirroring GFPT2 levels, AMDHD2 protein abundance was higher in mESCs compared to $\mathrm{N} 2 a$ and $\mathrm{C} 2 \mathrm{C} 12$ cells (Figure $5 \mathrm{C}$ ). Moreover, the $\mathrm{KO}$ of AMDHD2 in AN3-12 mESCs resulted in a drastic elevation of UDP-GlcNAc levels, while the loss of AMDHD2 in N2a cells had no significant effect (Figure 5D). In accordance, the loss of AMDHD2 in C2C12 myoblasts was not sufficient to increase UDP-GlcNAc levels compared to control cells (Figure 5-figure supplement 2A-B). This indicates that AMDHD2 was constitutively active in AN3-12 cells, while the catalysis of the reverse flux of the HBP by AMDHD2 seemed to be negligible in $\mathrm{N} 2 a$ and $\mathrm{C} 2 \mathrm{C} 12$ cells. We therefore hypothesized that AMDHD2 plays a key role in the HBP when GFPT2 is its first enzyme instead of the more common GFPT1. Our previous data indicate that GFPT1 is under constant UDP-GIcNAc inhibition, sufficient for full suppression of GFPT1 activity ${ }^{25}$. We reasoned that higher UDP-GIcNAc levels in mESCs can only be achieved by differences in UDP-GlcNAc feedback inhibition between GFPT1 and GFPT2. To address this point, we generated recombinant human GFPT1 and GFPT2 with an internal $\mathrm{His}_{6}$ tag and characterized the proteins in activity assays (Figure 5E, Table 2, Figure 5-figure 43.6/+49,5 $\mu \mathrm{M})$ compared to GFPT1 (57.0 -8.3/+9.7 $\mu \mathrm{M})$ (Figure 5E, Table 2). 
343 GFPT1 and, second, that AMDHD2 plays a crucial role in balancing GFPT2-

344 mediated HBP flux. Consistent with lower feedback inhibition of GFPT2,

345 UDP-GIcNAc levels in AN3-12 and E14 mESCs were significantly higher than in N2a and C2C12 cells with a GFPT1-regulated HBP (Figure 5F). We also tested

347 protein O-GIcNAc modification, which relies on UDP-GIcNAc as a precursor 348 molecule, in the different cell lines via Western blot analysis with an O-GlcNAc specific antibody (RL2). Consistent with the elevated UDP-GlcNAc levels, we observed significantly higher O-GICNAc modification in mESCs. Of note, both

OGA and OGT were more abundant in the mESCs compared to $\mathrm{N} 2 \mathrm{a}$ and

C2C12 cells (Figure 5G-J). Overall, these data demonstrate a mESC-specific configuration of the HBP, relying on the co-expression of GFPT2 and AMDHD2.

This balance appears to be tuned to elevate UDP-GlcNAc levels and O-GlcNAc modification in ESCs.

Differentiation of ESCs induces an enzymatic reconfiguration of the HBP by reducing the GFPT2:GFPT1 ratio

In a next step, we asked if differentiation of mESC might affect the HBP's enzymatic configuration. For this, we removed leukemia inhibitory factor (LIF) from the medium, initiating differentiation ${ }^{35}$. LIF removal for five days resulted in partial differentiation of AN3-12 cells as indicated by a decrease of stem cell markers (Figure 6-figure supplement 1A). Of note, GFPT2 protein as well as Gfpt2 mRNA levels decreased significantly with LIF removal (Figure 6A,B). GFPT1 and AMDHD2 mRNA and protein levels did not change in this partial differentiation paradigm (Figure 6-figure supplement 1B-D). A decrease in the GFPT2:GFPT1 ratio upon differentiation was also observed in published datasets: relative GFPT2 mRNA and protein levels decrease during neuronal 
368 differentiation ${ }^{36}$ and during the differentiation in the cardiac lineage ${ }^{37,38}$ in 369 human ESCs (Figure 6C,D). 


\section{Discussion}

371 HBP activation increases cellular UDP-GlcNAc levels that protect from TM

372 toxicity $^{3}$. We used this knowledge to interrogate the HBP for additional regulators in a forward genetic TM resistance screen using haploid mammalian cells. Random chemical DNA mutagenesis at high saturation in haploid cells is a unique strategy to identify recessive mutations including those leading to single amino acid substitutions. Using this approach, we identified the $\mathrm{N}$-acetylglucosamine-6-phosphate deacetylase AMDHD2 as a novel regulator of the mammalian HBP. With an independent random insertional mutagenesis screen we confirmed the importance of AMDHD2 for regulating HBP activity and confirmed the role of AMDHD2 through rescue experiments. We next solved the first crystal structure of human AMDHD2 and noted that resistanceassociated substitutions disturb protein folding or cluster in the catalytic pocket, likely interfering with substrate binding or catalysis. Finally, we found that mESCs utilize GFPT2 for metabolite entry into the HBP instead of the more widely expressed GFPT1. GFPT2 is under considerably reduced UDP-GIcNAc feedback inhibition explaining why loss of AMDHD2 activity was sufficient for HBP activation without GFPT mutations (Figure 6E).

Chemical mutagenesis-based screening in haploid cells represents a powerful and unique technique. This approach allows to dissect the entire spectrum of mutations including loss-of-function, gain-of-function, and neomorph alleles and at the same time allows structure-function analyses due to its amino acid resolution $^{28}$. The additional use of haploid cells not only enables detection of dominant but also recessive mutations due to the lack of a remaining and interfering WT allele. Of note, identification of AMDHD2 as a novel regulator of 
395 the HBP was only possible in this specific setup since Amdhd2 mutations are recessive as shown in the AMDHD2 KO mouse.

397 Besides the function as GlcNAc-6P deacetylase, AMDHD2 was shown to be involved in the degradation of N-glycolylneuraminic acid (Neu5Gc) in mice and in human cell culture ${ }^{11,39}$. Nevertheless, mammalian AMDHD2 is rather 400 unstudied and most knowledge is based on the bacterial homolog NagA. NagA catalyzes the deacetylation reaction in the HBP, contributing to recycling of cell wall components such as GlcNAc. Since breakdown of GlcNAc can be used as an energy source by bacteria and fungi, NagA plays a crucial role in their energy metabolism ${ }^{40-43}$. For this reason, HBP enzymes are attractive selective targets for antifungal and antibiotic drugs ${ }^{44-47}$. While catabolism of amino sugars connects GlcNAc with other important metabolic pathways, AMDHD2 had not been implicated in a regulatory role of the HBP and cellular UDP-GIcNAc homeostasis.

After identification of AMDHD2 as a key modulator of the mammalian HBP, we structurally and biochemically characterized human AMDHD2. We solved the structure of human AMDHD2, the first reported eukaryotic structure of an AMDHD2 homolog and confirmed that human AMDHD2 is an obligate dimeric enzyme. Residues from both monomers contribute to ligand binding in the active site, while the residues important for catalysis originate from one monomer. The oligomeric state of AMDHD2 is therefore a plausible target to modulate its catalytic properties.

417 We showed that the mutations identified in the screen cause a loss-of-function in human AMDHD2 by disrupting its folding or activity (Figure 4). AMDHD2 is composed of a deacetylase domain and a small domain with unknown function 
420 (DUF). We identified only one mutation, I38T, within the DUF domain and this mutant showed diminished expression yields and low solubility, potentially explaining the loss-of-function. Nonetheless, the soluble fraction of AMDHD2 I38T was as active as wildtype AMDHD2 in activity assays, indicating that the DUF domain might be dispensable for catalysis.

Further characterizing the HBP, we noticed a surprising configuration of HBP enzymes in AN3-12 and E14 mESCs. While N2a cells and C2C12 myoblasts rely on GFPT1 as the key HBP enzyme, the mESCs use GFPT2 that is abundantly expressed (Figure 6E). Consistently, genetic manipulation of GFPT1 did not show any effect on UDP-GIcNAc levels in AN3-12 mESCs, while introducing the G451E gain-of-function mutation in GFPT1 of N2a cells leads to the previously reported boost of HBP activity ${ }^{26}$. Additionally, AMDHD2 abundance was higher in mESCs (Figure 5C). In accordance, the AMDHD2 KO in AN3-12 mESCs massively elevated UDP-GIcNAc levels, while the loss of AMDHD2 in N2a cells and C2C12 myoblasts had no significant impact. Under physiological conditions, GFPT1 is strongly inhibited by UDP-GICNAc ${ }^{25}$. In this scenario, as is the case in $\mathrm{N} 2 \mathrm{a}$ and $\mathrm{C} 2 \mathrm{C} 12$ cells, loss of the reverse flux by AMDHD2 KO showed no drastic effect on UDP-GlcNAc levels (Figure 6E). Moreover, we showed that GFPT2 has altered substrate affinities and is less susceptible to UDP-GlcNAc feedback inhibition. $\mathrm{N}$ - or C-terminal tags in GFPT disturb the catalytic function, therefore the GFPT preparations used here carry an internal tag for purification at a position that is reported not to interfere with 442 the kinetic properties of GFPT1 ${ }^{48}$. Studies with other tagging strategies reported 443 only a weak inhibition of GFPT2 by UDP-GIcNAc ${ }^{49,50}$. In contrast, we 
approximately 6-fold higher $\mathrm{IC}_{50}$ value compared to GFPT1. Overall, our data suggest that GFPT1 is sufficiently regulated by feedback inhibition to determine 447 HBP flux under physiological conditions. Cells using GFPT2 in the HBP, in contrast, rely on AMDHD2 to balance forward and reverse flux in the HBP. This HBP configuration might be a general adaptation of mESCs as we could show similar results for AN3-12 and E14 mESCs. Differentiation might result in a switch of GFPT expression and indeed partial differentiation of AN3-12 cells by LIF removal induced a significant decrease in GFPT2 levels. GFPT1 and AMDHD2 levels were not affected likely due to the early differentiation state. Analysis of published data confirmed that GFPT2 is highly expressed in human ESCs, and abundance decreased during neuronal or myocyte differentiation, indicating a conserved mechanism in human ESCs. Consistent with these findings, intestinal stem cells in Drosophila melanogaster likewise express GFPT2 ${ }^{51}$. One potential consequence of this metabolic adaptation in ESCs is a higher baseline UDP-GIcNAc concentration compared to cells that use GFPT1 to control the HBP. This increase in UDP-GIcNAc concentration might affect downstream PTMs, which in turn can influence cell signaling. In particular, O-GIcNAc modifications already have been linked to stemness and pluripotency $^{52,53}$. Indeed, we detected increased O-GlcNAc levels in mESCs compared to cells utilizing GFPT1 in the HBP. Of note, not only UDP-GlcNAc levels but also the two essential enzymes for O-GlcNAc cycling OGA/OGT where significantly increased in mESCs, indicating a multilayered mechanism of maintaining high O-GlcNAc levels in mESCs. Additional significance of an ESCspecific HBP configuration might come from an adaptation to their special nutrient and energy requirements. ESCs show a specialized metabolic profile 
470 that likely affect the concentrations of GFPT substrates ${ }^{54}$. The kinetic properties 471 of GFPT2 might reflect an adaption to substrate availability in ESCs. 472 Consistently, GFPT2 is also upregulated in other rapidly proliferating cells with 473 similar metabolic profiles, like in various types of cancer cells ${ }^{21,55-57}$.

474 Taken together, we identify AMDHD2 as a novel essential gene in embryonic 475 development and describe a cell type-specific role of AMDHD2 acting in tandem 476 with GFPT2 to regulate the HBP in ESCs. Tuning HBP metabolic activity is 477 relevant in cellular stress resistance, oncogenic transformation, growth, and in 478 age-related diseases as cancer, diabetes, cardiovascular diseases or 479 neurodegenerative diseases ${ }^{1,21-23}$. Of note, eukaryotic AMDHD2 was barely 480 characterized and the identification of its critical role in HBP regulation paves 481 the way for novel approaches to tackle age-associated pathologies, among 482 other potential interventions. Our work advances the understanding of HBP 483 control and provides specific means to beneficially affect these processes in the 484 future. 
486 Cell lines and culture conditions

487 AN3-12 mouse embryonic haploid stem cells were cultured as previously 488 described $^{27}$. In brief, DMEM high glucose (Sigma-Aldrich) was supplemented 489 with glutamine, fetal bovine serum (15\%), penicillin/streptomycin, non-essential amino acids, sodium pyruvate (all Thermo Fisher Scientific, Waltham, Massachusetts), $\beta$-mercaptoethanol and LIF (both Merck Millipore) and used to 492 culture cells at $37^{\circ} \mathrm{C}$ in $5 \% \mathrm{CO}_{2}$ on non-coated tissue culture plates. For partial 493 differentiation of AN3-12 cells, cells were seeded at a density of 2000-3000 cells/6-well and incubated for 5 days in medium without LIF. $\mathrm{N} 2 \mathrm{a}$ mouse neuroblastoma cells (RRID:CVCL_0470) and C2C12 (RRID:CVCL_0188) cells were cultured in DMEM containing $4.5 \mathrm{~g} / \mathrm{l}$ glucose

497 (Gibco) supplemented with 10\% fetal bovine serum (Gibco) and 498 penicillin/streptomycin at $37^{\circ} \mathrm{C}$ in $5 \% \mathrm{CO}_{2}$. No mycoplasma contamination was 499 detected.

\section{Cell sorting}

To maintain a haploid cell population cells were stained with $10 \mu \mathrm{g} / \mathrm{ml} \mathrm{Hoechst}$ 33342 (Thermo Fisher Scientific) for $30 \mathrm{~min}$ at $37^{\circ} \mathrm{C}$. To exclude dead cells propidium iodide (Sigma-Aldrich) staining was added. Cells were sorted for

504 DNA content on a FACSAria Fusion sorter and flow profiles were recorded with 505 the FACSDiva software (BD Franklin Lakes).

\section{Cell viability assay (XTT)}

507 Relative cell viability was assessed using the XTT cell proliferation Kit II (Roche 508 Diagnostics) according to the manufacturer's instructions. Tunicamycin 
509 treatments were performed for 48 hours, starting 24 hours after cell seeding.

510 XTT turnover was normalized to corresponding untreated control cells.

\section{ENU mutagenesis screen, exome sequencing, and analysis}

512 The screening procedure and the data analysis were extensively described

513 previously ${ }^{28}$. In brief, AN3-12 mouse embryonic haploid stem cells were

514 mutagenized with $0.01 \mathrm{mg} / \mathrm{ml}$ Ethylnitrosourea for $2 \mathrm{~h}$ at room temperature prior

515 to drug selection starting 24 hours post mutagenesis using $0.5 \mu \mathrm{g} / \mathrm{ml}$

516 tunicamycin (Merck-Milipore). After 21 days of drug selection, resistant clones

517 were isolated and subjected to tunicamycin cytotoxicity assays and gDNA

518 extraction using the Gentra Puregene Tissue Kit (Qiagen). Paired end, 150 bp

519 whole exome sequencing was performed on an Illumina Novaseq 6000

520 instrument after precapture-barcoding and exome capture with the Agilent

521 SureSelect Mouse All Exon kit. For data analysis, raw reads were aligned to the

522 reference genome mm9. Variants were identified and annotated using GATK

523 (v.3.4.46) and snpEff (v.4.2). Tunicamycin resistance causing alterations were

524 identified by allelism only considering variants with moderate or high effect on

525 protein and a read coverage $>10$.

526 Retroviral-based insertional mutagenesis screen and integration site $527 \quad$ mapping

528 The generation of a comprehensive cell bank of haploid AN3-12 cells, 529 containing insertions in 16.970 mouse genes, was already created and 530 described elsewhere ${ }^{58}$ (www.haplobank.at). In short, for retroviral library 531 generation enhanced gene-trap (EGT) viruses carrying a neomycin-resistance 532 cassette were packaged in PlatinumE (Cell Biolabs) cells. The virus was 533 concentrated by centrifugation (25,000 r.p.m., $4^{\circ} \mathrm{C}, 4 \mathrm{~h}$ ) and haploid mESCs 
534 were infected for $8 \mathrm{~h}$ in the presence of $2 \mu \mathrm{g} / \mathrm{ml}$ polybrene. Upon infection for $53530 \mathrm{~h}$, cells were treated with $0.2 \mathrm{mg} / \mathrm{ml} \mathrm{G418} \mathrm{(Gibco)} \mathrm{for} \mathrm{selection} \mathrm{of} \mathrm{gene-trap}$ 536 insertions. To estimate numbers of integrations 500.000 cells were plated on 15

$537 \mathrm{~cm}$ dishes, selected for integrations using G418 selection and colonies counted 538 after 10 days. For comparison, 5.000 cells were plated without selection. From 539 the barcoded AN3-12 Retro Library, 3 million cells were plated on $15 \mathrm{~cm}$ plates 540 and drug selection was performed for 21 days starting $24 \mathrm{~h}$ post mutagenesis 541 using $0.5 \mu \mathrm{g} / \mathrm{ml}$ tunicamycin (Merck Millipore). Resistant clones were isolated 542 and subjected to tunicamycin cytotoxicity assays. Mapping of the genomic 543 integration site was performed by inverse PCR. The genomic region was 544 amplified using the primers "DS" and "US" (primers are listed in Supplementary 545 File 1). The PCR reaction was analyzed on an agarose gel, purified and used 546 for Sanger Sequencing with primer "DS". Sequences were analyzed manually 547 with the USCS Genome Browser.

\section{Generation of stable cell lines}

549 For the generation of stable cell lines human AMDHD2 isoform 1 was integrated 550 into the FLAG-HA-pcDNA3.1 plasmid (RRID:Addgene_52535) using Xbal and 551 Hindlll restriction sites. Cell lines stably overexpressing hAMDHD2 variants 552 were generated by transfection of WT or AMDHD2 KO AN3-12 cells with FLAGHA-hAMDHD2-pcDNA3.1 plasmids. For each variant, a 6 well was transfected 554 with $4 \mu \mathrm{g}$ of plasmid DNA with Lipofectamine 2000 (Life Technologies ${ }^{\mathrm{TM}}$ ) 555 according to the manufacturer's protocol. The selection was performed with 556 $0.4 \mathrm{mg} / \mathrm{ml}$ G418 (Gibco) for several weeks. 
557

558

559

560

561

562

563

564

565

566

567

568

569

570

571

572

573

574

575

576

577

578

579

580

581

\section{Gene editing and genotyping by Sanger sequencing}

The specific GFPT1 G451E substitution as well as the KO of GFPT1 and AMDHD2 was engineered in AN3-12 cells (for the AMDHD2 KO also in N2a cells and $\mathrm{C} 2 \mathrm{C} 12$ cells) using the CRISPR/Cas9 technology as described previously ${ }^{59}$. DNA template sequences for small guide RNAs were designed online (http://crispor.org, Supplementary File 1), purchased from Sigma, and cloned into the Cas9-GFP expressing plasmid PX458 (RRID:Addgene_48138). Corresponding guide and Cas9 expressing plasmids were co-transfected with a single stranded DNA repair template (Integrated DNA technologies), using Lipofectamine 3000 (Thermo Fisher Scientific) according to manufacturer's instructions. For the AN3-12 cells three different AMDHD2 KO lines were generated, using different guide combinations (clone 1 = guide $1+2$, clone $2=$ guide $3+4$, clone $3=$ guide $1+5$ ). GFP positive cells were singled using FACSAria Fusion sorter and subjected to genotyping. DNA was extracted (DNA extraction solution, Epicentre Biotechnologies) and edited regions were specifically amplified by PCR (primers are listed in Supplementary File 1). Sanger sequencing was performed at Eurofins Genomics GmbH (Ebersberg, Germany).

\section{RNA isolation and qPCR}

Cells were collected in QIAzol (Qiagen) and snap frozen in liquid nitrogen. Samples were subjected to three freeze/thaw cycles (liquid nitrogen/ $37^{\circ} \mathrm{C}$ water bath) before addition of another half of the total QIAzol volume. After incubation for $5 \mathrm{~min}$ at RT, $200 \mu \mathrm{l}$ chloroform were added per $1 \mathrm{ml}$ QIAzol. Samples were vortexed, incubated for $2 \mathrm{~min}$ at RT, and centrifuged at $10.000 \mathrm{rpm}$ and $4^{\circ} \mathrm{C}$ for $15 \mathrm{~min}$. The aqueous phase was mixed with an equal volume of $70 \%$ ethanol 
and transferred to a RNeasy Mini spin column (Qiagen). The total RNA was isolated using the RNeasy Mini Kit (Qiagen) and cDNA was subsequently generated by iScript cDNA Synthesis Kit (BioRad). qPCR was performed with Power SYBR Green master mix (Applied Biosystems) on a ViiA 7 Real-Time PCR System (Applied Biosystems). GAPDH expression functioned as internal control. All used primers for qPCR analysis are listed in Supplementary File 1.

\section{Anion exchange chromatography mass spectrometry (IC-MS) analysis of} UDP-GICNAC and UDP-GaINAC

Cells were subjected to methanol:acetonitrile:mili-Q ultrapure water (40:40:20 [v:v:v]) extraction. UDP-GlcNAc and UDP-GalNAc (UDP-HexNAc) concentrations were measured using IC-MS analysis. Extracted metabolites were re-suspended in $500 \mu \mathrm{l}$ of Optima LC/MS grade water (Thermo Fisher Scientific) of which $100 \mu$ were transferred to polypropylene autosampler vials (Chromatography Accessories Trott, Germany). The samples were analyzed using a Dionex ionchromatography system (ICS5000, Thermo Fisher Scientific) connected to a triple quadrupole MS (Waters, TQ). In brief, $10 \mu \mathrm{l}$ of the metabolite extract were injected in full loop mode using an overfill factor of 3 , onto a Dionex lonPac AS11-HC column $(2 \mathrm{~mm} \times 250 \mathrm{~mm}, 4 \mu \mathrm{m}$ particle size, Thermo Scientific) equipped with a Dionex IonPac AG11-HC guard column (2 mm $\times 50 \mathrm{~mm}, 4 \mu \mathrm{m}$, Thermo Scientific). The column temperature was held at $30^{\circ} \mathrm{C}$, while the auto sampler was set to $6^{\circ} \mathrm{C}$. The metabolite separation was carried using a $\mathrm{KOH}$ gradient at a flow rate of $380 \mu \mathrm{l} / \mathrm{min}$, applying the following gradient conditions: 0-8 min, 30-35 mM KOH; 8-12 min, 35-100 mM KOH; $12-$ $15 \mathrm{~min}, 100 \mathrm{mM} \mathrm{KOH}, 15-15.1 \mathrm{~min}, 10 \mathrm{mM} \mathrm{KOH}$. The column was reequilibrated at $10 \mathrm{mM}$ for $4 \mathrm{~min}$. UDP-HexNAcs were detected using multiple 
607 reaction monitoring (MRM) mode with the following settings: capillary voltage $2.7 \mathrm{kV}$, desolvation temperature $550^{\circ} \mathrm{C}$, desolvation gas flow $800 \mathrm{l} / \mathrm{h}$, collision cell gas flow $0.15 \mathrm{ml} / \mathrm{min}$. The transitions for UDP-GalNAc, as well as for UDP-GlcNAc were m/z $606[\mathrm{M}-\mathrm{H}+]+$ for the precursor mass and m/z 385 [M$\mathrm{H}+]+$ for the first and $\mathrm{m} / \mathrm{z} 282[\mathrm{M}-\mathrm{H}+]+$ for the second transition mass. The cone voltage was set to $46 \mathrm{~V}$ and the collision energy was set to $22 \mathrm{~V}$. UDP-GalNAc eluted at $10.48 \mathrm{~min}$ and UDP-GIcNAc eluted at $11.05 \mathrm{~min}$. MS data analysis was performed using the TargetLynx Software (Version 4.1, Waters). Absolute compound concentrations were calculated from response curves of differently diluted authentic standards treated and extracted as the samples.

\section{Immunoblot analysis}

618 Protein concentration of cell lysates was determined using the Pierce ${ }^{\mathrm{TM}} \mathrm{BCA}$ 619 protein assay kit according to manufacturer's instructions (ThermoFisher 620 Scientific). Samples were adjusted in 5xLDS sample buffer containing $50 \mathrm{mM}$

DTT. After boiling and a sonication step, equal protein amounts were subjected to SDS-PAGE and blotted on a nitrocellulose membrane using the Trans-Blot Turbo Transfer system (BioRad). All antibodies were used in 5\% low-fat milk or 5\% BSA in TBS-Tween. After incubation with HRP-conjugated secondary antibody, the blot was developed using ECL solution (Merck Millipore) on a ChemiDoc MP Imaging System (BioRad). The following antibodies were used in this study: GFPT1 (RRID:AB_10975709, 1:1000), GFPT2 (RRID:AB_2868470, 1:5000), O-Linked N-Acetylglucosamine 629 Antibody (ms, clone RL2, MABS157, Sigma-Aldrich, 1:1000), OGA 630 (RRID:AB_10672079, 1:500), OGT (RRID:AB_2798857, 1:1000), FLAG (RRID:AB_262044, 1:2000), AMDHD2 (ms, S6 clone, in-house produced, 
$632 \quad 1: 500), \quad \alpha$-TUBULIN $\quad$ (RRID:AB_477593, $1: 5000), \quad$ rabbit $\quad \lg$

633 (RRID:AB_2536530,1:5000), and mouse IgG (RRID:AB_2536527, 1:5000).

\section{Generation of anti-AMDHD2 antibody}

635 To generate monoclonal antibodies directed against AMDHD2, His-tagged 636 human AMDHD2 was expressed in Escherichia coli, affinity purified, and used 637 for immunization of eight-week-old male Balb/cJRj mice. The first immunization 638 with $80 \mu \mathrm{g}$ of recombinant protein was enhanced by Freund's complete 639 adjuvant; subsequent injections used $40 \mu \mathrm{g}$ protein with Freund's incomplete 640 adjuvant. After multiple immunizations, the serum of the mice was tested for 641 immunoreaction by enzyme-linked immunosorbent assay (ELISA) with the 642 recombinant His-hAMDHD2 protein. In addition, the serum was used to stain 643 immunoblots with lysates of HEK293T cells overexpressing FLAG-HA644 hAMDHD2. After this positive testing, cells from the popliteal lymph node were 645 fused with mouse myeloma SP2/0 cells by a standard fusion protocol. 646 Monoclonal hybridoma lines were characterized, expanded, and subcloned 647 according to standard procedures ${ }^{60}$. Initial screening of clones was performed by ELISA with recombinant His-AMDHD2 protein and immunoblots using FLAGHA-hAMDHD2 overexpressed in HEK293T cells. Isotyping of selected clones was performed with Pierce Rapid Isotyping Kit (Thermo Scientific, \#26179).

651 Final validation of antibody specificity was done by immunoblots of WT N2a 652 cells compared to cells overexpressing FLAG-HA-hAMDHD2 and AMDHD2 KO 653 cells. 
655 A pET28a(+)-AMDHD2 plasmid was purchased from BioCat (Heidelberg, 656 Germany), where human AMDHD2 isoform 1 was integrated in pET28a(+) 657 using Ndel and Hindlll restriction sites. This vector was used to recombinantly 658 express human AMDHD2 isoform 1 with $\mathrm{N}$-terminal $\mathrm{His}_{6}$ tag and a thrombin 659 cleavage site under the control of the T7 promoter in BL21 (DE3) E. coli. LB 660 cultures were incubated at $37^{\circ} \mathrm{C}$ and $180 \mathrm{rpm}$ until an $\mathrm{OD}_{600}$ of $0.4-0.6$ was reached. Then, protein expression was induced by addition of $0.5 \mathrm{mM}$ isopropyl- $\beta$-D-1-thiogalactopyranosid (IPTG) and incubated for $20-22 \mathrm{~h}$ at $20^{\circ} \mathrm{C}$ 663 and $180 \mathrm{rpm}$. Before harvest, a sample corresponding to an $\mathrm{OD}_{600}$ of 0.5 was taken, lysed in BugBuster® Master Mix (Merck Millipore) and the total lysate, the supernatant after centrifugation of the total lysate, as well as the insoluble pellet, which was reconstituted by $8 \mathrm{M}$ urea, were analyzed by SDS-PAGE. The main cultures were harvested and pellets stored at $-80^{\circ} \mathrm{C}$. The purification buffers were modified from Bergfeld et al. ${ }^{11}$. E. coli were lysed in $50 \mathrm{mM}$ Tris/ $\mathrm{HCl}$ $\mathrm{pH}$ 7.5, $100 \mathrm{mM} \mathrm{NaCl}, 20 \mathrm{mM}$ imidazole, $1 \mathrm{mM}$ Tris(2-carboxyethyl)phosphin 670 (TCEP) with complete EDTA-free protease inhibitor cocktail (Roche) and $67110 \mu \mathrm{g} / \mathrm{ml}$ DNAsel (Sigma) by sonication. The lysate was clarified by centrifugation and the supernatant loaded on Ni-NTA Superflow affinity resin (Qiagen). The resin was washed with wash buffer (50 mM Tris-HCl, $100 \mathrm{mM}$ $674 \mathrm{NaCl}, 50 \mathrm{mM}$ imidazole, $1 \mathrm{mM}$ TCEP; $\mathrm{pH}$ 7.5) and the protein was eluted with 675 wash buffer containing $250 \mathrm{mM}$ imidazole. The His 6 -tag was proteolytically removed using 5 Units of thrombin (Sigma-Aldrich) per mg protein overnight at $4^{\circ} \mathrm{C}$. AMDHD2 was further purified according to its size on a HiLoad ${ }^{\mathrm{TM}} 16 / 60$ 678 Superdex ${ }^{\mathrm{TM}} 200$ prep grade prepacked column (GE Healthcare) using an 
679 ÄKTAprime chromatography system at $4^{\circ} \mathrm{C}$ with a SEC buffer containing $50 \mathrm{mM}$

680 Tris- $\mathrm{HCl}, 100 \mathrm{mM} \mathrm{NaCl}, 1 \mathrm{mM}$ TCEP, 5 \% glycerol; pH 7.5. 


\section{Site-directed mutagenesis}

682 The AMDHD2 mutations were introduced into the pET28a(+)-AMDHD2 plasmid 683 by site-directed mutagenesis as described previously ${ }^{61}$ (Mutagenesis primers are listed in Supplementary File 1). This protocol was also used to integrate an internal His 6 -tag between Ser300 and Asp301 in human GFPT2 in the plasmid FLAG-HA-hGFPT2-pcDNA3.1 $\quad\left(\right.$ pcDNA $^{\mathrm{TM}} 3.1^{(+)}, \quad$ ThermoFisher Scientific \#V79020). This position is equivalent to the internal His 6 -tag in human GFPT1, which does not interfere with GFPT kinetic properties ${ }^{48}$. The GFPT2 gene with internal $\mathrm{His}_{6}$-tag was subsequently subcloned into the $\mathrm{pFL}$ vector for the generation of baculoviruses using Xbal and HindlII entry sites.

\section{Thermal shift assay}

The thermal stability of AMDHD2 was analyzed by thermal shift (thermofluor) assays. For this purpose, the proteins were incubated with SYPRO orange dye (Sigma-Aldrich), which binds specifically to hydrophobic amino acids leading to an increased fluorescence at $610 \mathrm{~nm}$ when excited with a wavelength of $490 \mathrm{~nm}$. The melting temperature is defined as the midpoint of temperature of the protein-unfolding transition ${ }^{62}$. This turning point of the melting curve was extracted from the derivative values of the RFU curve, where a turning point to the right is a minimum. The influence of several divalent cations on the thermal stability of AMDHD2 was tested. For this, the SEC buffer was supplemented with $\mathrm{MgCl}_{2}, \mathrm{CaCl}_{2}, \mathrm{MnCl}_{2}, \mathrm{CoCl}_{2}, \mathrm{NiCl}_{2}, \mathrm{CuSO}_{4}, \mathrm{ZnCl}_{2}$, or $\mathrm{CdCl}_{2}$ at a final concentration of $10 \mu \mathrm{M}$. The reaction mixtures were pipetted in white RT-PCR plates and contained $5 \mu \mathrm{L}$ SYPRO orange dye (1:500 dilution in $\mathrm{ddH}_{2} \mathrm{O}$ ) and 5$10 \mu \mathrm{g}$ protein in a total volume of $50 \mu \mathrm{l}$. The plates were closed with optically clear tape and placed in a BioRad CFX-96 Real-Time PCR machine. The 
melting curves were measured at $1^{\circ} \mathrm{C} / \mathrm{min}$ at the FRET channel in triplicate measurements and the data analyzed with CFX Manager ${ }^{\mathrm{TM}}$ (BioRad).

\section{AMDHD2 activity assay}

The deacetylase activity of AMDHD2 was determined by following the cleavage of the amide/peptide bond of the N-acetyl amino sugars GlcNAc6P, GalNAc6P, or GlcNAc6S at $205 \mathrm{~nm}$ in UV transparent 96 well microplates (F-bottom, Brand \#781614). The assay mix contained $1 \mathrm{mM} \mathrm{N}$-acetyl amino sugar in $50 \mathrm{mM}$ Tris$\mathrm{HCl} \mathrm{pH} 7.5$ and was pre-warmed for $10 \mathrm{~min}$ at $37^{\circ} \mathrm{C}$ in the plate reader. The reaction was started by adding $20 \mathrm{pmol}$ AMDHD2 and was monitored several minutes at $37^{\circ} \mathrm{C}$. The initial reaction rates $(0-1 \mathrm{~min})$ were determined by Excel (Microsoft) and the amount of consumed GlcNAc6P was calculated from a GlcNAc6P standard curve. All measurements were performed in duplicates. For the analysis of the impact of several divalent metal ions on the activity of AMDHD2, the protein was incubated for 10 min with $0.1 \mu \mathrm{M}$ EDTA and afterwards $10 \mu \mathrm{M}$ divalent was added to potentially restore activity.

\section{Human AMDHD2 crystallization and crystal soaking}

Human AMDHD2 was co-crystallized with a $1.25 x$ ratio (molar) of $\mathrm{ZnCl}_{2}$ at a concentration of $9 \mathrm{mg} / \mathrm{ml}$ in sitting-drops by vapor diffusion at $20^{\circ} \mathrm{C}$. Intergrown crystal plates formed in the PACT premier ${ }^{\mathrm{TM}}$ HT-96 (Molecular Dimensions) screen in condition $\mathrm{H} 5$ with a reservoir solution containing $0.1 \mathrm{M}$ bis-tris propane $\mathrm{pH} 8.5,0.2 \mathrm{M}$ sodium nitrate, and 20\% (w/v) PEG3350. In an optimization screen, the concentration of PEG3350 was constant at $20 \%(\mathrm{w} / \mathrm{v})$, while the $\mathrm{pH}$ value of bis-tris propane and the concentration of sodium nitrate were varied. The drops were set up in $1.5 \mu$ protein solution to $1.5 \mu$ precipitant solution and $2 \mu \mathrm{l}$ protein solution to $1 \mu \mathrm{l}$ precipitant solution. Best crystals were 
731 obtained with a drop ratio of $2 \mu$ l protein solution to $1 \mu$ l precipitant solution at

$7320.1 \mathrm{M}$ bis tris propane $\mathrm{pH} 8.25,0.25 \mathrm{M}$ sodium nitrate, and 20\% (w/v) PEG3350.

$7335 \mathrm{mM}$ GlcN6P in reservoir solution was soaked into the crystals for 2 to $24 \mathrm{~h}$. For

734 crystal harvesting, the intergrown plates were separated with a needle and $15 \%$

735 glycerol was used as cryoprotectant.

\section{Data collection and refinement}

737 X-ray diffraction measurements were performed at beamline P13 at PETRA III,

738 DESY, Hamburg (Germany) and beamline X06SA at the Swiss Light Source,

739 Paul Scherrer Institute, Villigen (Switzerland). The diffraction images were

740 processed by $\mathrm{XDS}^{63}$. The structure of human AMDHD2 was determined by

741 molecular replacement ${ }^{64,65}$ with phenix.phaser ${ }^{66,67}$ using the models of

742 B. subtilis AMDHD2 (PDB 2VHL) as search model. The structures were further

743 manually built using $\mathrm{COOT}^{68}$ and iterative refinement rounds were performed

744 using phenix.refine ${ }^{67}$. The structure of GlcN6P soaked crystals was solved by

745 molecular replacement using our human AMDHD2 structure as search model.

746 Geometry restraints for GlcN6P was generated with phenix.elbow software ${ }^{67}$.

747 Structures were visualized using PyMOL (Schrödinger) and 2D ligand-protein 748 interaction diagrams were generated using LigPlot $+{ }^{69}$.

\section{Analytical size-exclusion chromatography}

750 The molecular weight of AMDHD2 and several mutants was determined by 751 analytical size-exclusion chromatography on a Superdex ${ }^{\mathrm{TM}} 200$ Increase 752 10/300 GL prepacked column (GE Healthcare) using an ÄKTApurifier 753 chromatography system at $20^{\circ} \mathrm{C}$. The measurement was performed with $100 \mu \mathrm{l}$ protein $(5 \mathrm{mg} / \mathrm{ml})$ in $50 \mathrm{mM}$ Tris- $\mathrm{HCl}, 100 \mathrm{mM} \mathrm{NaCl}, 1 \mathrm{mM}$ TCEP, $5 \%$ glycerol; $\mathrm{pH}$ 7.5. All measurements were performed in triplicates and the molecular 
756 weight was calculated from a standard curve from proteins with known 757 molecular weights.

\section{Dynamic Light Scattering (DLS)}

759 DLS measurements were performed to analyze the size distribution of AMDHD2 760 in solution. Directly before measurement, $100 \mu \mathrm{l}$ protein solution was 761 centrifuged for $10 \mathrm{~min}$ at $15,000 \mathrm{~g}$ to remove any particles from solution and $76270 \mu \mathrm{l}$ of the supernatant was transferred into a UV disposable cuvette (UVette®) 220-1600 nm, Eppendorf \#952010051). The cuvette was placed in a Wyatt

764 NanoStar DLS machine and the measurement performed with 10 frames with $10 \mathrm{sec} /$ frame. Data were analyzed with the software Dynamics and converted to particle size distribution functions. The scattering intensity (\%) was plotted

767 against the particle radius ( $\mathrm{nm})$ in a histogram.

\section{Baculovirus generation and insect cell expression of GFPT}

769 Sf21 (RRID:CVCL_0518) suspension cultures were maintained in 770 SFM4Insect ${ }^{\mathrm{TM}}$ HyClone $^{\mathrm{TM}}$ medium with glutamine (GE Lifesciences) in shaker 771 flasks at $27^{\circ} \mathrm{C}$ and $90 \mathrm{rpm}$ in an orbital shaker. GFPT1 and GFPT2 were 772 expressed in Sf21 cells using the MultiBac baculovirus expression system ${ }^{70}$. In 773 brief, GFPT (from the pFL vector) was integrated into the baculovirus genome 774 via $\operatorname{Tn} 7$ transposition and maintained as bacterial artificial chromosome in 775 DH10EMBacY E. coli cells. Recombinant baculoviruses were generated by 776 transfection of Sf21 with bacmid DNA. The obtained baculoviruses were used to 777 induce protein expression in Sf21 cells. 


\section{GFPT1 and GFPT2 purification}

Sf21 cells were lysed by sonication in lysis buffer $(50 \mathrm{mM}$ Tris/ $\mathrm{HCl} \mathrm{pH} 7.5$, $200 \mathrm{mM} \mathrm{NaCl}, 10 \mathrm{mM}$ Imidazole, $2 \mathrm{mM}$ TCEP, $0.5 \mathrm{mM} \mathrm{Na} 2 \mathrm{Frc6P}, 10 \%$ (v/v) glycerol) supplemented with complete EDTA-free protease inhibitor cocktail (Roche) and $10 \mu \mathrm{g} / \mathrm{ml}$ DNAsel (Sigma-Aldrich). Cell debris and protein aggregates were removed by centrifugation and the supernatant was loaded on a Ni-NTA Superflow affinity resin (Qiagen). The resin was washed with lysis buffer and the protein eluted with lysis buffer containing $200 \mathrm{mM}$ imidazole. The proteins were further purified according to their size on a HiLoad ${ }^{\mathrm{TM}} 16 / 60$ Superdex ${ }^{\mathrm{TM}} 200$ prep grade prepacked column (GE Healthcare) using an ÄKTAprime chromatography system at $4^{\circ} \mathrm{C}$ with a SEC buffer containing $50 \mathrm{mM}$ Tris/HCl, pH 7.5, 2 mM TCEP, $0.5 \mathrm{mM} \mathrm{Na}_{2} \mathrm{Frc6P}$, and 10\% (v/v) glycerol.

\section{GDH-coupled activity assay and UDP-GIcNAc inhibition}

GFPT's amidohydrolysis activity was measured with a coupled enzymatic assay using bovine glutamate dehydrogenase (GDH, Sigma-Aldrich G2626) in 96 well standard microplates (F-bottom, BRAND \#781602) as previously described ${ }^{48}$ with small modifications. In brief, the reaction mixtures contained $6 \mathrm{mM}$ Frc6P, $1 \mathrm{mM}$ APAD, $1 \mathrm{mM}$ EDTA, $50 \mathrm{mM} \mathrm{KCl}, 100 \mathrm{mM}$ potassium-phosphate buffer $\mathrm{pH} 7.5,6.5 \mathrm{U} \mathrm{GDH}$ per 96 well and for L-Gln kinetics varying concentrations of L-Gln. For UDP-GIcNAc inhibition assays the L-Gln concentration was kept at $10 \mathrm{mM}$. The plate was pre-warmed at $37^{\circ} \mathrm{C}$ for $10 \mathrm{~min}$ and the activity after enzyme addition was monitored continuously at $363 \mathrm{~nm}$ in a microplate reader. The amount of formed APADH was calculated with $\varepsilon_{(363 \mathrm{~nm}, \text { APADH })}=$ $9100 \mathrm{I}^{*} \mathrm{~mol}^{-1 *} \mathrm{~cm}^{-1}$. Reaction rates were determined by Excel (Microsoft) and $\mathrm{K}_{\mathrm{m}}$, 
$802 \mathrm{~V}_{\max }$, and $\mathrm{IC}_{50}$ were obtained from Michaelis Menten or dose response curves, 803 which were fitted by Prism 8 software (Graphpad).

804 GNA1 expression and purification

805 The expression plasmid for human GNA1 with N-terminal His $\sigma_{6}$-tag was cloned 806 previously ${ }^{25}$. Human GNA1 with $\mathrm{N}$-terminal $\mathrm{His}_{6}$-tag was expressed in Rosetta 807 (DE3) E. coli cells. LB cultures were incubated at $37^{\circ} \mathrm{C}$ and $180 \mathrm{rpm}$ until an $808 \mathrm{OD}_{600}$ of 0.4-0.6 was reached. Then, protein expression was induced by addition of $0.5 \mathrm{mM}$ IPTG and incubated for $3 \mathrm{~h}$ at $37^{\circ} \mathrm{C}$ and $180 \mathrm{rpm}$. Cultures were harvested and pellets stored at $-80^{\circ} \mathrm{C}$. Human GNA1 purification protocol was adopted from Hurtado-Guerrero et al. ${ }^{71}$ with small modifications. E. coli were lysed in $50 \mathrm{mM}$ HEPES/ $\mathrm{NaOH}$ pH 7.2, $500 \mathrm{mM} \mathrm{NaCl}, 10 \mathrm{mM}$ imidazole, $2 \mathrm{mM}$ 2-mercaptoethanol, 5\% (v/v) glycerol with complete EDTA-free protease inhibitor cocktail (Roche) and $10 \mu \mathrm{g} / \mathrm{ml}$ DNAsel (Sigma-Aldrich) by sonication. The lysate was clarified by centrifugation and the supernatant loaded on $\mathrm{Ni}$ NTA Superflow affinity resin (Qiagen). The resin was washed with wash buffer 817 (50 mM HEPES/NaOH pH 7.2, $500 \mathrm{mM} \mathrm{NaCl}, 50 \mathrm{mM}$ imidazole, 5\% (v/v) glycerol) and the protein was eluted with wash buffer containing $250 \mathrm{mM}$ imidazole. Eluted protein was then dialyzed against storage buffer $(20 \mathrm{mM}$ HEPES/NaOH pH 7.2, $500 \mathrm{mM} \mathrm{NaCl,} \mathrm{5 \%} \mathrm{(v/v)} \mathrm{glycerol).}$

\section{GNA1 and GNA1-coupled activity assays}

822 The activity of human GNA1 was measured in 96 well standard microplates (F823 bottom, BRAND \#781602) as described previously ${ }^{72}$. For kinetic measurements, the assay mixture contained $0.5 \mathrm{mM}$ Ac-CoA, $0.5 \mathrm{mM}$ DTNB, $1 \mathrm{mM}$ EDTA, $50 \mathrm{mM}$ Tris/HCl pH 7.5 and varying concentrations of D-GlcN6P. 
826 The plates were pre-warmed at $37^{\circ} \mathrm{C}$ and reactions were initiated by addition of

827 GNA1. The absorbance at $412 \mathrm{~nm}$ was followed continuously at $37^{\circ} \mathrm{C}$ in a 828 microplate reader. The amount of produced TNB, which matches CoA 829 production, was calculated with $\varepsilon_{(412 \mathrm{~nm}, \mathrm{TNB})}=13800 \mathrm{I}^{*} \mathrm{~mol}^{-1 *} \mathrm{~cm}^{-1}$. Typically,

830 GNA1 preparations showed a $\mathrm{K}_{\mathrm{m}}$ of $0.2 \pm 0.1 \mathrm{mM}$ and a $\mathrm{k}_{\mathrm{cat}}$ of $41 \pm 8 \mathrm{sec}^{-1}$.

831 GFPT's D-GlcN6P production was measured in a GNA1-coupled activity assay 832 following the consumption of $\mathrm{AcCoA}$ at $230 \mathrm{~nm}$ in UV transparent 96 well 833 microplates (F-bottom, Brand \#781614) as described by Li et al. ${ }^{72}$. In brief, the assay mixture contained $10 \mathrm{mM} \mathrm{L-Gln,} 0.1 \mathrm{mM} \mathrm{AcCoA}, 50 \mathrm{mM}$ Tris/ $\mathrm{HCl} \mathrm{pH} \mathrm{7.5,}$ $2 \mu \mathrm{g}$ hGNA1 and varying concentrations of Frc6P. The plates were incubated at $37^{\circ} \mathrm{C}$ for $4 \mathrm{~min}$ and reactions started by adding L-Gln. Activity was monitored continuously at $230 \mathrm{~nm}$ and $37^{\circ} \mathrm{C}$ in a microplate reader. The amount of consumed AcCoA was calculated with $\varepsilon_{(230 \mathrm{~nm}, \mathrm{AcCoA})}=6436 \mathrm{I}^{*} \mathrm{~mol}^{-1 *} \mathrm{~cm}^{-1}$. As UDP-GIcNAc absorbs light at $230 \mathrm{~nm}$, the GNA-1-coupled assay cannot be used to analyze UDP-GIcNAc effects on activity.

\section{CRISPR/Cas9-mediated generation of transgenic mice}

842 CRIPSR/Cas9-mediated generation of AMDHD2 KO mice was performed by 843 ribonucleoprotein complex injection in mouse zygotes. Guide RNAs (crRNAs) 844 targeting exon 4 of the Amdhd2 locus were designed online (crispor.org) and purchased from IDT. crRNA and tracrRNA were resuspended in injection buffer (1 mM Tris-HCl pH 7.5, 0.1 mM EDTA) and annealed at 1:1 molar concentration 847 in a thermocycler $\left(95^{\circ} \mathrm{C}\right.$ for $5 \mathrm{~min}$, ramp down to $25^{\circ} \mathrm{C}$ at $\left.5^{\circ} \mathrm{C} / \mathrm{min}\right)$. To prepare 848 the injection mix $(100 \mu \mathrm{l})$, two guide RNAs and the Cas9 enzyme (S. pyogenes, NEB) were diluted to a final concentration of $20 \mathrm{ng} / \mu \mathrm{l}$ each in injection buffer. 850 The $\operatorname{mix}$ was incubated for $10-15 \mathrm{~min}$ at room temperature to allow 
851 ribonucleoprotein complex assembly. After centrifugation, $80 \mu \mathrm{l}$ of the 852 supernatant were passed through a filter (Millipore, UFC30VV25). Both centrifugation steps were performed for $5 \mathrm{~min}$ at $13.000 \mathrm{rpm}$ at room temperature. The filtered injection mix was used for zygote injections.

\section{Mouse Zygote Microinjections}

3- to 4-week-old $\mathrm{C} 57 \mathrm{BI} / 6 \mathrm{~J}$ females were superovulated by intraperitoneal injection of Pregnant Mare Serum Gonadotropin (5 IU) followed by intraperitoneal injection of Human Chorionic Gonadotropin hormone (5 IU Intervet Germany) 48h later. Superovulated females were mated with 10 to 20 week old stud males. The mated females were euthanized the next day and zygotes were collected in M2 media (Sigma-Aldrich) supplemented with hyaluronidase (Sigma-Aldrich).

863 Fertilized oocytes were injected into the pronuclei or cytoplasma with the prepared CRIPSR/Cas9 reagents. Injections were performed under an inverted

microscope (Zeiss AxioObserver) associated micromanipulator (Eppendorf NK2) and the microinjection apparatus (Eppendorf Femtojet) with in-house pulled glass capillaries. Injected zygotes were incubated at $37^{\circ} \mathrm{C}, 5 \% \mathrm{CO}_{2}$ in KSOM (Merck) until transplantation. 25 zygotes were surgically transferred into one oviduct of pseudo-pregnant CD1 female mice.

All procedures have been performed in our specialized facility, followed all relevant animal welfare guidelines and regulations, and were approved by LANUV NRW 84-02.04.2015.A025.

\section{Isolation of mouse genomic DNA from ear clips}

874 Ear clips were taken by the Comparative Biology Facility at the Max Planck Institute for Biology of Ageing (Cologne, Germany) at weaning age (3-4 weeks 
876 of age) and stored at $-20^{\circ} \mathrm{C}$ until use. $150 \mu \mathrm{lddH_{2 }} \mathrm{O}$ and $150 \mu$ directPCR Tail 877 Lysis reagent (Peqlab) were mixed with $3 \mu$ proteinase $\mathrm{K}(20 \mathrm{mg} / \mathrm{ml}$ in $25 \mathrm{mM}$ 878 Tris- $\mathrm{HCl}, 5 \mathrm{mM} \mathrm{Ca}_{2} \mathrm{Cl}, \mathrm{pH} 8.0$, Sigma-Aldrich). This mixture was applied to the ear clips, which were then incubated at $56^{\circ} \mathrm{C}$ overnight (maximum $16 \mathrm{~h}$ ) shaking 880 at $300 \mathrm{rpm}$. Proteinase $\mathrm{K}$ was inactivated at $85^{\circ} \mathrm{C}$ for $45 \mathrm{~min}$ without shaking. 881 The lysis reaction $(2 \mu \mathrm{l})$ was used for genotyping PCR without further 882 processing. For genotyping of mouse genomic DNA DreamTaq DNA polymerase (ThermoFisher Scientific) was used.

884

Alignments

885

Following UnitProt IDs were used for the protein sequence alignment of

AMDHD2: Homo sapiens isoform 1: Q9Y303-1, Mus musculus: Q8JZV7, Caenorhabditis elegans: P34480, Candida albicans: Q9C0N5, Escherichia coli: POAF18,

Bacillus

subtilis:

O34450.

ClustalOmega

889 (https://www.ebi.ac.uk/Tools/msa/clustalo/) was used to generate a multiple sequence alignment ${ }^{73}$. The alignment was formatted with the ESPript3 server (espript.ibcp.fr/) $)^{74}$ and further modified.

\section{Statistical analysis}

893 Data are presented as mean \pm SEM/SD or as mean + SEM/SD. The mean of technical replicates is plotted for each biological replicate. Biological replicates represent different passages of the cells that were seeded on independent days. Statistical significance was calculated using GraphPad Prism (GraphPad Software, San Diego, California). The statistical test used is indicated in the respective figure legend. Significance levels are ${ }^{*} p<0.05,{ }^{* *} p<0.01$, ${ }^{* * *} p<0.001$ versus the respective control. 
900 Data availability

901 Structural data reported in this study have been deposited in the Protein Data

902 Bank with the accession codes 7NUT [https://doi.org/10.2210/pdb7NUT/pdb]

903 and 7NUU [https://doi.org/10.2210/pdb7NUU/pdb].

904 


\section{References}

9061 Marshall, S., Bacote, V. \& Traxinger, R. R. Discovery of a metabolic pathway mediating glucose-induced desensitization of the glucose transport system. Role of hexosamine biosynthesis in the induction of insulin resistance. J Biol Chem 266, 4706-4712 (1991).

2 Ghosh, S., Blumenthal, H. J., Davidson, E. \& Roseman, S. Glucosamine metabolism. V. Enzymatic synthesis of glucosamine 6-phosphate. J Biol Chem 235, 1265-1273 (1960).

3 Denzel, M. S. et al. Hexosamine pathway metabolites enhance protein quality control and prolong life. Cell 156, 1167-1178, doi:10.1016/j.cell.2014.01.061 (2014).

4 Wellen, K. E. et al. The hexosamine biosynthetic pathway couples growth factor-induced glutamine uptake to glucose metabolism. Genes Dev 24, 2784-2799, doi:10.1101/gad.1985910 (2010).

5 Yamashita, K., Tachibana, Y., Ohkura, T. \& Kobata, A. Enzymatic basis for the structural changes of asparagine-linked sugar chains of membrane glycoproteins of baby hamster kidney cells induced by polyoma transformation. J Biol Chem 260, 3963-3969 (1985).

6 McClain, D. A. \& Crook, E. D. Hexosamines and insulin resistance. Diabetes 45, 1003-1009, doi:10.2337/diab.45.8.1003 (1996).

7 Oki, T., Yamazaki, K., Kuromitsu, J., Okada, M. \& Tanaka, I. cDNA cloning and mapping of a novel subtype of glutamine:fructose-6-phosphate amidotransferase (GFAT2) in human and mouse. Genomics 57, 227-234, doi:10.1006/geno.1999.5785 (1999).

8 Arreola, R., Valderrama, B., Morante, M. L. \& Horjales, E. Two mammalian glucosamine-6-phosphate deaminases: a structural and genetic study. FEBS Lett 551, 63-70, doi:10.1016/s0014-5793(03)00896-2 (2003).

9 Wang, J., Liu, X., Liang, Y. H., Li, L. F. \& Su, X. D. Acceptor substrate binding revealed by crystal structure of human glucosamine-6-phosphate Nacetyltransferase $\quad 1 . \quad F E B S \quad$ Lett 582, 2973-2978, doi:10.1016/j.febslet.2008.07.040 (2008).

10 Weidanz, J. A. et al. N-acetylglucosamine kinase and N-acetylglucosamine 6phosphate deacetylase in normal human erythrocytes and Plasmodium falciparum. British journal of haematology 95, 645-653 (1996).

11 Bergfeld, A. K., Pearce, O. M., Diaz, S. L., Pham, T. \& Varki, A. Metabolism of vertebrate amino sugars with N-glycolyl groups: elucidating the intracellular fate of the non-human sialic acid N-glycolylneuraminic acid. $J$ Biol Chem 287, 28865-28881, doi:10.1074/jbc.M112.363549 (2012).

12 Ricciardiello, F. et al. Inhibition of the Hexosamine Biosynthetic Pathway by targeting PGM3 causes breast cancer growth arrest and apoptosis. Cell Death Dis 9, 377, doi:10.1038/s41419-018-0405-4 (2018).

13 Mio, T., Yabe, T., Arisawa, M. \& Yamada-Okabe, H. The eukaryotic UDP-Nacetylglucosamine pyrophosphorylases. Gene cloning, protein expression, and catalytic mechanism. J Biol Chem 273, 14392-14397, doi:10.1074/jbc.273.23.14392 (1998).

14 Thoden, J. B., Wohlers, T. M., Fridovich-Keil, J. L. \& Holden, H. M. Human UDP-galactose 4-epimerase. Accommodation of UDP-N-acetylglucosamine within the active site. J Biol Chem 276, 15131-15136, doi:10.1074/jbc.M100220200 (2001). 
15 Hanisch, F. G. O-glycosylation of the mucin type. Biol Chem 382, 143-149, doi:10.1515/bc.2001.022 (2001).

16 Parodi, A. J. Role of N-oligosaccharide endoplasmic reticulum processing reactions in glycoprotein folding and degradation. The Biochemical journal 348 Pt 1, 1-13 (2000).

17 Martinez-Seara Monne, H., Danne, R., Róg, T., Ilpo, V. \& Gurtovenko, A. Structure of Glycocalyx. Biophysical Journal 104, 251a, doi:https://doi.org/10.1016/j.bpj.2012.11.1412 (2013).

18 Hart, G. W. Dynamic 0-linked glycosylation of nuclear and cytoskeletal proteins. Annu Rev Biochem 66, 315-335, doi:10.1146/annurev.biochem.66.1.315 (1997).

19 Haltiwanger, R. S., Blomberg, M. A. \& Hart, G. W. Glycosylation of nuclear and cytoplasmic proteins. Purification and characterization of a uridine diphospho-N-acetylglucosamine:polypeptide beta-Nacetylglucosaminyltransferase. Journal of Biological Chemistry 267, 90059013, doi:https://doi.org/10.1016/S0021-9258(19)50380-5 (1992).

20 Dong, D. L. \& Hart, G. W. Purification and characterization of an 0-GlcNAc selective N-acetyl-beta-D-glucosaminidase from rat spleen cytosol. J Biol Chem 269, 19321-19330 (1994).

21 Oikari, S. et al. UDP-sugar accumulation drives hyaluronan synthesis in breast cancer. Matrix Biology 67, 63-74 (2018).

22 Arnold, C. S. et al. The microtubule-associated protein tau is extensively modified with O-linked N-acetylglucosamine. J Biol Chem 271, 2874128744, doi:10.1074/jbc.271.46.28741 (1996).

23 Champattanachai, V., Marchase, R. B. \& Chatham, J. C. Glucosamine protects neonatal cardiomyocytes from ischemia-reperfusion injury via increased protein-associated O-GlcNAc. American Journal of Physiology-Cell Physiology 292, C178-C187 (2007).

24 Heifetz, A., Keenan, R. W. \& Elbein, A. D. Mechanism of action of tunicamycin on the UDP-GlcNAc:dolichyl-phosphate Glc-NAc-1-phosphate transferase. Biochemistry 18, 2186-2192, doi:10.1021/bi00578a008 (1979).

25 Ruegenberg, S. et al. Loss of GFAT-1 feedback regulation activates the hexosamine pathway that modulates protein homeostasis. Nat Commun 11, 687, doi:10.1038/s41467-020-14524-5 (2020).

26 Horn, M. et al. Hexosamine Pathway Activation Improves Protein Homeostasis through the Integrated Stress Response. iScience 23, 100887, doi:10.1016/j.isci.2020.100887 (2020).

27 Elling, U. et al. Forward and reverse genetics through derivation of haploid mouse embryonic stem cells. Cell Stem Cell 9, 563-574, doi:10.1016/j.stem.2011.10.012 (2011).

28 Horn, M. et al. Unbiased compound-protein interface mapping and prediction of chemoresistance loci through forward genetics in haploid stem cells. (2018).

29 Allmeroth, K. et al. Bortezomib resistance mutations in PSMB5 determine response to second-generation proteasome inhibitors in multiple myeloma. Leukemia, doi:10.1038/s41375-020-0989-4 (2020).

30 Elling, U. et al. A reversible haploid mouse embryonic stem cell biobank resource for functional genomics. Nature 550, 114-118, doi:10.1038/nature24027 (2017). 
31 White, R. J. \& Pasternak, C. A. The purification and properties of Nacetylglucosamine 6-phosphate deacetylase from Escherichia coli. The Biochemical journal 105, 121-125, doi:10.1042/bj1050121 (1967).

32 Hall, R. S., Xiang, D. F., Xu, C. \& Raushel, F. M. N-Acetyl-D-glucosamine-6phosphate deacetylase: substrate activation via a single divalent metal ion. Biochemistry 46, 7942-7952, doi:10.1021/bi700543x (2007).

33 Bliven, S., Lafita, A., Parker, A., Capitani, G. \& Duarte, J. M. Automated evaluation of quaternary structures from protein crystals. PLOS Computational Biology 14, e1006104, doi:10.1371/journal.pcbi.1006104 (2018).

34 Ahangar, M. S. et al. Structural and functional determination of homologs of the Mycobacterium tuberculosis N-acetylglucosamine-6-phosphate deacetylase (NagA). J Biol Chem 293, 9770-9783, doi:10.1074/jbc.RA118.002597 (2018).

35 Hocke, G. M., Cui, M. Z. \& Fey, G. H. The LIF response element of the alpha 2 macroglobulin gene confers LIF-induced transcriptional activation in embryonal stem cells. Cytokine 7, 491-502, doi:10.1006/cyto.1995.0067 (1995).

36 Saez, I., Koyuncu, S., Gutierrez-Garcia, R., Dieterich, C. \& Vilchez, D. Insights into the ubiquitin-proteasome system of human embryonic stem cells. Scientific reports 8, 4092, doi:10.1038/s41598-018-22384-9 (2018).

37 Frank, S. et al. yylncT Defines a Class of Divergently Transcribed lncRNAs and Safeguards the T-mediated Mesodermal Commitment of Human PSCs. Cell Stem Cell 24, 318-327.e318, doi:10.1016/j.stem.2018.11.005 (2019).

38 Bartsch, D. et al. Translational specialization in pluripotency by RBPMS poises future lineage-decisions. bioRxiv, 2021.2004.2012.439420, doi:10.1101/2021.04.12.439420 (2021).

39 Campbell, P., Laurent, T. C. \& Roden, L. Assay and properties of Nacetylglucosamine-6-phosphate deacetylase from rat liver. Analytical biochemistry 166, 134-141 (1987).

40 Liu, Y. et al. Pathway engineering of Bacillus subtilis for microbial production of N-acetylglucosamine. Metab Eng 19, 107-115, doi:10.1016/j.ymben.2013.07.002 (2013).

41 Plumbridge, J. An alternative route for recycling of $\mathrm{N}$-acetylglucosamine from peptidoglycan involves the $\mathrm{N}$-acetylglucosamine phosphotransferase system in Escherichia coli. J Bacteriol 191, 5641-5647, doi:10.1128/JB.00448-09 (2009).

42 Popowska, M., Osinska, M. \& Rzeczkowska, M. N-acetylglucosamine-6phosphate deacetylase (NagA) of Listeria monocytogenes EGD, an essential enzyme for the metabolism and recycling of amino sugars. Arch Microbiol 194, 255-268, doi:10.1007/s00203-011-0752-3 (2012).

43 Yadav, V. et al. N-acetylglucosamine 6-phosphate deacetylase (nagA) is required for $\mathrm{N}$-acetyl glucosamine assimilation in Gluconacetobacter xylinus. PLoS One 6, e18099, doi:10.1371/journal.pone.0018099 (2011).

44 Zhang, Y. et al. Genetic and structural validation of phosphomannomutase as a cell wall target in Aspergillus fumigatus. Mol Microbiol, doi:10.1111/mmi.14706 (2021).

45 Swiatek, M. A., Tenconi, E., Rigali, S. \& van Wezel, G. P. Functional analysis of the $\mathrm{N}$-acetylglucosamine metabolic genes of Streptomyces coelicolor and 
role in control of development and antibiotic production. J Bacteriol 194, 1136-1144, doi:10.1128/JB.06370-11 (2012).

46 Świątek, M. A., Urem, M., Tenconi, E., Rigali, S. \& van Wezel, G. P. Engineering of $\mathrm{N}$-acetylglucosamine metabolism for improved antibiotic production in Streptomyces coelicolor $\mathrm{A} 3(2)$ and an unsuspected role of NagA in glucosamine metabolism. Bioengineered 3, 280-285, doi:10.4161/bioe.21371 (2012).

47 Lockhart, D. E. A. et al. Targeting a critical step in fungal hexosamine biosynthesis. J Biol Chem 295, 8678-8691, doi:10.1074/jbc.RA120.012985 (2020).

48 Richez, C. et al. Expression and purification of active human internal His(6)tagged L-glutamine: D-Fructose-6P amidotransferase I. Protein Expr Purif 54, 45-53, doi:10.1016/j.pep.2007.01.015 (2007).

49 Hu, Y., Riesland, L., Paterson, A. J. \& Kudlow, J. E. Phosphorylation of mouse glutamine-fructose-6-phosphate amidotransferase 2 (GFAT2) by cAMPdependent protein kinase increases the enzyme activity. J Biol Chem 279, 29988-29993, doi:10.1074/jbc.M401547200 (2004).

50 Oliveira, I. A. et al. Enzymatic and structural properties of human glutamine:fructose-6-phosphate amidotransferase 2 (hGFAT2). J Biol Chem, doi:10.1074/jbc.RA120.015189 (2020).

51 Mattila, J., Kokki, K., Hietakangas, V. \& Boutros, M. Stem Cell Intrinsic Hexosamine Metabolism Regulates Intestinal Adaptation to Nutrient Content. Developmental cell 47, 112-121.e113, doi:10.1016/j.devcel.2018.08.011 (2018).

52 Constable, S., Lim, J. M., Vaidyanathan, K. \& Wells, L. O-GlcNAc transferase regulates transcriptional activity of human Oct4. Glycobiology 27, 927-937, doi:10.1093/glycob/cwx055 (2017).

53 Jang, H. et al. 0-GlcNAc regulates pluripotency and reprogramming by directly acting on core components of the pluripotency network. Cell Stem Cell 11, 62-74, doi:10.1016/j.stem.2012.03.001 (2012).

54 Intlekofer, A. M. \& Finley, L. W. S. Metabolic signatures of cancer cells and stem cells. Nature Metabolism 1, 177-188, doi:10.1038/s42255-019-0032-0 (2019).

55 Shaul, Y. D. et al. Dihydropyrimidine accumulation is required for the epithelial-mesenchymal transition. Cell 158, 1094-1109 (2014).

56 Zhang, W. et al. GFPT2-Expressing Cancer-Associated Fibroblasts Mediate Metabolic Reprogramming in Human Lung Adenocarcinoma. Cancer Res 78, 3445-3457, doi:10.1158/0008-5472.Can-17-2928 (2018).

57 Szymura, S. J. et al. NF- $\kappa \mathrm{B}$ upregulates glutamine-fructose-6-phosphate transaminase 2 to promote migration in non-small cell lung cancer. Cell Communication and Signaling 17, 24, doi:10.1186/s12964-019-0335-5 (2019).

58 Elling, U. et al. Derivation and maintenance of mouse haploid embryonic stem cells. Nature protocols, doi:10.1038/s41596-019-0169-z (2019).

59 Ran, F. A. et al. Genome engineering using the CRISPR-Cas9 system. Nature protocols 8, 2281-2308, doi:10.1038/nprot.2013.143 (2013).

60 Köhler, G. \& Milstein, C. Continuous cultures of fused cells secreting antibody of predefined specificity. Nature 256, 495-497, doi:10.1038/256495a0 (1975). 
61 Zheng, L., Baumann, U. \& Reymond, J. L. An efficient one-step site-directed and site-saturation mutagenesis protocol. Nucleic Acids Res 32, e115, doi:10.1093/nar/gnh110 (2004).

62 Ericsson, U. B., Hallberg, B. M., Detitta, G. T., Dekker, N. \& Nordlund, P. Thermofluor-based high-throughput stability optimization of proteins for structural studies. Anal Biochem 357, 289-298, doi:10.1016/j.ab.2006.07.027 (2006).

63 Kabsch, W. Xds. Acta Crystallogr D Biol Crystallogr 66, 125-132, doi:10.1107/S0907444909047337 (2010).

64 Hoppe, W. Die Faltmolekülmethode: Eine neue Methode zur Bestimmung der Kristallstruktur bei ganz oder teilweise bekannten Molekülstrukturen. Acta Crystallogr A 10, 750-751 (1957).

65 Huber, R. Die automatisierte Faltmolekülmethode. Acta Crystallogr A 19, 353-356 (1965).

66 McCoy, A. J. Solving structures of protein complexes by molecular replacement with Phaser. Acta Crystallogr D Biol Crystallogr 63, 32-41, doi:10.1107/S0907444906045975 (2007).

67 Adams, P. D. et al. PHENIX: a comprehensive Python-based system for macromolecular structure solution. Acta Crystallogr D Biol Crystallogr 66, 213-221, doi:10.1107/S0907444909052925 (2010).

68 Emsley, P., Lohkamp, B., Scott, W. G. \& Cowtan, K. Features and development of Coot. Acta Crystallogr D Biol Crystallogr 66, 486-501, doi:10.1107/S0907444910007493 (2010).

69 Laskowski, R. A. \& Swindells, M. B. LigPlot+: multiple ligand-protein interaction diagrams for drug discovery. J Chem Inf Model 51, 2778-2786, doi:10.1021/ci200227u (2011).

70 Berger, I., Fitzgerald, D. J. \& Richmond, T. J. Baculovirus expression system for heterologous multiprotein complexes. Nat Biotechnol 22, 1583-1587, doi:10.1038/nbt1036 (2004).

71 Hurtado-Guerrero, R. et al. Structural and kinetic differences between human and Aspergillus fumigatus D-glucosamine-6-phosphate $\mathrm{N}$ acetyltransferase. Biochem J 415, 217-223, doi:10.1042/BJ20081000 (2008).

72 Li, Y. et al. An enzyme-coupled assay for amidotransferase activity of glucosamine-6-phosphate synthase. Anal Biochem 370, 142-146, doi:10.1016/j.ab.2007.07.031 (2007).

73 Sievers, F. et al. Fast, scalable generation of high-quality protein multiple sequence alignments using Clustal Omega. Mol Syst Biol 7, 539, doi:10.1038/msb.2011.75 (2011).

74 Robert, X. \& Gouet, P. Deciphering key features in protein structures with the new ENDscript server. Nucleic Acids Res 42, W320-324, doi:10.1093/nar/gku316 (2014). 
1146 We thank all M.S.D. and U.B. laboratory members as well as L. Kurian, H.

1147 Bazzi, and D. Vilchez for helpful discussions. The FLAG-HA-hGFPT-21148 pcDNA3.1 plasmid was kindly provided by C. Geisen (Max Planck Institute for 1149 Biology of Ageing, MPI-AGE). We thank Y. Hinze, S. Perin, and P. Giavalisco 1150 from the MPI-AGE metabolomics core facility. We thank K. Folz-Donahue, L. 1151 Schumacher, A. Just, and C. Kukat from the MPI-AGE FACS and imaging core 1152 facility. We thank F. Metge, and J. Boucas from the MPI-AGE bioinformatics 1153 core facility. We thank I. Vogt from the MPI-AGE transgenesis core facility. We 1154 thank the MPI-AGE comparative biology facility. We thank M. Grzonka for 1155 support with the E14 mESCs. We are grateful to S. Birkmann for support in the 1156 insect cell maintenance. We thank I. Grimm and S. Schäfer for their help with 1157 the AMDHD2 production and D. Feind for the site-directed mutagenesis of 1158 monomeric AMDHD2 mutants. Crystals were grown in the Cologne 1159 Crystallization facility $\left(\mathrm{C}_{2} \mathrm{f}\right)$. We thank the staff of beamline X06SA at the Swiss 1160 Light Source, Paul Scherrer Institute, Villigen (Switzerland) and beamline P13 at 1161 PETRA III, DESY, Hamburg (Germany) for their support during data collection. 1162 This work was supported by the German Federal Ministry of Education and 1163 Research (BMBF, grant 01GQ1423A EndoProtect), by the German Research 1164 Foundation (DFG, Projektnummer 73111208-SFB 829, B11 and B14), by the 1165 European Commission (ERC-2014-StG-640254-MetAGEn), and by the Max 1166 Planck Society. The Cologne Crystallization Facility $\mathrm{C}_{2} f$ was supported by DFG 1167 grant INST 216/949-1 FUGG.

\section{Competing interests}

1169 The authors declare no competing interest. 
Figure legends

Figure 1: Chemical mutagenesis screen for tunicamycin resistance in haploid mESCs identifies AMDHD2

(A) Schematic representation of experimental workflow for TM resistance screen using ENU mutagenesis in combination with whole exome sequencing. (B) Schematic representation of the mouse Amdhd2 locus. Amino acid substitutions identified in the screen are highlighted. (C) Cell viability (XTT assay) of four TM resistant clones (clone 1-4) identified via insertional mutagenesis compared to control WT AN3-12 mESCs. Cells were treated with $0.5 \mu \mathrm{g} / \mathrm{ml} \mathrm{TM}$ for $48 \mathrm{~h}$ (mean $\pm \mathrm{SEM}, \mathrm{n}=4,{ }^{*} \mathrm{p}<0.05$, ${ }^{* *} \mathrm{p}<0.01$, One-way ANOVA Dunnett post-test). (D) Western blot analysis of CRISPR/Cas9 generated AMDHD2 KO AN3-12 mESCs compared to wildtype cells (WT). (E) Cell viability (XTT assay) of WT and AMDHD2 KO AN3-12 cells treated with $0.5 \mu \mathrm{g} / \mathrm{ml}$ TM for $48 \mathrm{~h}$ (mean $\pm \mathrm{SEM}, \mathrm{n}=4$, ${ }^{* *} \mathrm{p}<0.01$, unpaired t-test). (F) Representative images of WT and AMDHD2 KO AN3-12 cells treated with $0.5 \mu \mathrm{g} / \mathrm{ml} \mathrm{TM}$ for $48 \mathrm{~h}$ or respective control. Scale bar, $275 \mu \mathrm{m}$. Figure supplements are available in Figure 1-figure supplement 1. Source data for this figure are available in Figure 1-source data 1-6.

Figure 2: Disruption of AMDHD2 mediates tunicamycin resistance via elevated HBP flux

(A) Schematic overview of the hexosamine pathway (blue box). The intermediate Frc6P from glycolysis is converted to UDP-GlcNAc, which is a precursor for glycosylation reactions. The enzymes are glutamine fructose-6phosphate amidotransferase (GFPT1/2), glucosamine-6-phosphate $\mathrm{N}$-acetyltransferase (GNA1), phosphoglucomutase (PGM3), UDP$\mathrm{N}$-acetylglucosamine pyrophosphorylase (UAP1), glucosamine-6-phosphate deaminase (GNPDA1/2), N-acetylglucosamine deacetylase (AMDHD2), UDPGlcNAc:dolichylphosphate GlcNAc-1-phosphotransferase (GPT), and UDPgalactose-4'-epimerase (GALE). Red line indicates negative feedback inhibition of GFPT by UDP-GIcNAc. UDP-HexNAc is a precursor for various glycosylation reactions including $\mathrm{N}$-glycosylation, O-glycosylation, and O-GlcNAcylation or the synthesis of proteoglycans and other glycoconjugates. N-glycosylation is inhibited by tunicamycin (TM). (B) IC-MS analysis of UDP-HexNAc levels of four TM resistant clones (clone 1-4) generated in insertional mutagenesis screen compared to control WT and AMDHD2 KO AN3-12 mESCs (mean \pm SEM, $n=5$, ${ }^{* *} p<0.01,{ }^{* * *} p<0.001$, One-way ANOVA Dunnett post-test). (C) IC-MS analysis of UDP-GlcNAc levels in WT and AMDHD2 KO AN3-12 cells expressing WT FLAG-HA-hAMDHD2 (hAMDHD2) and mutant FLAG-HA-hAMDHD2 D294A (hAMDHD2 D294A) (mean \pm SEM, $n=7,{ }^{*} p<0.05,{ }^{* *} p<0.01$, ns $=$ not significant, One-way ANOVA Tukey post-test). (D) Cell viability (XTT assay) of 
WT and AMDHD2 KO AN3-12 mESCs expressing WT FLAG-HA-hAMDHD2 (hAMDHD2) and mutant FLAG-HA-hAMDHD2 D294 (hAMDHD2 D294A). Cells were treated with $0.5 \mu \mathrm{g} / \mathrm{ml} \mathrm{TM}$ for $48 \mathrm{~h}$ (mean $\pm \mathrm{SEM}, \mathrm{n}=6,{ }^{* *} \mathrm{p}<0.01$, ns = not significant, One-way ANOVA Tukey post-test). (E) Genotyping results for the AMDHD2 deletion in dissected (E7-8) embryos and weaned mice. Figure supplements are available in Figure 2-figure supplements 1-3. Source data for this figure are available in Figure 2-source data 1-3.

Figure 3: Structural and biochemical characterization of human AMDHD2

(A) Influence of divalent addition $(10 \mu \mathrm{M})$ on the stability of AMDHD2 in SEC buffer in thermal shift assays (mean + SEM, $n=3$, ns = not significant, ${ }^{* * *} p<0.0001$ versus wildtype, one-way ANOVA). (B) Deacetylase activity of AMDHD2 in the presence of EDTA and several indicated divalents (mean + SEM, $n=3, n s=$ not significant, ${ }^{*} p<0.05$, ${ }^{* * *} p<0.0001$ versus wildtype, oneway ANOVA). (C) Overview of the human AMDHD2 dimer in cartoon representation. Monomer $A$ is colored in gray and monomer $B$ in blue. The two deacetylase domains are interacting with each other. The DUF domain is formed by residues of the $\mathrm{N}$-terminus (light gray, light blue) and residues of the C-terminus (black, dark blue). GlcN6P (yellow sticks), $\mathrm{Zn}^{2+}$ (green sphere), and the putative active site lid (wheat) are highlighted. (D) Domains and secondary structure elements within one AMDHD2 monomer. The deacetylase domain (left) shows a TIM barrel-like fold, while the small DUF domain (right) is composed of a $\beta$-sandwich fold. $\alpha$-helices are colored in blue, $\beta$-strands in red, and loops in gray. GlcN6P (yellow sticks) and $\mathrm{Zn}^{2+}$ (green sphere) are highlighted. (E) Close-up view of the active site in cartoon representation. Residues involved in ligand binding or catalysis are highlighted as sticks, as well as GlcN6P (yellow sticks), $\mathrm{Zn}^{2+}$ (green sphere) and two water molecules (red spheres). The GlcN6P binding site is formed by two deacetylase domains. Black dashed lines indicate key interactions to GlcN6P and green dashed lines the coordination of $\mathrm{Zn}^{2+}$. (F) Close-up view of the dimer interface in cartoon representation. His242, Arg243, and Ile280, which were mutated for further characterization of the dimer, are highlighted as sticks. (G) Representative chromatogram of an analytical size-exclusion chromatography of human AMDHD2 variants using a Superdex ${ }^{\mathrm{TM}} 200$ Increase $10 / 300$ GL column. Absorption at $280 \mathrm{~nm}$ (mAU: milli absorbance units) was plotted against the elution volume. (H) Molecular weight of human AMDHD2 based on analytical size-exclusion chromatography measurements (mean + $\mathrm{SD}, \mathrm{n}=3$.) (I) Deacetylase activity of wildtype (WT) and mutant human AMDHD2 (mean + SEM, $n=6,{ }^{* * *} p<0.0001$ versus wildtype, one-way ANOVA). (J) Anomalous map of $\mathrm{Zn}^{2+}$ with a contour level of 5.0 RMSD (violet). Figure supplements are available in Figure 3-figure supplements 1-9. Source data for this figure are available in Figure 3-source data 1-5. 
Figure 4: Characterization of AMDHD2 loss-of-function mutants

(A) SDS-gels stained with Coomassie brilliant blue of a representative bacterial test expression of the human AMDHD2 variants. The experiment was repeated three times with similar results. BI: before induction, Al: after induction, TL: total lysate, SN: soluble fraction/ supernatant. A band corresponding to the molecular weight of human AMDHD2 with $\mathrm{His}_{6}$-tag (46 kDa) was present in all total lysates after induction. (B) Overview of the position of the potential loss-offunction mutations in human AMDHD2 in cartoon representation. GlcN6P (yellow sticks), the metal co-factor (green spheres), the active site Asp294 (violet sticks), and the eleven putative loss-of-function mutations (cyan sticks) are highlighted. (C) Deacetylase activity of wildtype (WT) and mutant human AMDHD2 (mean + SEM, $n=6,{ }^{* * *} p<0.0001$ versus wildtype, one-way ANOVA). Figure supplements are available in Figure 4-figure supplement 1. Source data for this figure are available in Figure 4-source data 1-5.

Figure 5: AMDHD2 limits HBP activity when GFPT2 replaces GFPT1 as the first enzyme

(A) Relative GFPT1 and GFPT2 mRNA levels (qPCR) in WT AN3-12 cells (mean \pm SEM, $n=4,{ }^{* * *} p<0.001$, unpaired t-test). (B) Western blot analysis of purified human GFPT1 and GFPT2 protein lysates of indicated cell lines. (C) Western blot analysis of AMDHD2 in indicated cell lines. (D) IC-MS analysis of UDP-GlcNAc levels in WT and AMDHD2 KO AN3-12 mESCs and N2a cells (mean \pm SEM, $n=5,{ }^{* * *} p<0.001$, one-way ANOVA). (E) Representative UDP-GlcNAc dose-response assay with hGFPT1 (black circle) and hGFPT2 (teal square) (mean $\pm S D, n=3$ ). (F) Relative UDP-GlcNAc levels in indicated cell lines measured by IC-MS. Levels are normalized to those in AN3-12 mESCs (mean \pm SEM, $n \geq 3$, ${ }^{* * *} p<0.001$, one-way ANOVA). (G) Western blot analysis of O-GlcNAc-modified proteins (RL2), OGA, OGT, and tubulin in the indicated cell lines (H-J) Quantification of Western blot in $(G)$ (mean $\pm S D, n=4$, ${ }^{*} \mathrm{p}<0.05,{ }^{* *} p<0.01,{ }^{* * *} p<0.001$, ns = not significant, One-way ANOVA Dunnett post-test). Figure supplements are available in Figure 5-figure supplements 1-3. Source data for this figure are available in Figure 5-source data 1-25.

Figure 6: Differentiation of ESCs induces an enzymatic reconfiguration of the HBP by reducing the GFPT2:GFPT1 ratio

(A) Western blot analysis and quantification (mean $\pm S D, n=4,{ }^{*} p<0.05$, unpaired t-test) of GFPT2 in WT AN3-12 control cells and upon partial differentiation by a 5-day LIF removal. (B) Relative Gfpt2 mRNA level (qPCR) in WT AN3-12 cells and upon partial differentiation by a 5-day LIF removal (mean

(C) Relative GFPT2/GFPT1 mRNA and 
GFPT2/GFPT1 protein ratios in human ESCs and upon differentiation into cardiomyocytes (data obtained from: Frank et al. 2019, Bartsch et al. 2021). (D) Relative GFPT2/GFPT1 mRNA and GFPT2/GFPT1 protein ratios in human ESCs and upon differentiation into neurons (data obtained from: Saez et al. 2018). (E) Model: Enzymatic configuration of the HBP in ESCs and somatic cells. The HBP (blue box) generates UDP-GlcNAc in multiple enzymatic steps. While ESCs mainly rely on GFPT2, more differentiated cells use GFPT1 for HBP entry. GFPT2 is less susceptible to UDP-GIcNAc inhibition than GFPT1 (indicated by red arrow). As an alternative regulatory mechanism ESCs require AMDHD2. Differentiation of ESCs induces an HBP reconfiguration, resulting in a decreased GFPT2:GFPT1 ratio. GFPT: glutamine fructose-6-phosphate amidotransferase, GNPDA: D-glucosamine-6-phosphate deaminase, GNA1: Dglucosamine-6-phosphate-Nacetyltransferase, AMDHD2: N-acetylglucosamine6-phosphatedeacetylase, PGM3: phosphoglucomutase, UAP1: UDP-Nacetylglucosamine pyrophosphorylase. Figure supplements are available in Figure 6-figure supplement 1. Source data for this figure are available in Figure 6-source data 1-5.

List of Figure supplements

1324

Figure 1-figure supplement 1

1325

Figure 2-figure supplements 1-3

1326

Figure 3-figure supplements 1-9

1327 Figure 4-figure supplements 1

1328 Figure 5-figure supplements 1-3

1329 Figure 6-figure supplement 1

\section{List of source data}

1333

Figure 1-source data 1: XTT assay of four TM resistant clones identified via insertional mutagenesis compared to control WT AN3-12 cells. (Figure 1C)

Figure 1-source data 2: anti-AMDHD2 Western Blot (raw) (Figure 1D)

Figure 1-source data 3: anti-AMDHD2 Western Blot (labelled) (Figure 1D)

Figure 1-source data 4: anti-Tubulin Western Blot (raw) (Figure 1D)

Figure 1-source data 5: anti-Tubulin Western Blot (labelled) (Figure 1D)

1339 Figure 1-source data 6: Cell viability (XTT assay) of WT and AMDHD2 KO AN3-12 cells (Figure 1E)

Figure 1-figure supplement 1-source data 1: Cell viability (XTT assay) of WT mutagenesis (Figure 1-figure supplement 1A) 
Figure 1-figure supplement 1-source data 2: Cell viability (XTT assay) of WT and two additional AMDHD2 KO AN3-12 cell lines (\#2-3) (Figure 1- figure supplement 1D)

Figure 2-source data 1: IC-MS analysis of UDP-HexNAc levels of four TM resistant clones identified via insertional mutagenesis compared to control WT and AMDHD2 KO AN3-12 cells (Figure 2B)

1352 Figure 2-source data 2: IC-MS analysis of UDP-GlcNAc levels of WT and AMDHD2 KO AN3-12 cells and both lines stably overexpressing FLAG-HAhAMDHD2 and FLAG-HA-hAMDHD2 D294A respectively (Figure 2C)

Figure 2-source data 3: Cell viability (XTT assay) of WT and AMDHD2 KO AN3-12 cells and both lines stably overexpressing FLAG-HA-hAMDHD2 and FLAG-HA-hAMDHD2 D294A respectively (Figure 2D)

Figure 2-figure supplement 1-source data 1: IC-MS analysis of UDP-HexNAC levels of WT and two additional AMDHD2 KO AN3-12 cell lines (\#2-3) (Figure 2figure supplement 1)

Figure 2-figure supplement 2-source data 1: anti-AMDHD2 Western Blot (raw) (Figure 2-figure supplement 2A)

1364 Figure 2-figure supplement 2-source data 2: anti-AMDHD2 Western Blot 1365 (labelled) (Figure 2-figure supplement 2A)

1366 Figure 2-figure supplement 2-source data 3: anti-TUBULIN Western Blot 1367 (raw) (Figure 2-figure supplement 2A)

1368 Figure 2-figure supplement 2-source data 4: anti-TUBULIN Western Blot 1369 (labelled) (Figure 2-figure supplement 2A)

1370 Figure 2-figure supplement 2-source data 5: anti-FLAG Western Blot (raw) 1371 (Figure 2- figure supplement 2B)

1372 Figure 2-figure supplement 2-source data 6: anti-FLAG Western Blot 1373 (labelled) (Figure 2-figure supplement 2B)

1374 Figure 2-figure supplement 2-source data 7: anti-TUBULIN Western Blot 1375 (raw) (Figure 2-figure supplement 2B)

1376 Figure 2-figure supplement 2-source data 8: anti-TUBULIN Western Blot

Figure 3-source data 1: Thermal Shift Assay, melting temperatures of AMDHD2 in SEC buffer in the presence of varying divalents (Figure $3 A$ )

Figure 3-source data 2: Deacetylase activity of AMDHD2 in the presence of EDTA and several indicated divalents (Figure $3 B$ )

Figure 3- source data 3: Representative analytical size-exclusion chromatography of AMDHD2 variants (Figure 3G)

Figure 3-source data 4: Molecular weight of wildtype (WT) and mutant human AMDHD2 based on analytical size-exclusion chromatography measurements (Figure 3H)

Figure 3-source data 5: Deacetylase activity of wildtype (WT) and mutant human AMDHD2 (Figure 3l) 
Figure 3-figure supplement 3-source data 1: Representative dynamic light scattering measurement of AMDHD2 (Figure 3-figure supplement 3)

Figure 3-figure supplement 9-source data 1: Deacetylase activity of human AMDHD2 towards GlcNAc6P, GaINAc6P, and GlcNAc6S

Figure 4-source data 1: First SDS-gel stained with Coomassie brilliant, provided as full raw unedited and labeled JPG files (Figure 4A)

Figure 4-source data 2: Second SDS-gel stained with Coomassie brilliant, provided as full raw unedited and labeled JPG files (Figure 4A)

1400 Figure 4-source data 3: Third SDS-gel stained with Coomassie brilliant, provided as full raw unedited and labeled JPG files (Figure 4A)

Figure 4-source data 4: Fourth SDS-gel stained with Coomassie brilliant, provided as full raw unedited and labeled JPG files (Figure 4A)

1404 Figure 4-source data 1-4: SDS-gels stained with Coomassie brilliant blue of a 1405 representative bacterial test expression of the human AMDHD2 variants in an Excel file (full raw unedited and labeled) (Figure 4A)

Figure 4-source data 5: Deacetylase activity of wildtype (WT) and mutant human AMDHD2 (Figure 4C)

Figure 4-figure supplement 1-source data 1: First SDS-gel stained with Coomassie brilliant, provided as full raw unedited and labeled JPG files (Figure 4-figure supplement 1)

Figure 4-figure supplement 1-source data 2: Second SDS-gel stained with Coomassie brilliant, provided as full raw unedited and labeled JPG files (Figure 4-figure supplement 1)

Figure 4- figure supplement 1-source data 1-2: SDS-gels stained with Coomassie brilliant blue of a representative bacterial test expression of the human AMDHD2 variants in an Excel file (full raw unedited and labeled) (Figure 4-figure supplement 1)

Figure 5-source data 1: Relative GFPT1 and GFPT2 mRNA levels (qPCR) in WT AN3-12 cells (Figure 5A)

1423 Figure 5-source data 2: anti-GFPT1 Western Blot (raw) (Figure 5B)

1424 Figure 5-source data 3: anti-GFPT1 Western Blot (labelled) (Figure 5B)

1425 Figure 5-source data 4: anti-Tubulin Western Blot (raw) (Figure 5B)

1426 Figure 5-source data 5: anti-Tubulin Western Blot (labelled) (Figure 5B)

1427 Figure 5-source data 6: anti-GFPT2 Western Blot (raw) (Figure 5B)

1428 Figure 5-source data 7: anti-GFPT2 Western Blot (labelled) (Figure 5B)

1429 Figure 5-source data 8: anti-Tubulin Western Blot (raw) (Figure 5B)

1430 Figure 5-source data 9: anti-Tubulin Western Blot (labelled) (Figure 5B)

1431 Figure 5-source data 10: anti-AMDHD2 Western Blot (raw) (Figure 5C)

1432 Figure 5-source data 11: anti-AMDHD2 Western Blot (labelled) (Figure 5C)

1433 Anti-TUBULIN: same as Figure 5- source data 4 (Figure 5C)

1434 Anti-TUBULIN: same as Figure 5- source data 5 (Figure 5C)

1435 Figure 5-source data 12: IC-MS analysis of UDP-GlcNAc levels of AMDHD2 1436 KO compared to WT cells (Figure 5D) 
Figure 5-source data 13: UDP-GlcNAc dose-response assay with hGFPT1 and hGFPT2 (Figure 5E)

1439 Figure 5-source data 14: Relative UDP-GlcNAc levels in indicated cell lines 1440 measured by IC-MS (Figure 5F)

1441 Figure 5-source data 15: anti-RL2 Western Blot (raw) (Figure 5G)

1442 Figure 5-source data 16: anti-RL2 Western Blot (labelled) (Figure 5G)

1443 Figure 5-source data 17: anti-OGA Western Blot (raw) (Figure 5G)

1444 Figure 5-source data 18: anti-OGA Western Blot (labelled) (Figure 5G)

1445 Figure 5-source data 19: anti-OGT Western Blot (raw) (Figure 5G)

1446 Figure 5-source data 20: anti-OGT Western Blot (labelled) (Figure 5G)

1447 Figure 5-source data 21: anti-TUBULIN Western Blot (raw) (Figure 5G)

1448 Figure 5-source data 22: anti-TUBULIN Western Blot (labelled) (Figure 5G)

1449 Figure 5-source data 23: Quantification of O-GlcNAc modified proteins (RL2)

1450 (Figure 5H)

1451 Figure 5-source data 24: Quantification of OGA expression (Figure 5I)

1452 Figure 5-source data 25: Quantification of OGT expression (Figure 5J)

Figure 5-figure supplement 1-source data 1: Relative UDP-GlcNAc levels of distinct mutants compared to WT AN3-12 mESCs (Figure 5-figure supplement 1)

Figure 5-figure supplement 2-source data 1: anti-AMDHD2 Western Blot (raw) (Figure 5-figure supplement 2A)

1459 Figure 5-figure supplement 2-source data 2: anti-AMDHD2 Western Blot 1460 (labelled) (Figure 5-figure supplement 2A)

1461 Figure 5-figure supplement 2-source data 3: anti-TUBULIN Western Blot 1462 (raw) (Figure 5-figure supplement 2A)

1463 Figure 5- figure supplement 2-source data 4: anti-TUBULIN Western Blot 1464 (labelled) (Figure 5-figure supplement 2A)

1465 Figure 5-figure supplement 2-source data 5: IC-MS analysis of UDP-GlcNAc 1466 levels of WT and AMDHD2 KO C2C12 myoblasts (Figure 5-figure supplement 1467 2B)

1468 Figure 5-figure supplement 3-source data 1: L-Gln kinetic of WT human 1469 GFPT1 and WT human GFPT2 (Figure 5-figure supplement 3A)

1470 Figure 5-figure supplement 3-source data 2: Fructose-6-Phosphate kinetic of WT human GFPT1 and WT human GFPT2 (Figure 5-figure supplement 3B)

Figure 6-source data 1: anti-GFPT2 Western Blot (raw) (Figure 6A)

1474 Figure 6-source data 2: anti-GFPT2 Western Blot (labelled) (Figure 6A)

1475 Figure 6-source data 3: anti-TUBULIN Western Blot (raw) (Figure 6A)

1476 Figure 6-source data 4: anti-TUBULIN Western Blot (labelled) (Figure 6A)

1477 Figure 6-source data 5: Relative Gfpt2 mRNA level (qPCR) in WT AN3-12 cells and upon partial differentiation by a 5-day LIF removal (-Lif) (Figure 6B) 
1480 Figure 6-figure supplement 1-source data 1: Relative Nanog and Klf4 mRNA 1481 level (qPCR) in WT AN3-12 cells and upon partial differentiation by a 5-day LIF 1482 removal (-Lif) (Figure 6-figure supplement 6A)

1483 Figure 6-figure supplement 1-source data 2: Relative Gfpt1 and Amdhd2 1484 mRNA level (qPCR) in WT AN3-12 cells and upon partial differentiation by a 51485 day LIF removal (-Lif) (Figure 6-figure supplement 6B)

1486 Figure 6-figure supplement 1-source data 3: anti-GFPT1 Western Blot (raw) 1487 (Figure 6-figure supplement $6 \mathrm{C}$ )

1488 Figure 6-figure supplement 1-source data 4: anti-GFPT1 Western Blot 1489 (labelled) (Figure 6-figure supplement 6C)

1490 Figure 6-figure supplement 1-source data 5: anti-AMDHD2 Western Blot 1491 (raw) (Figure 6-figure supplement 6C)

1492 Figure 6-figure supplement 1-source data 6: anti-AMDHD2 Western Blot 1493 (labelled) (Figure 6-figure supplement 6C)

1494 Figure 6-figure supplement 1-source data 7: anti-TUBULIN Western Blot 1495 (raw) (Figure 6-figure supplement 6C)

1496 Figure 6-figure supplement 1-source data 8: anti-TUBULIN Western Blot 1497 (labelled) (Figure 6-figure supplement 6C)

1498 Figure 6-figure supplement 1-source data 9: Quantification of GFPT1 1499 expression (Figure 6-figure supplement 6D)

1500 Figure 6-figure supplement 1-source data 10: Quantification of AMDHD2 1501 expression (Figure 6-figure supplement 6D) 
Table 1 - Data collection and refinement statistics of human AMDHD2

\begin{tabular}{|c|c|c|}
\hline & $\begin{array}{l}\text { AMDHD2 } \\
+\mathrm{Zn}+\mathrm{GIcN6P}\end{array}$ & $\begin{array}{l}\text { AMDHD2 } \\
+\mathrm{Zn}\end{array}$ \\
\hline Wavelength $(\dot{A})$ & 1.00 & 1.00 \\
\hline $\begin{array}{l}\text { Resolution range } \\
\text { (A) }\end{array}$ & $\begin{array}{l}45.71-1.90 \\
(1.97-1.90)\end{array}$ & $\begin{array}{l}48.21-1.84 \\
(1.90-1.84)\end{array}$ \\
\hline Space group & $P 2_{1} 2_{1} 2_{1}$ & $\mathrm{P} 22_{1} 2_{1} 2_{1}$ \\
\hline$a, b, c(\AA)$ & 63.3161 .486 .6 & 61.884 .3154 .2 \\
\hline$\alpha, \beta, y\left({ }^{\circ}\right)$ & 909090 & 909090 \\
\hline Total reflections & 428727 (42693) & 468961 (46539) \\
\hline Unique reflections & 70760 (6907) & 71036 (6953) \\
\hline Multiplicity & $6.1(6.2)$ & $6.6(6.7)$ \\
\hline Completeness (\%) & $99.7(98.3)$ & $99.9(99.2)$ \\
\hline Mean I/sigma(I) & $11.46(1.16)$ & $12.53(1.06)$ \\
\hline Wilson B-factor & 34.7 & 29.7 \\
\hline $\mathbf{R}_{\text {merge }}(\%)$ & $9.5(140.4)$ & $10.2(150.6)$ \\
\hline $\mathbf{R}_{\text {meas }}(\%)$ & $10.4(153.3)$ & $11.0(163.3)$ \\
\hline $\mathbf{R}_{\text {pim }}(\%)$ & $4.2(60.9)$ & $4.3(62.5)$ \\
\hline $\mathrm{CC}_{1 / 2}(\%)$ & $99.9(49.4)$ & $99.9(49.9)$ \\
\hline $\mathrm{CC}^{*}(\%)$ & $100(81.3)$ & $100(81.6)$ \\
\hline $\begin{array}{l}\text { Reflections used } \\
\text { in refinement }\end{array}$ & 70751 (6906) & 71024 (6952) \\
\hline $\begin{array}{l}\text { Reflections used } \\
\text { for R-free }\end{array}$ & $1980(194)$ & $1992(195)$ \\
\hline $\mathbf{R}_{\text {work }}(\%)$ & $18.5(31.7)$ & $18.2(31.2)$ \\
\hline $\mathbf{R}_{\text {free }}(\%)$ & $21.3(29.6)$ & $20.6(33.6)$ \\
\hline $\mathbf{C C}_{\text {work }}(\%)$ & $96.6(73.4)$ & $96.6(75.7)$ \\
\hline $\mathbf{C C}_{\text {free }}(\%)$ & $94.4(73.1)$ & $95.4(72.8)$ \\
\hline $\begin{array}{l}\text { Number of non- } \\
\text { hydrogen atoms }\end{array}$ & 6361 & 6331 \\
\hline macromolecules & 5997 & 5999 \\
\hline ligands & 34 & 14 \\
\hline solvent & 330 & 318 \\
\hline Protein residues & 801 & 798 \\
\hline RMS (bonds) ( $\dot{A})$ & 0.005 & 0.004 \\
\hline RMS (angles) $\left(^{\circ}\right)$ & 0.69 & 0.70 \\
\hline $\begin{array}{l}\text { Ramachandran } \\
\text { favored (\%) }\end{array}$ & 96.9 & 97.1 \\
\hline $\begin{array}{l}\text { Ramachandran } \\
\text { allowed (\%) }\end{array}$ & 2.9 & 2.7 \\
\hline $\begin{array}{l}\text { Ramachandran } \\
\text { outliers (\%) }\end{array}$ & 0.25 & 0.25 \\
\hline $\begin{array}{l}\text { Rotamer outliers } \\
\text { (\%) }\end{array}$ & 0.32 & 0.32 \\
\hline Clashscore & 0.67 & 0.92 \\
\hline Average B-factor & 43.59 & 37.67 \\
\hline macromolecules & 43.81 & 37.76 \\
\hline ligands & 40.19 & 41.98 \\
\hline solvent & 40.10 & 35.72 \\
\hline $\begin{array}{l}\text { Number of TLS } \\
\text { groups }\end{array}$ & 4 & 4 \\
\hline PDB ID & 7NUT & $7 \mathrm{NUU}$ \\
\hline
\end{tabular}

Statistics for the highest-resolution shell are shown in parentheses. 
Table 2 - Kinetic parameters of human GFPT1 and GFPT2

1510

\begin{tabular}{|c|c|c|c|c|c|c|c|}
\hline & \multicolumn{3}{|c|}{ L-Glu production } & \multicolumn{3}{|c|}{ D-GIcN6P production } & \multirow{2}{*}{$\begin{array}{c}\text { UDP-GIcNAC } \\
\text { inhibition } \\
\mathrm{IC}_{50} \\
{[\mu \mathrm{M}]}\end{array}$} \\
\hline & $\begin{array}{c}\mathrm{K}_{\mathrm{m}} \mathrm{L}-\mathrm{G} \mathrm{In} \\
{[\mathrm{mM}]}\end{array}$ & $\begin{array}{l}\mathbf{k}_{\mathrm{cat}} \\
{\left[\mathbf{s}^{-1}\right]}\end{array}$ & $\begin{array}{c}\mathbf{k}_{\text {cat }} / \mathbf{K}_{\mathbf{m}} \\
{\left[\mathrm{mM}^{-1} \mathbf{s}^{-1}\right]}\end{array}$ & $\begin{array}{c}\mathrm{K}_{\mathrm{m}} \text { Frc6P } \\
{[\mathrm{mM}]}\end{array}$ & $\begin{array}{l}\mathbf{k}_{\mathrm{cat}} \\
{\left[\mathbf{s}^{-1}\right]}\end{array}$ & $\mid \begin{array}{c}\mathbf{k}_{\text {cat }} / \mathbf{K}_{\mathbf{m}} \\
{\left[\mathrm{mM}^{-1} \mathbf{s}^{-1}\right]}\end{array}$ & \\
\hline GFPT1 & $1.1 \pm 0.19$ & $\begin{array}{l}3.6 \pm \\
0.18\end{array}$ & 3.3 & $0.08 \pm 0.01$ & $\begin{array}{l}1.7 \pm \\
0.09\end{array}$ & 21.3 & $\begin{array}{c}57.0 \\
-8.3 /+9.7\end{array}$ \\
\hline GFPT2 & $0.5 \pm 0.06$ & $\begin{array}{l}3.7 \pm \\
0.10\end{array}$ & 7.4 & $0.29 \pm 0.05$ & $\begin{array}{l}1.8 \pm \\
0.09\end{array}$ & 6.2 & $\begin{array}{c}367.3 \\
-43.6 /+49.5\end{array}$ \\
\hline $\begin{array}{l}\text { Unpaired } \\
\text { t-test } \\
\text { (two- } \\
\text { sided) }\end{array}$ & ${ }^{* *} p=0.005$ & & & ${ }^{* *} p=0.0027$ & & & ${ }^{* * *} p=0.0002$ \\
\hline
\end{tabular}


Figure supplement legends

Figure 1-figure supplement 1, Identification and confirmation of AMDHD2 as the causative gene for mediating TM resistance by elevated UDP-GlcNAc levels. (A) Representative cell viability (XTT assay) of WT AN3-12 mESCs and four TM resistant clones (clone $A-D$ ) identified by the chemical (ENU) mutagenesis and that were used for whole exome sequencing. Cells were treated with $0.5 \mu \mathrm{g} / \mathrm{ml} \mathrm{TM}$ for $48 \mathrm{~h}$. (B) Table listing all mutations in the Amdhd2 locus identified in the TM resistance screen. (C) Schematic representation of experimental workflow for TM resistance screen using retroviral-based gene trap insertional mutagenesis. (D) Cell viability (XTT assay) of WT and two additional AMDHD2 KO AN3-12 cell lines (\#2-3), generated with distinct guide combinations. Cells were treated with $0.5 \mu \mathrm{g} / \mathrm{ml}$ TM for $48 \mathrm{~h}$ (mean $\pm \mathrm{SEM}, \mathrm{n}=6$, ${ }^{* * *}$ $\mathrm{p}<0.001$, One-way ANOVA Dunnett post-test). 

resistance via elevated HBP flux

Figure 2-figure supplement 1, AMDHD2 disruption in AN3-12 mESCs increases HBP 1541 flux.

1542 UDP-HexNAc concentration of the two additional AMDHD2 KO cell lines (\#2-3), generated with distinct guide combinations compared to WT AN3-12 mESCs (mean \pm SEM, $n \geq 3,{ }^{* * *} p<0.001$, one-way ANOVA). UDP-HexNAc is the combined pool of the UDP-GIcNAc and UDP-GalNAc epimer pools.

Figure 2-figure supplement 2, Generation of different AN3-12 mESC lines stably over-expressing WT FLAG-HA-hAMDHD2 and mutant FLAG-HA-hAMDHD2 D294A protein. (A) Western blot analysis of AMDHD2 expression in WT and AMDHD2 KO AN3-12 cells expressing WT FLAG-HA-hAMDHD2 (hAMDHD2) and mutant FLAG-HAhAMDHD2 D294A (hAMDHD2 D294A). The asterisk $\left({ }^{*}\right)$ indicates the band for the recombinant WT FLAG-HA-hAMDHD2 and mutant FLAG-HA-hAMDHD2 D294A protein. The lower band deemed to be a mixture of endogenous mAMDHD2 and recombinant hAMDHD2/ hAMDHD2 D294A protein upon cleavage of the N-terminal FLAG-HA-tag. (B) Western blot analysis of FLAG expression in WT and AMDHD2 KO AN3-12 cells expressing WT FLAG-HA-hAMDHD2 (hAMDHD2) and mutant FLAG-HAhAMDHD2 D294A (hAMDHD2 D294A).

Figure 2-figure supplement 3, Generation of AMDHD2 KO founder mice. (A) 1566 Schematic representation of the CRISPR/Cas9-targeted exon of the mouse Amdhd2 locus. Deletions in founder lines 1-4 are indicated in red. (B) Table listing used guide combinations and deletion details of the AMDHD2 $\mathrm{KO}$ founder lines. (C) Representative genotyping results of heterozygous AMDHD2 KO mice. The WT PCR 

human AMDHD2

Figure 3-figure supplement 1, Stereo image of the human AMDHD2 dimer in cartoon representation. Monomer $\mathrm{A}$ is colored in gray and monomer $\mathrm{B}$ in blue. The two deacetylase domains are interacting with each other. The DUF domain is formed by residues of the $\mathrm{N}$-terminus (light gray, light blue) and residues of the C-terminus (black, dark blue). GlcN6P (yellow sticks), $\mathrm{Zn}^{2+}$ (green sphere), and the putative active site lid (wheat) are highlighted.

Figure 3-figure supplement 2, B-factor representation of WT human AMDHD2. The protein is presented as putty cartoon and colored from low to high B-factors (24-108 $A^{2}$, blue to red).

Figure 3-figure supplement 3, Oligomeric state of human AMDHD2. Representative DLS measurement of WT AMDHD2. Table: Parameters of the representative DLS measurement showing a dimeric assembly.

Figure 3-figure supplement 4, Superposition of GlcN6P-bound AMDHD2 monomer A (gray) and monomer B (blue) in cartoon representation. GlcN6P (yellow sticks) and $\mathrm{Zn}^{2+}$ (green spheres) are highlighted.

Figure 3-figure supplement 5, Close-up view of the active site in cartoon representation. Residues involved in ligand binding or catalysis are highlighted as sticks, as well as GlcN6P (yellow sticks), $\mathrm{Zn}^{2+}$ (green sphere) and two water molecules (red spheres). Three antiparallel $\beta$-strands ( $\beta 15-\beta 17$, colored wheat) build a $\beta$-sheet close to the active site.

Figure 3-figure supplement 6, Superposition of the structures of GlcN6P-bound (gray, blue) and GlcN6P-free (green, red) human AMDHD2 with RMSD of $0.67 \AA$ over 792 main chain residues in cartoon representation. GlcN6P (yellow sticks) and $\mathrm{Zn}^{2+}$ (green spheres) are highlighted.

Figure 3-figure supplement 7, Active site of human AMDHD2. (A) Omit map of the active site of human AMDHD2 in cartoon representation. Residues involved in ligand binding or catalysis are highlighted as sticks, as well as GlcN6P (yellow sticks). The Fo-Fc omit map is colored in green and its contour level is at 1.5 RMSD. (B) 2D ligandprotein interaction diagram of GlcN6P interacting with human AMDHD2. Ligand bonds are colored in gray and amino acid side chain bonds in black. Green dashed lines indicate hydrogen bonds and red spiked arcs present residues making non-bonded contacts with the ligands.

Figure 3-figure supplement 8, Protein sequence alignment of AMDHD2. Red boxes indicate identical residues, red letters indicate similar residues. The deacetylase domain and secondary structure elements are annotated, as well as the positions of insertions and extensions in AMDHD2 isoform 2 and isoform 3. Residues involved in 
1628 product binding, catalysis, or metal binding are highlighted. The putative active site lid 1629 is marked. Moreover, the positions of the potential loss-of-function mutations and the 1630 control mutations are labeled.

Figure 3-figure supplement 9, Deacetylase activity of human AMDHD2 towards 1633 GlcNAc6P, GalNAc6P, and GlcNAc6S (mean + SEM, $n=6,{ }^{* * *} p<0.0001$ versus GlcNAc6P, one-way ANOVA). 
1637 Figure 4-figure supplements | Characterization of AMDHD2 loss-of-function 1638 mutants

1639

1640

1641

1642

1643

1644

1645

1646

1647

Figure 4-figure supplement 1, SDS-gels stained with Coomassie brilliant blue of a representative bacterial test expression of the human AMDHD2 variants. The experiment was repeated three times with similar results. BI: before induction, Al: after induction, TL: total lysate, SN: soluble fraction/ supernatant, PL: pellet fraction solubilized in $8 \mathrm{M}$ urea. 
Figure 5-figure supplements | AMDHD2 limits HBP activity when GFPT2 replaces

Figure 5-figure supplement 1, Manipulation of GFPT1 in AN3-12 cells has no influence on UDP-GIcNAc levels. IC-MS analysis of relative UDP-GlcNAc levels of WT, GFPT1 G451E, GFPT1 KO and AMDHD2 KO AN3-12 cells. (mean \pm SEM, $n=7$, ${ }^{* * *} p<0.001$, one-way ANOVA Dunnett post-test)

Figure 5-figure supplement 2, Deletion of AMDHD2 has no effect on HBP flux in C2C12 myoblasts. (A) Western blot analysis of AMDHD2 expression in two AMDHD2 $\mathrm{KO}$ lines (clone 1-2) compared to WT C2C12 myoblasts. (B) IC-MS analysis of relative UDP-GlcNAc levels of two AMDHD2 KO lines (clone 1-2) compared to WT C2C12 myoblasts (mean \pm SEM, $n=6$, ns = not significant, one-way ANOVA Dunnett post-test).

1665

1666

1667

1668

Figure 5-figure supplement 3, Biochemical characterization of human GFPT2 compared to human GFPT1. (A) L-Gln kinetic of WT human GFPT1 (black circle) and WT human GFPT2 (teal square) (mean \pm SEM, hGFPT1 $n=5$, hGFPT2 $n=4$ ). (B) Frc6P kinetic of WT hGFPT1 (black circle) and WT hGFPT2 (teal square) (mean \pm SEM, hGFPT1 $n=5$, hGFPT2 $n=8$ ). 
1674 Figure 6-figure supplements | Differentiation of ESCs induces an enzymatic 1675 reconfiguration of the HBP by reducing the GFPT2:GFPT1 ratio

1676

1677

1678

1679

1680

1681

1682

1683

1684

1685

1686

1687

1688

1689

1690

Figure 6-figure supplement 1, The effect of partial differentiation upon LIF removal in AN3-12 cells on the enzymatic HBP composition. (A) Relative Nanog and Klf4 mRNAlevel (qPCR) of WT AN3-12 cells and upon partial differentiation by 5 days of LIF removal (SEM $\pm n=4$, ns $=$ not significant, unpaired t-test). (B) Relative Gfpt1 and Amdhd2 mRNA-level (qPCR) of WT AN3-12 cells and upon partial differentiation by 5 days of LIF removal (mean $\pm S E M, n=4$, ns $=$ not significant, unpaired t-test). (C) Representative Western blot analysis of GFPT1 and AMDHD2 in WT AN3-12 cells and upon partial differentiation by 5 days of LIF removal. (D) Quantification of Western blot as shown in $(C)$ (mean $\pm S D, n=4$, ns = not significant, unpaired t-test). 
A

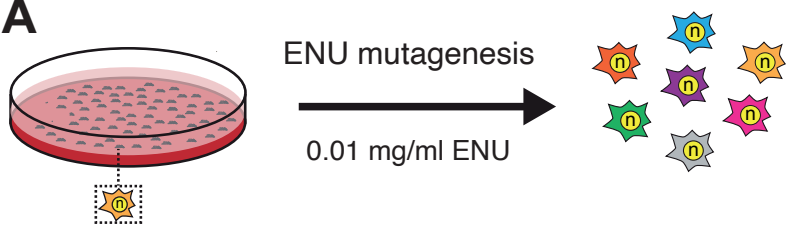

27 million cells

List of candidates

chr17 $24300270 \quad A \rightarrow G$ Amdhd2 (38\%)

chr1 $107564115 \mathrm{C} \rightarrow \mathrm{G} \ldots$.

chr7 $51506462 \quad \mathrm{C} \rightarrow \mathrm{G} \ldots$.

Selection for resistance

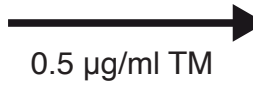

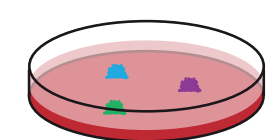

29 clones $\begin{aligned} & \text { Pooling of DNA of } \\ & \text { resistant clones }\end{aligned}$

Whole Exome

Sequencing

B

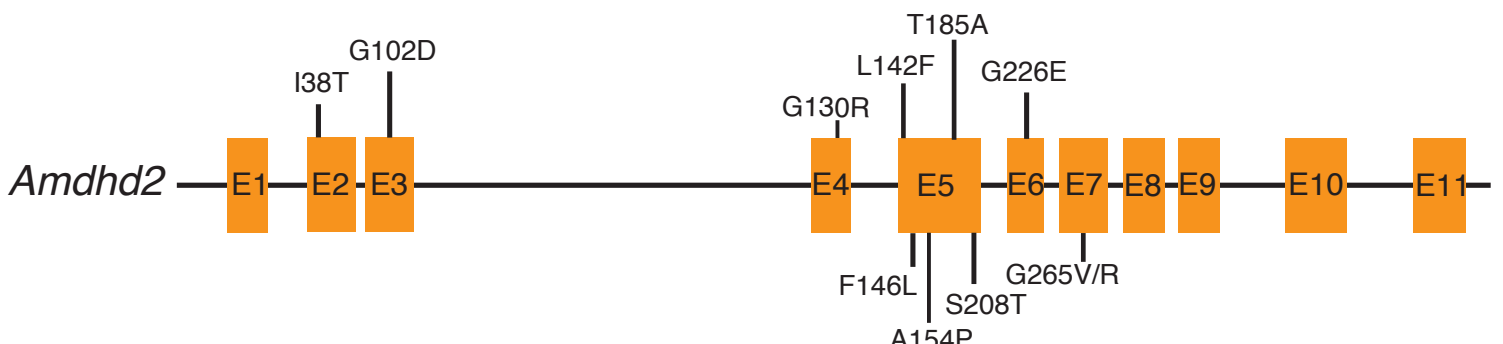

C Insertional mutagenesis screen $0.5 \mu \mathrm{g} / \mathrm{ml} \mathrm{TM}$; 48h

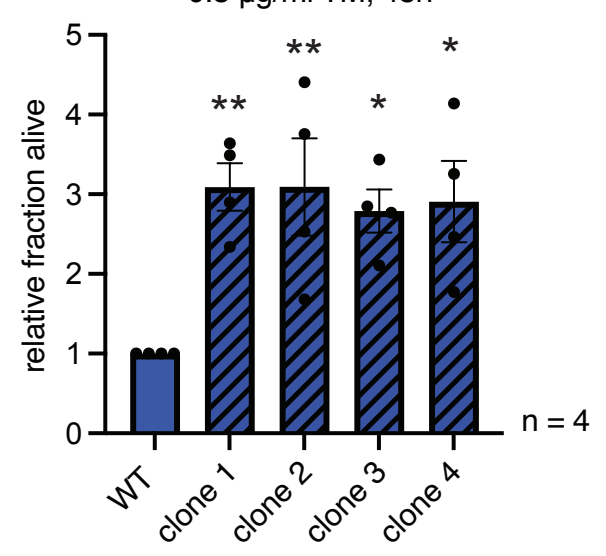

$\mathbf{F}$

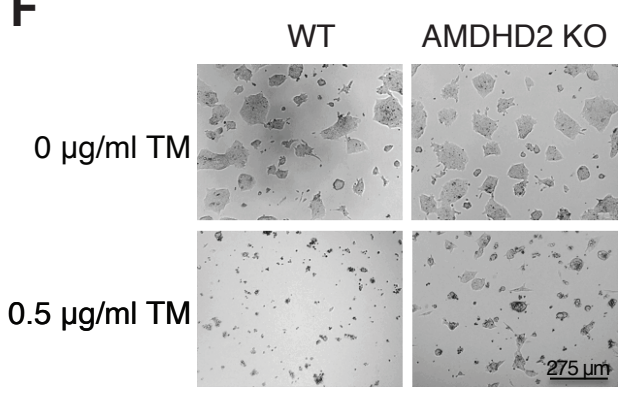

D

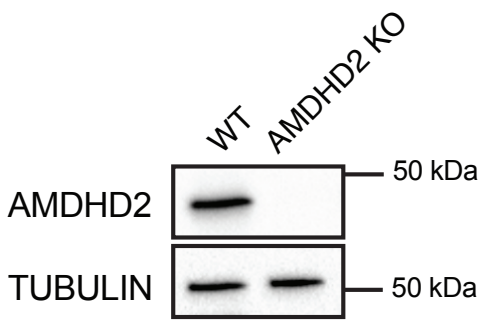

E

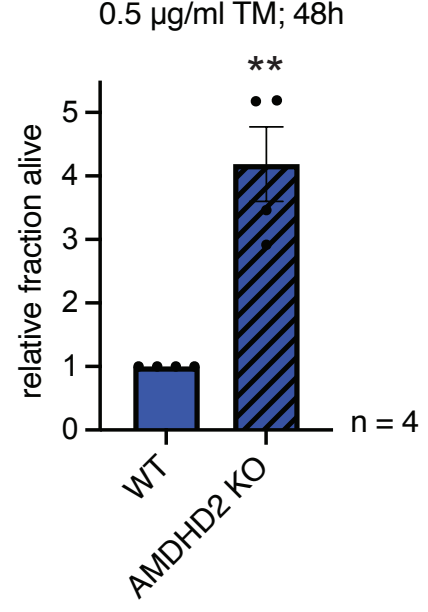


A

hexosamine

pathway
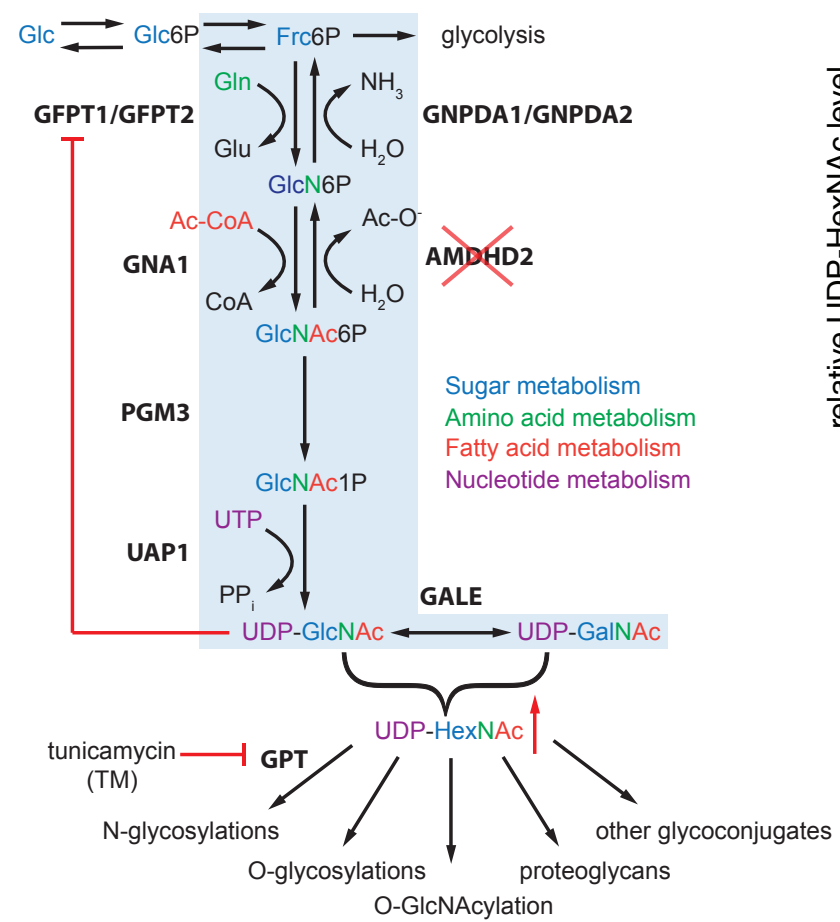

C
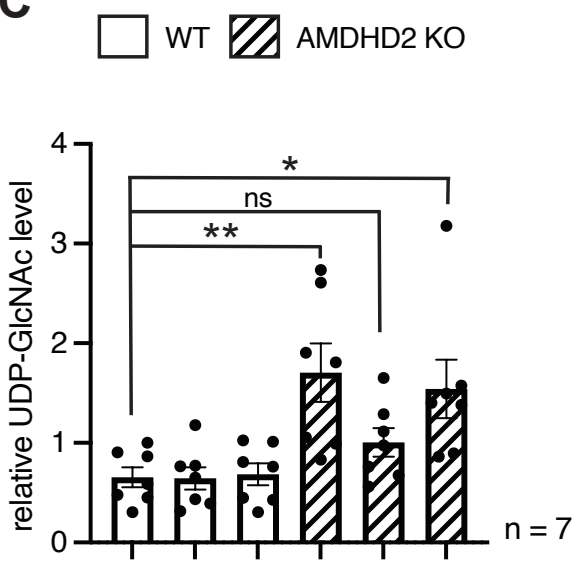

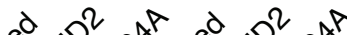

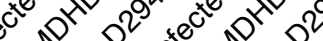

$4^{4} s^{2} s^{2}+n^{2}$

D

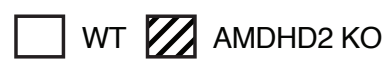

$0.5 \mu \mathrm{g} / \mathrm{ml} \mathrm{TM} ; 48 \mathrm{~h}$

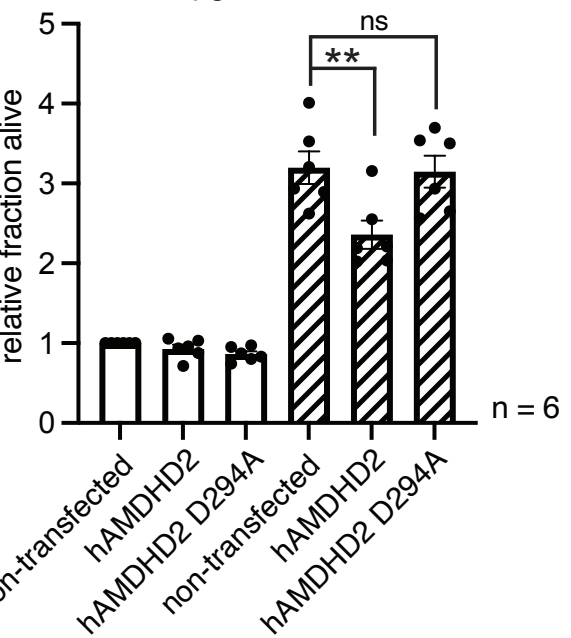

E

Prenatal dissection

\begin{tabular}{c:c:c} 
Genotype & No. of mice & $\%$ \\
\hline WT & 10 & 22 \\
\hdashline AMDHD2 $^{+/-}$ & 25 & 54 \\
\hdashline AMDHD2 $^{-/-}$ & 11 & 24 \\
\hdashline Total $^{-1}$ & 46 & 100 \\
\hline
\end{tabular}

Postnatal

\begin{tabular}{c:c:c} 
Genotype & No. of mice & $\%$ \\
\hdashline WT & 56 & 54 \\
\hdashline AMDHD2 $^{+/}$ & 48 & 46 \\
\hdashline AMDHD2 $^{-/}$ & 0 & 0 \\
\hdashline Total & 104 & 100
\end{tabular}


A

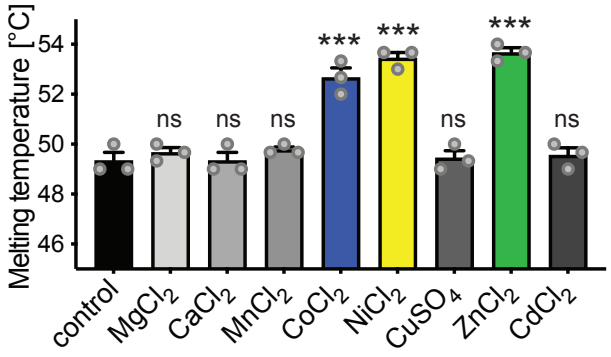

B

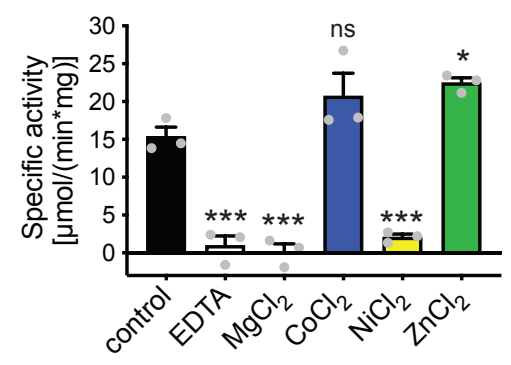

D

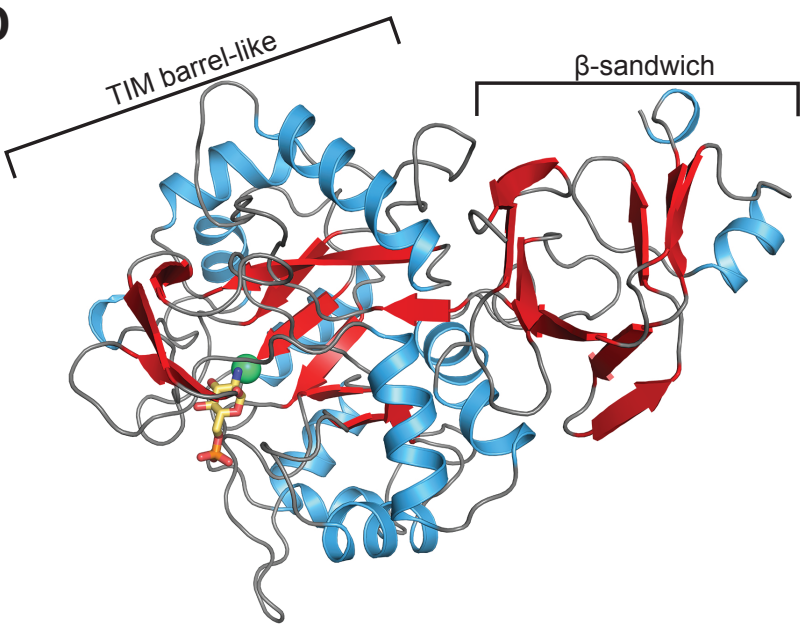

F

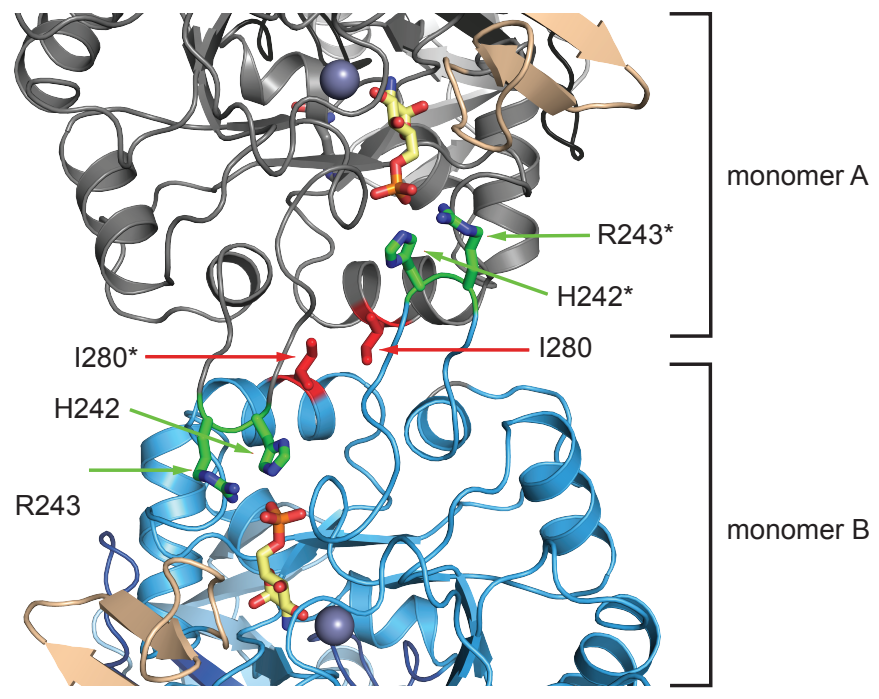

I

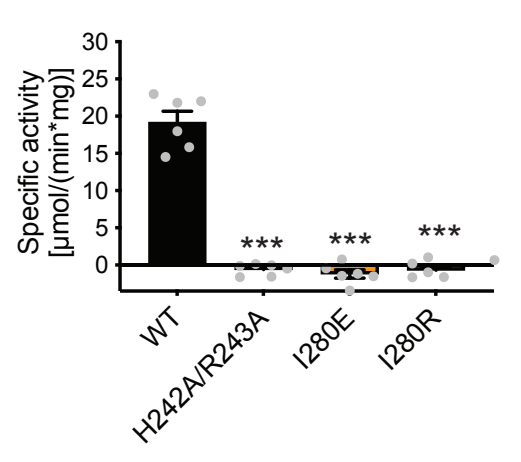

C

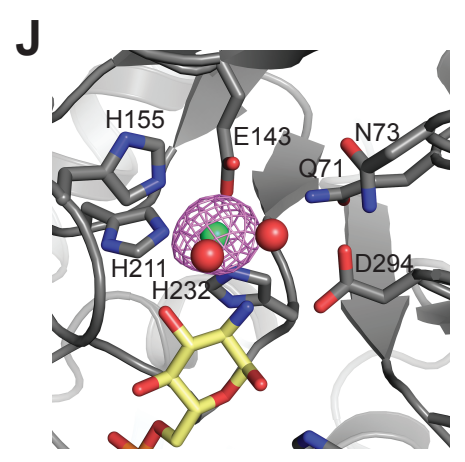

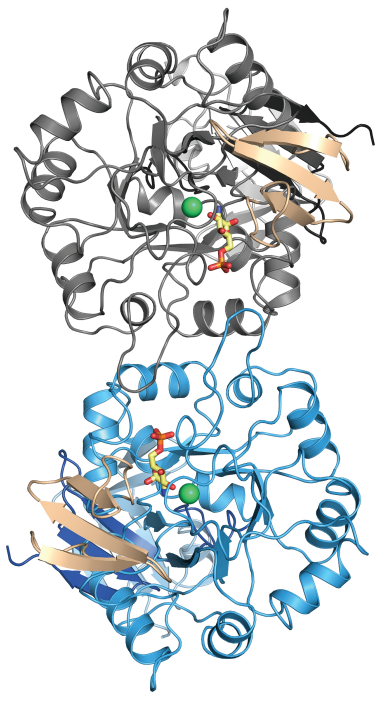

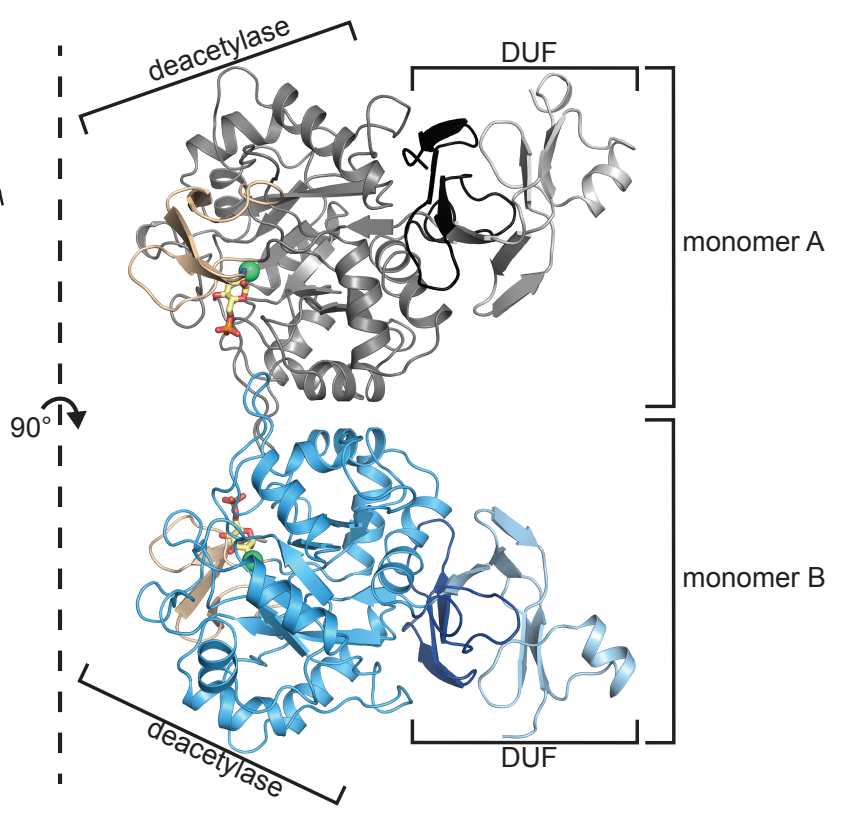

E

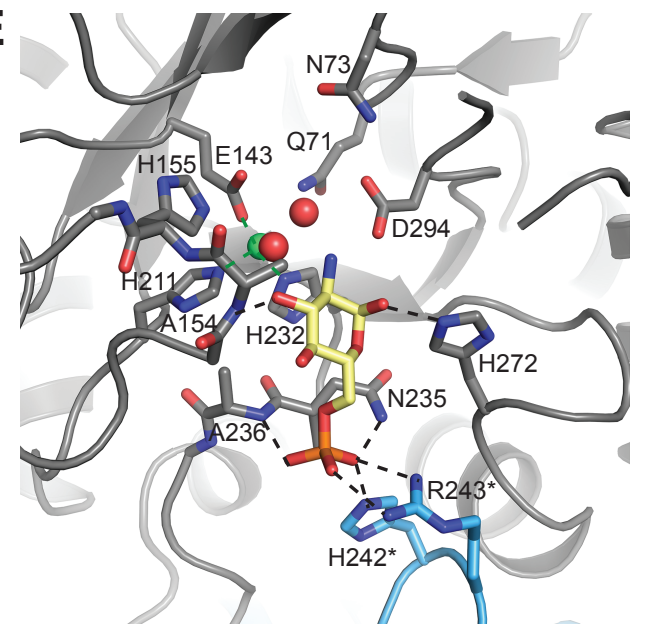

G
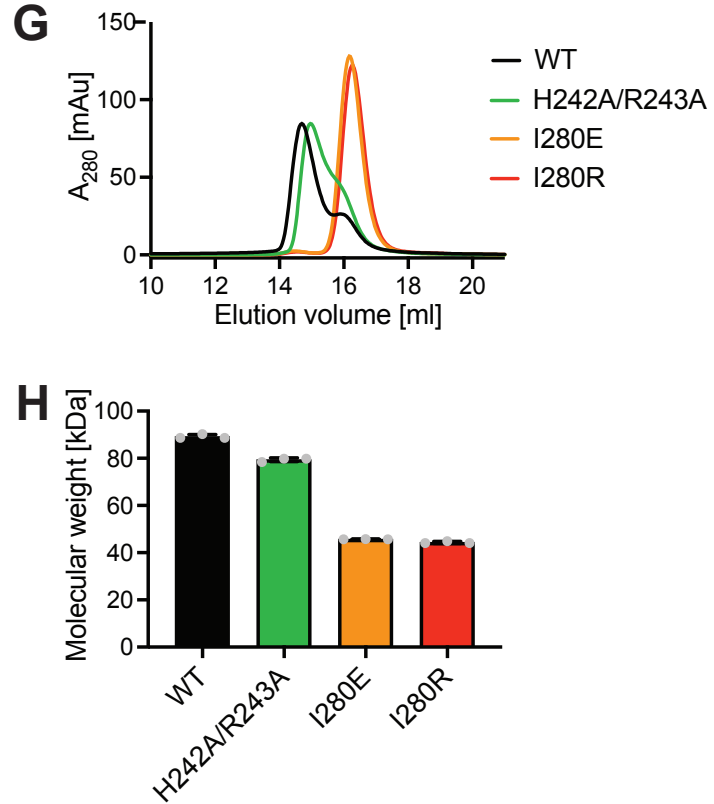
A

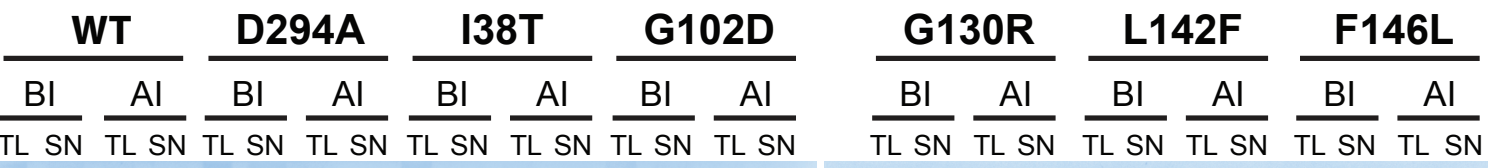
$\mathrm{kDa}$

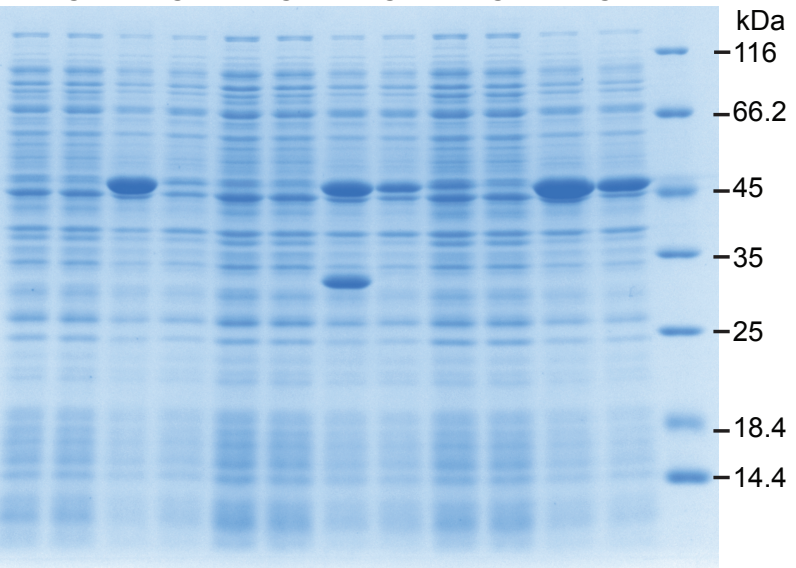

18.4-

$14.4-$

$\frac{\text { WT }}{\frac{B I}{T L S N} \frac{A l}{T L S N}} \frac{\text { A154P }}{\frac{B I}{T L S N} \frac{A l}{T L S N}} \frac{\text { T185A }}{\frac{B I}{T L S N} \frac{A l}{T L S N}} \frac{\text { S208T }}{\frac{B l}{T L S N} \frac{A l}{T L S N}}$

$\frac{\text { G226E }}{\frac{B I}{T L ~ S N ~} \frac{A l}{T L ~ S N ~}} \frac{\text { G265R }}{\frac{B l}{T L ~ S N ~} \frac{A l}{T L ~ S N}} \frac{\text { G265V }}{\frac{B I}{T L ~ S N ~} \frac{A l}{T L ~ S N ~}}$

$\mathrm{kDa}$ $116--$

$66.2-$

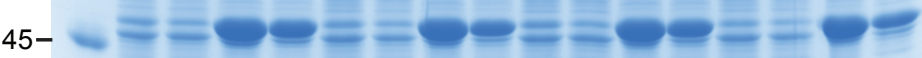
$35->$ $\frac{B}{T L S N} \frac{A}{T L S N} \frac{B}{T L S N} \frac{A}{T L S N} \frac{B}{T L S N} \frac{A}{T L S N}$

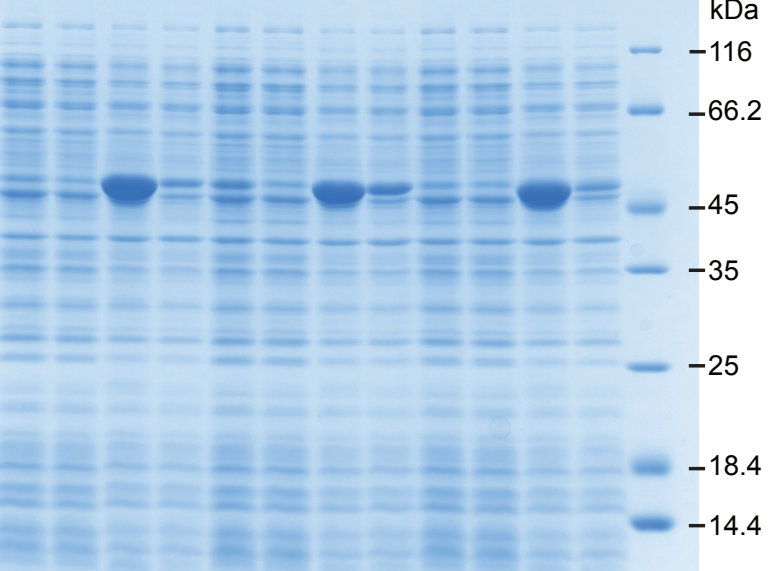

B

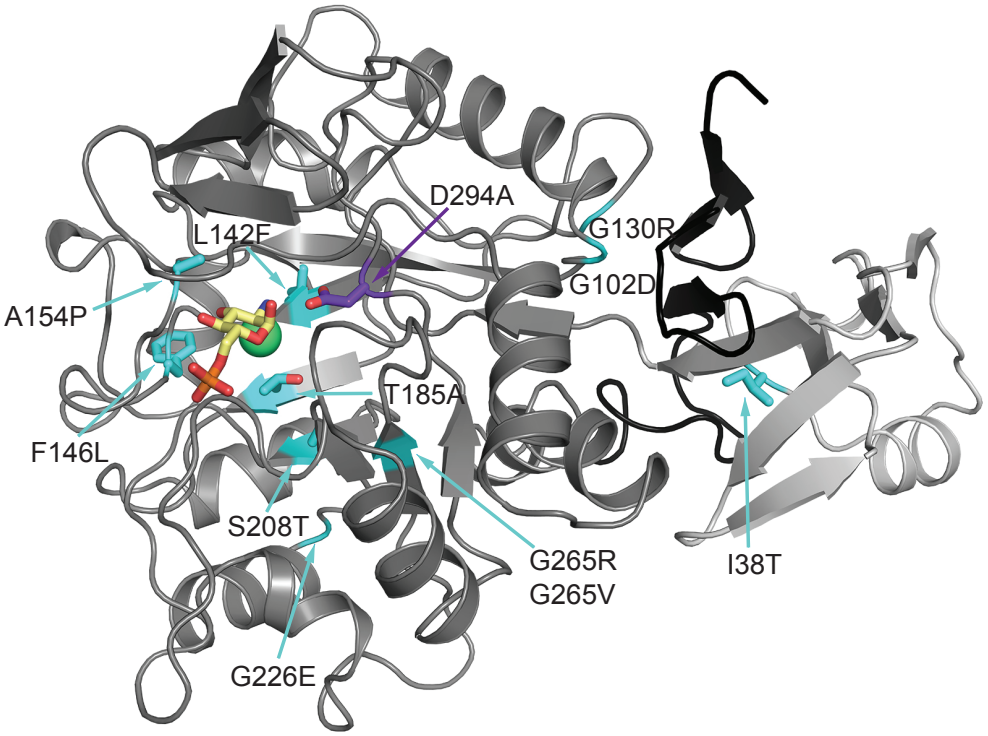

C

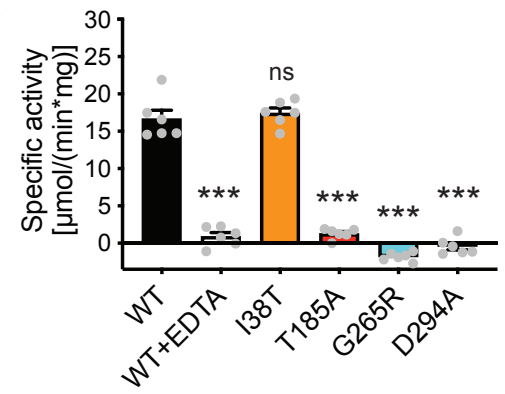




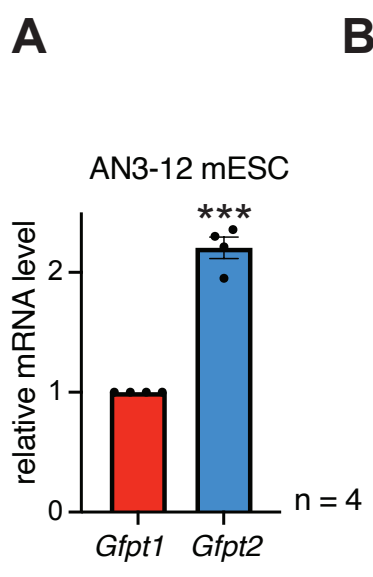

B
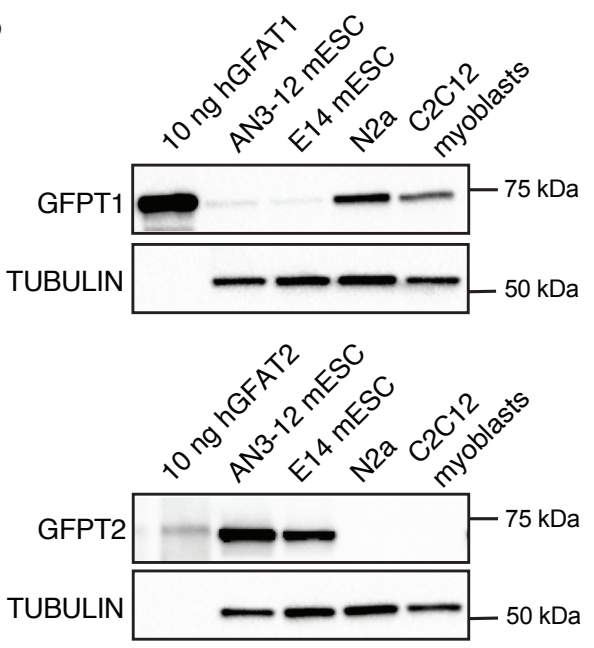

E

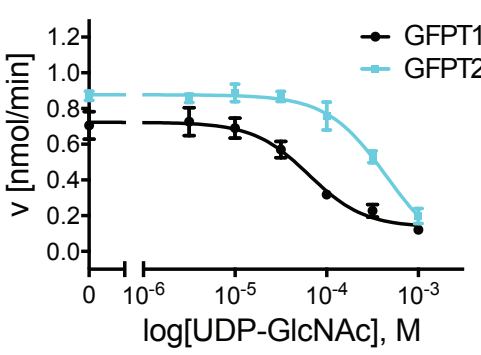

F

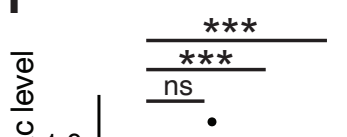

C

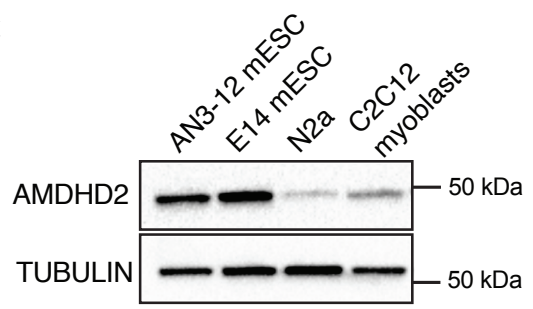

D

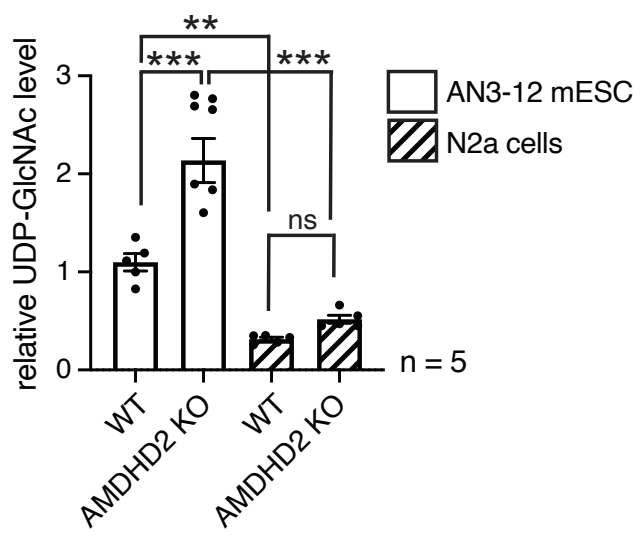

G
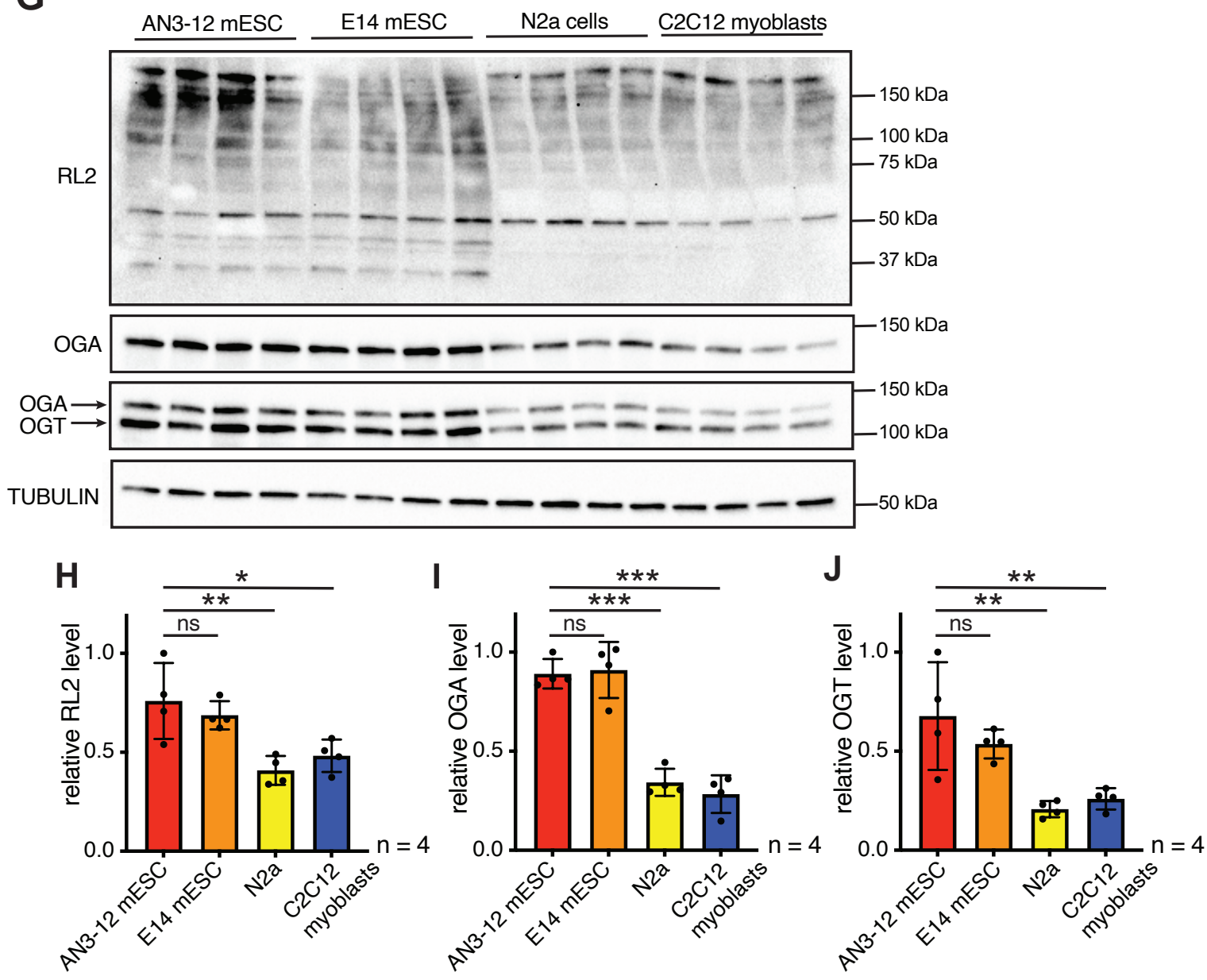
A

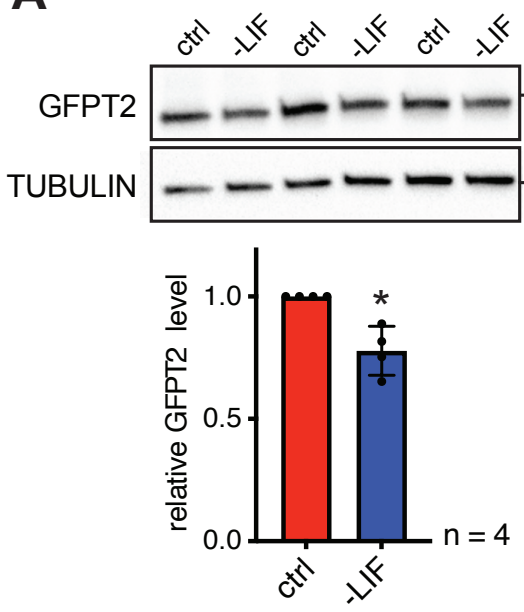

C

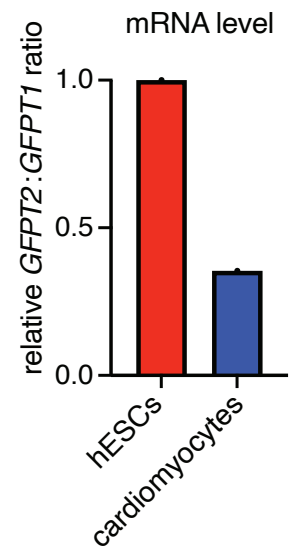

E

ESCs

high GFPT2:GFPT1 ratio

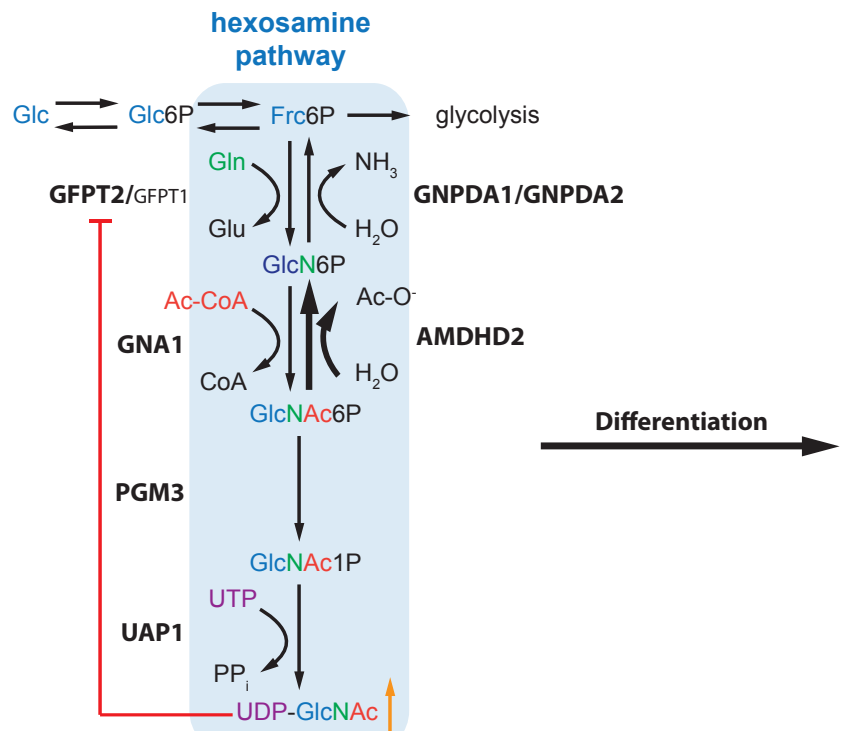

B

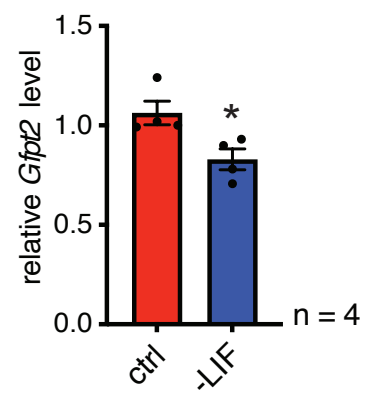

D

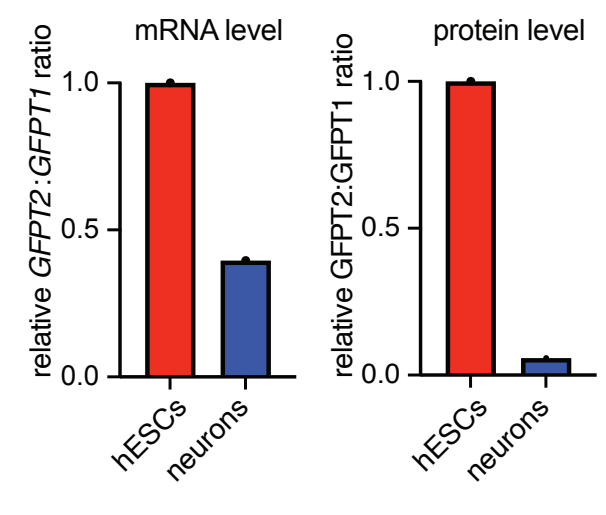

somatic cells

low GFPT2:GFPT1 ratio

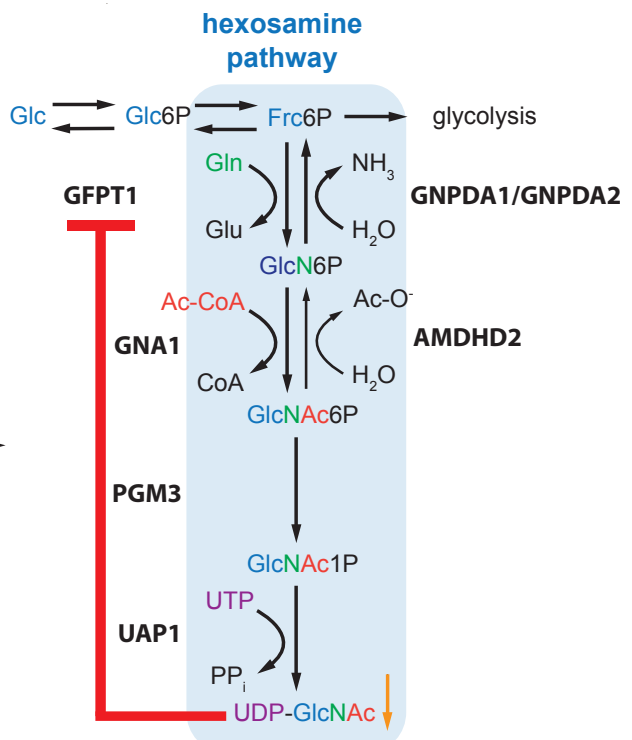


Figure 1-figure supplement 1

A ENU mutagenesis screen

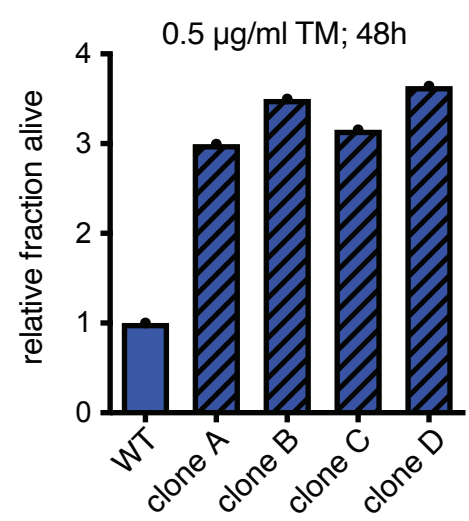

C

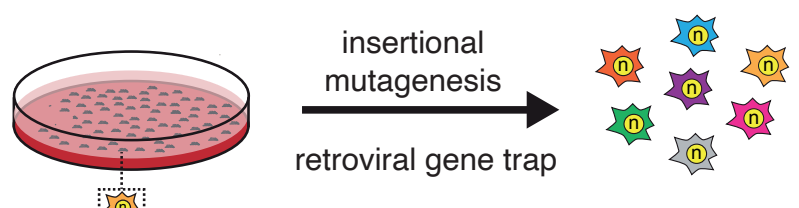

(i)

D

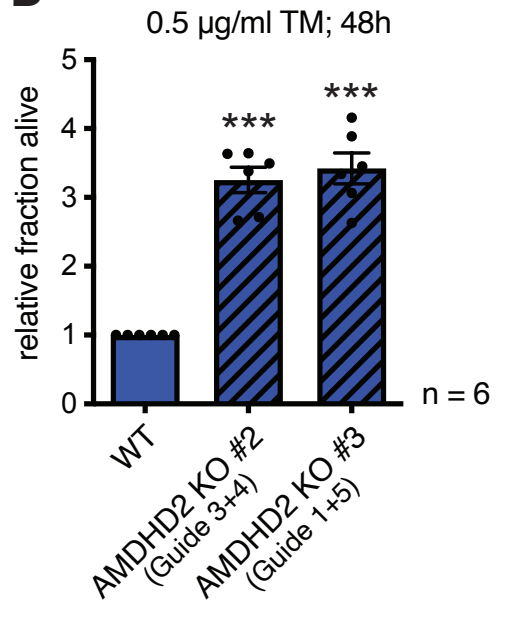

B

\begin{tabular}{|c|c|c|c|c|c|c|c|}
\hline clone & chrom & position & $\begin{array}{c}\text { REF } \\
\text { base }\end{array}$ & $\begin{array}{c}\text { ALT } \\
\text { base }\end{array}$ & gene & mutation type & $\begin{array}{c}\text { protein } \\
\text { consequence }\end{array}$ \\
\hline 1 & chr17 & 24300270 & A & G & Amdhd2 & missense variant & I38T \\
\hline 2 & chr17 & 24299998 & C & T & Amdhd2 & missense variant & G102D \\
\hline 3 & chr17 & 24295634 & C & T & Amdhd2 & missense variant & G130R \\
\hline 4 & chr17 & 24295479 & C & A & Amdhd2 & missense variant & L142F \\
\hline 5 & chr17 & 24295469 & A & G & Amdhd2 & missense variant & F146L \\
\hline 6 & chr17 & 24295445 & C & G & Amdhd2 & missense variant & A154P \\
\hline 7 & chr17 & 24295352 & T & C & Amdhd2 & missense variant & T185A \\
\hline 8 & chr17 & 24295283 & A & T & Amdhd2 & missense variant & S208T \\
\hline 9 & chr17 & 24295151 & C & T & Amdhd2 & missense variant & G226E \\
\hline 10 & chr17 & 24294954 & C & T & Amdhd2 & missense variant & G265R \\
\hline 11 & chr17 & 24294953 & C & A & Amdhd2 & missense variant & G265V \\
\hline
\end{tabular}

Selection for resistance

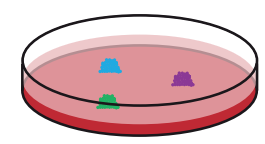

$0.5 \mu \mathrm{g} / \mathrm{ml} \mathrm{TM}$

Amdhd2 (20 \%)

$$
20 \text { clones } \begin{gathered}
\text { Mapping of integration site } \\
\text { by inverse PCR }
\end{gathered}
$$

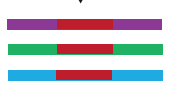


Figure 2-figure supplement 1

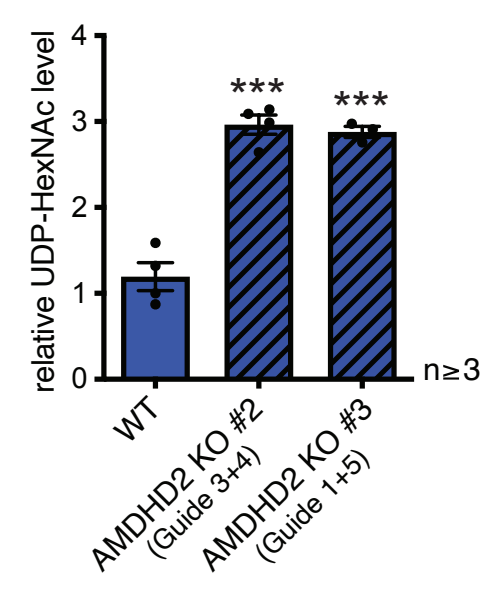


Figure 2-figure supplement 2
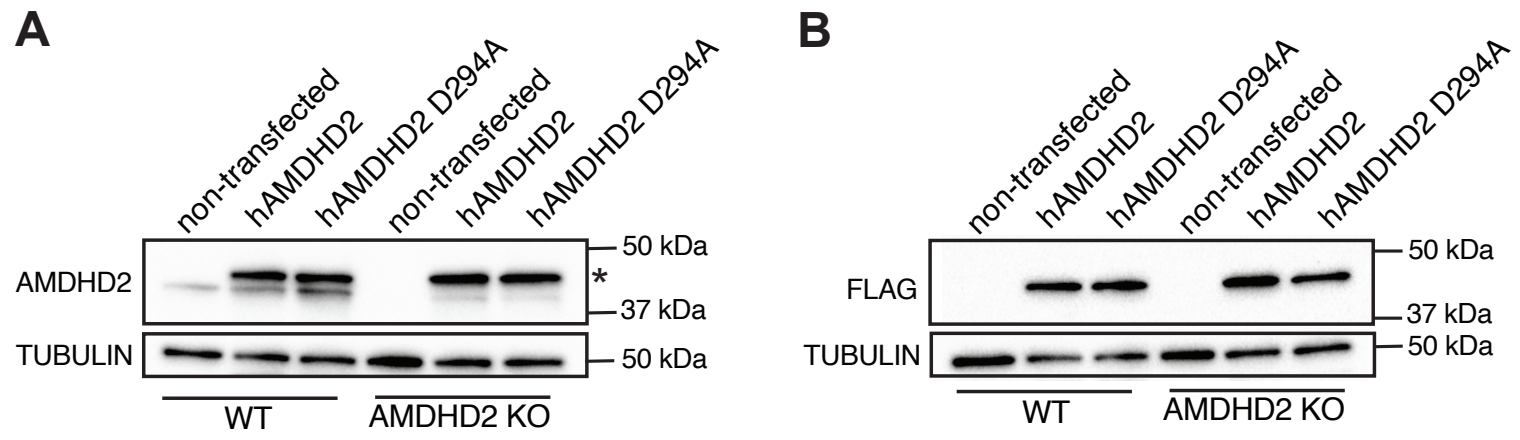
Figure 2-figure supplement 3

A

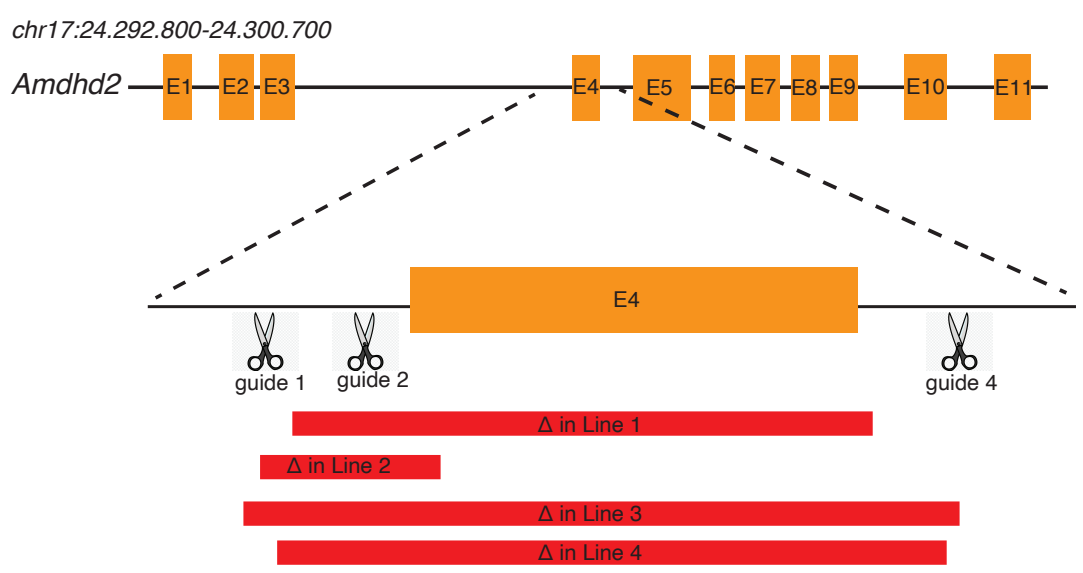

B

\begin{tabular}{c:c:c} 
Mouse Line & Guides & Deletion $(\Delta)$ \\
\hdashline 1 & $2+4$ & complete exon 4 \\
\hdashline 2 & $1+4$ & first 4 bp of exon 4 \\
\hdashline 3 & $1+4$ & complete exon 4 \\
\hdashline 4 & $1+4$ & complete exon 4 \\
\hdashline & $1+. .$. \\
\hdashline
\end{tabular}

C

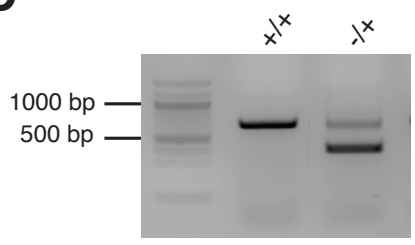


Figure 3-figure supplement 1
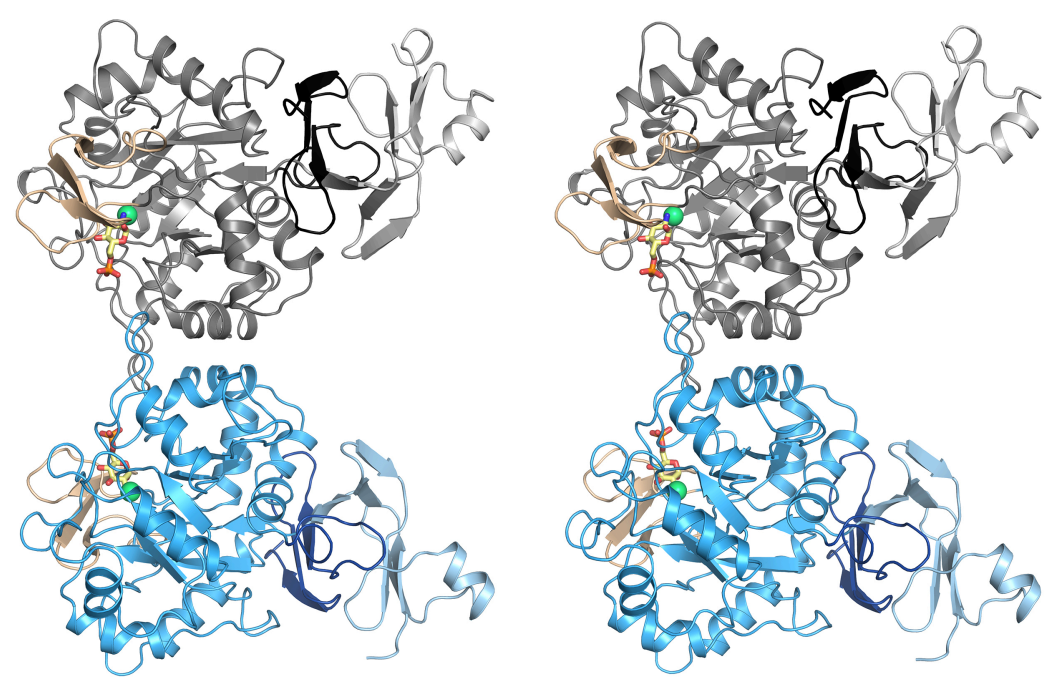
Figure 3-figure supplement 2
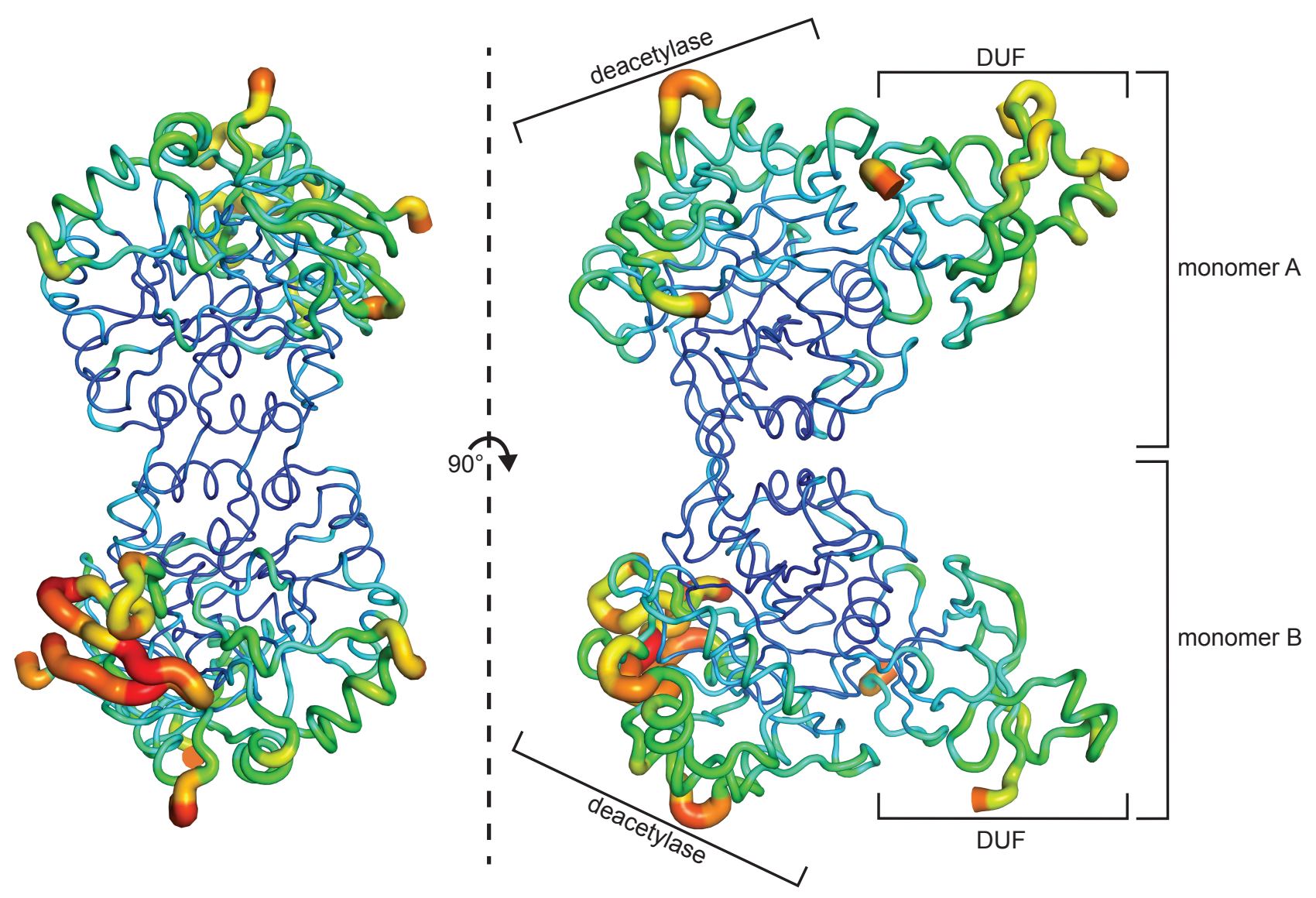
Figure 3-figure supplement 3

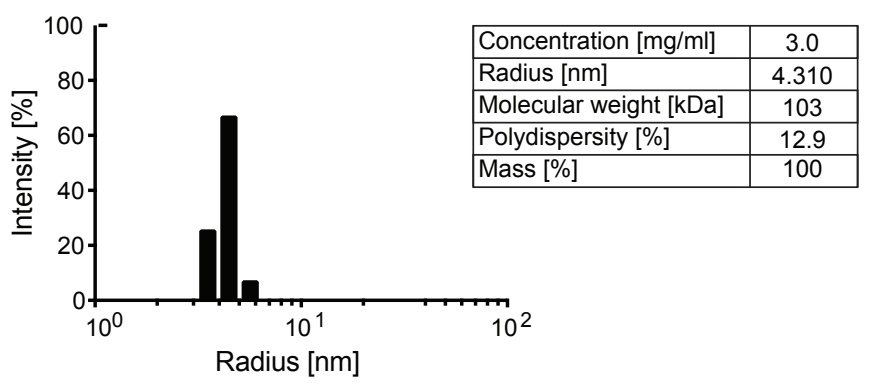


Figure 3-figure supplement 4

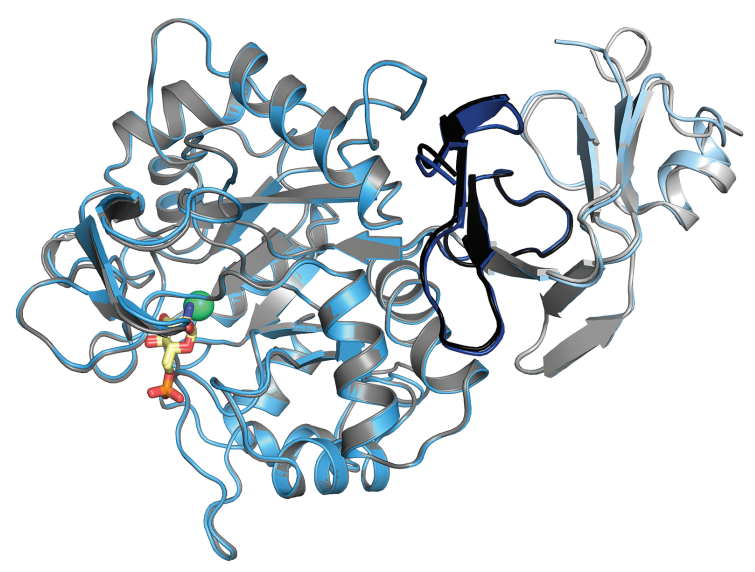


Figure 3-figure supplement 5

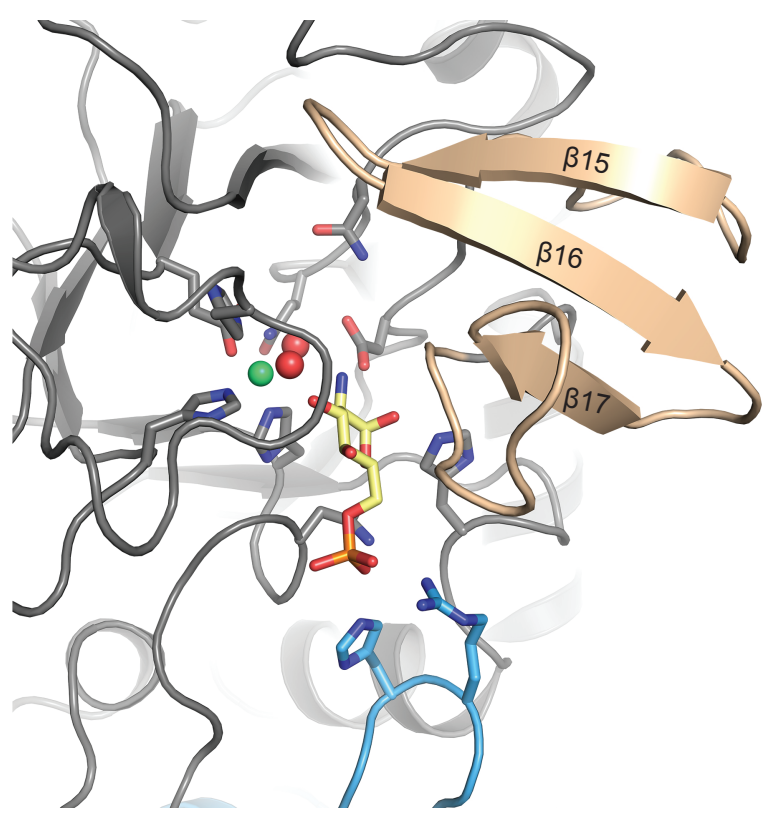


Figure 3-figure supplement 6
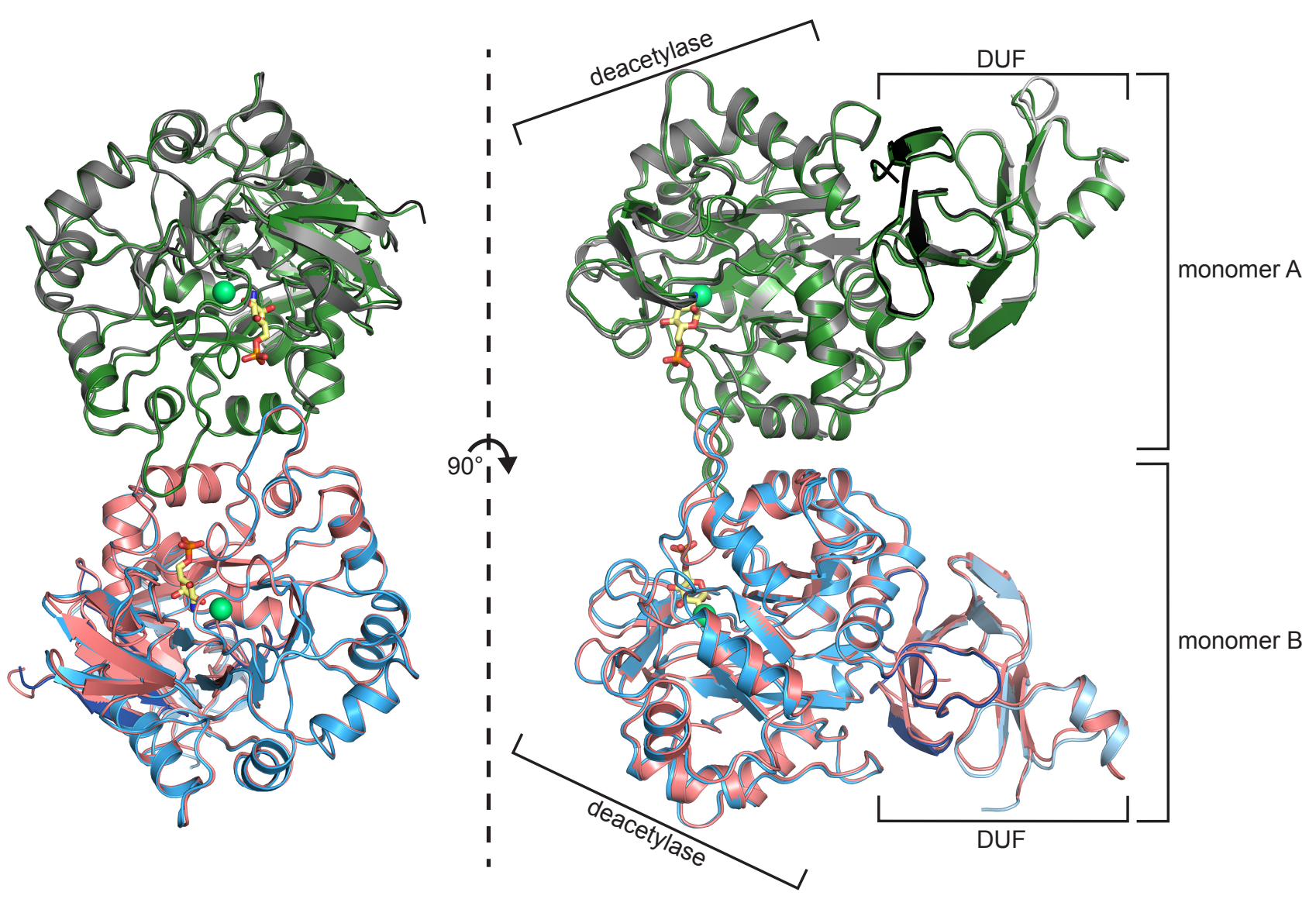
Figure 3-figure supplement 7
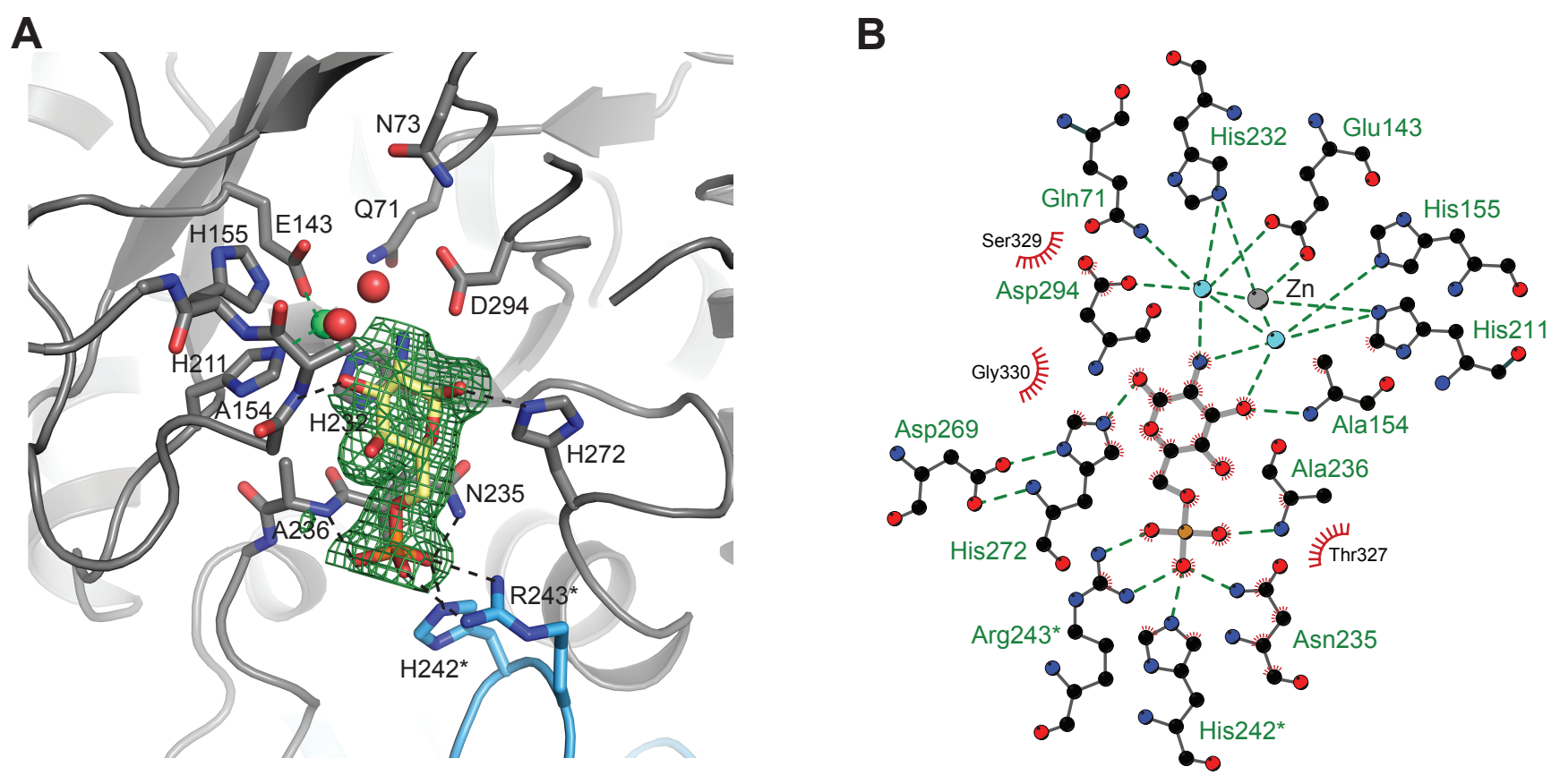
Figure 3-figure supplement 8
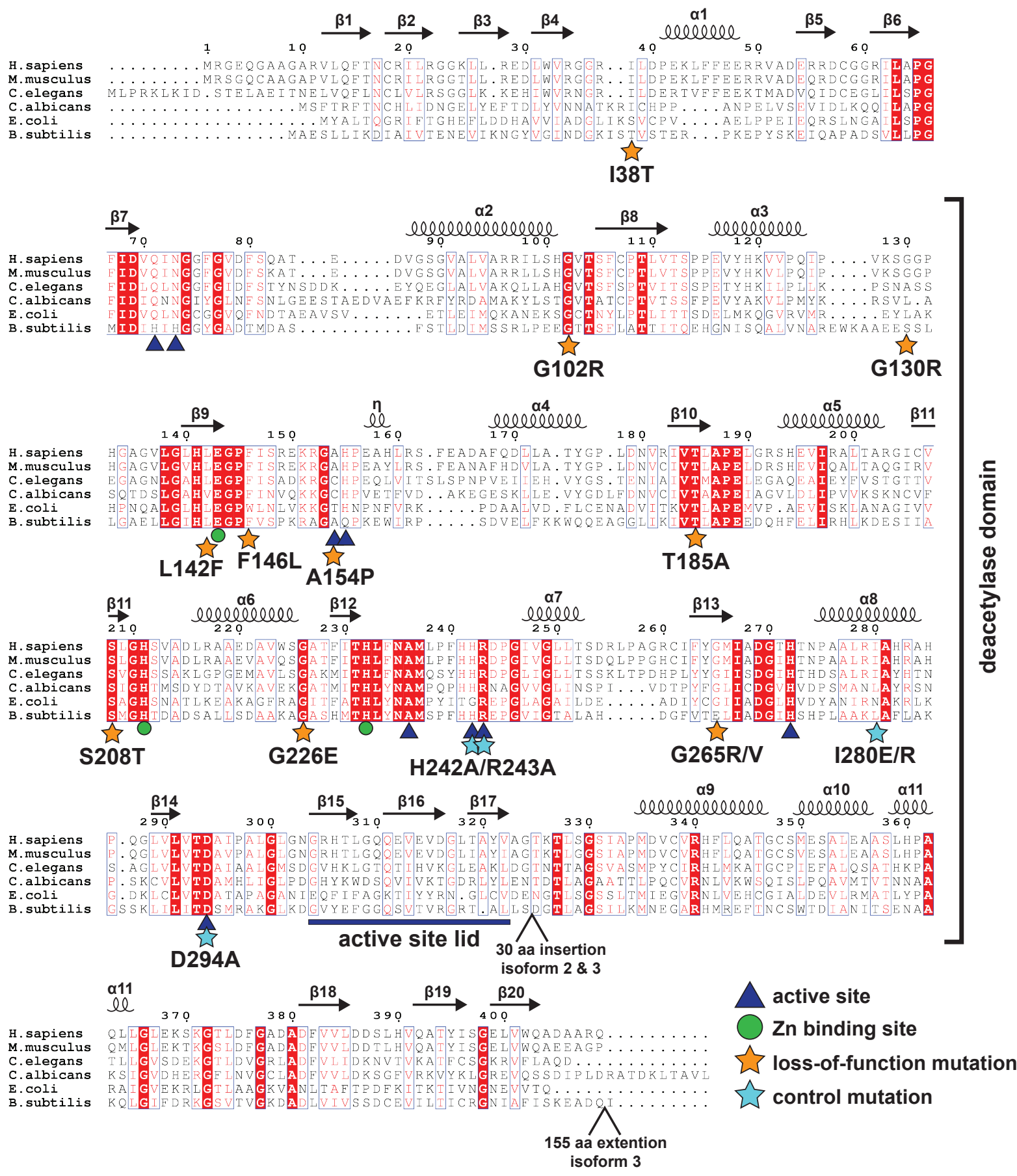
Figure 3-figure supplement 9

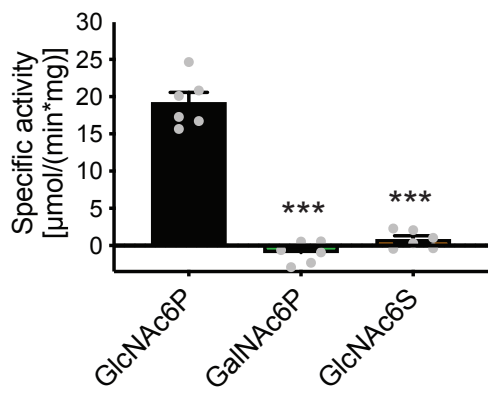


Figure 4-figure supplement 1

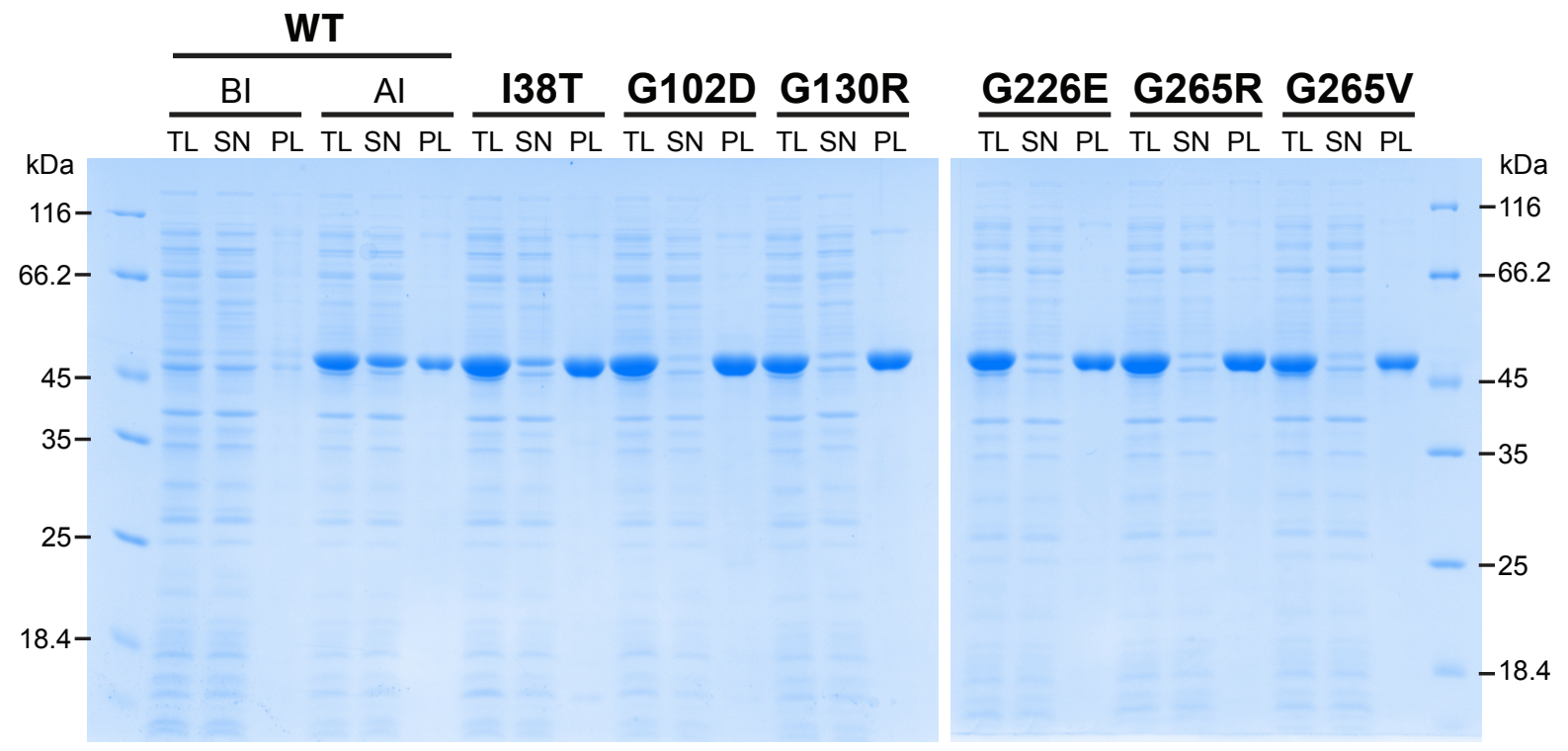


Figure 5-figure supplement 1

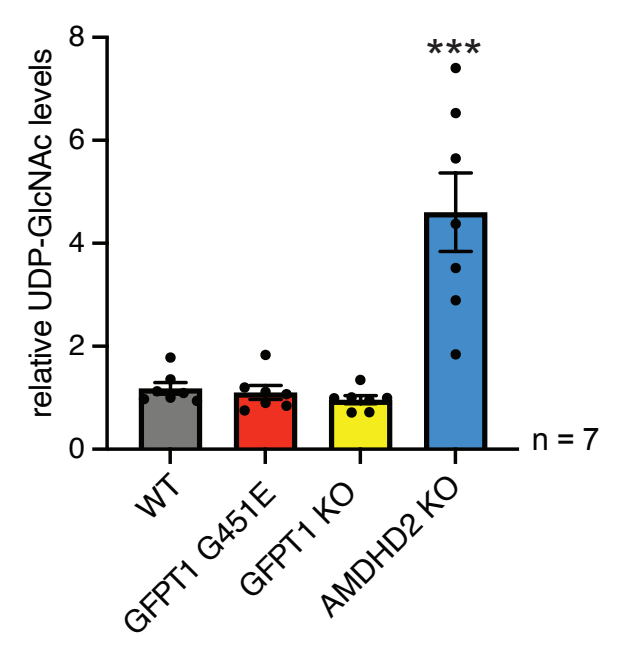


Figure 5-figure supplement 2

A

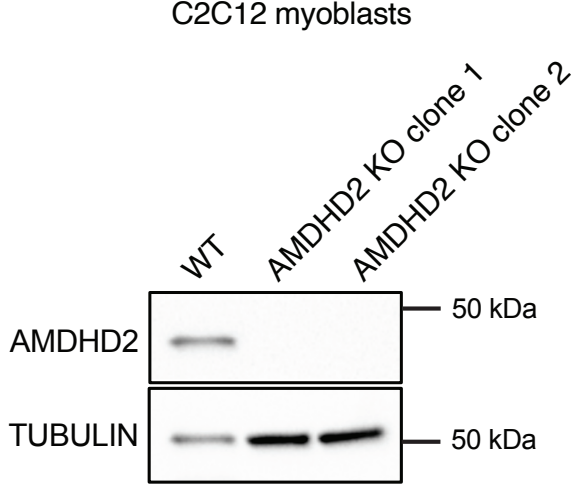

B C2C12 myoblasts

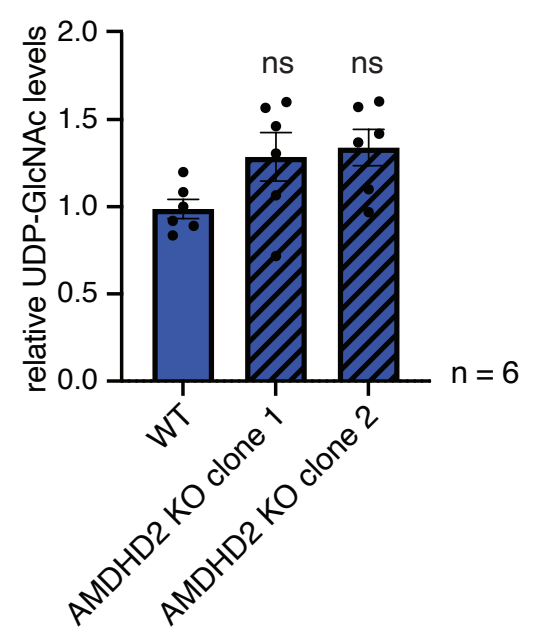


Figure 5-figure supplement 3

A

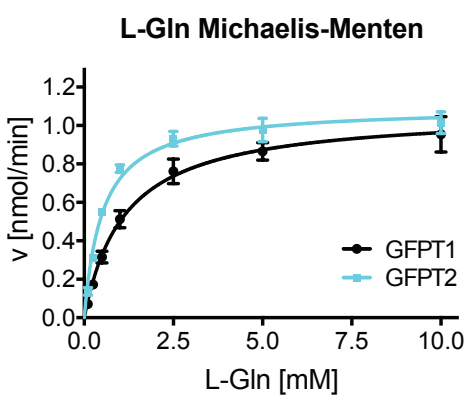

B

Frc6P Michaelis-Menten

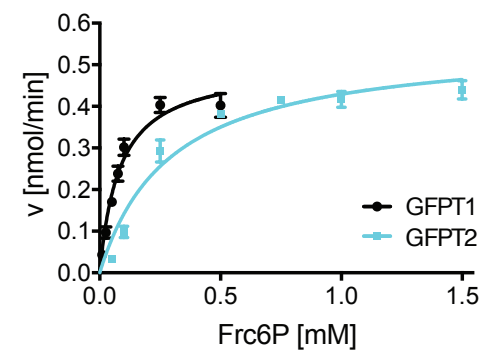


Figure 6-figure supplement 1
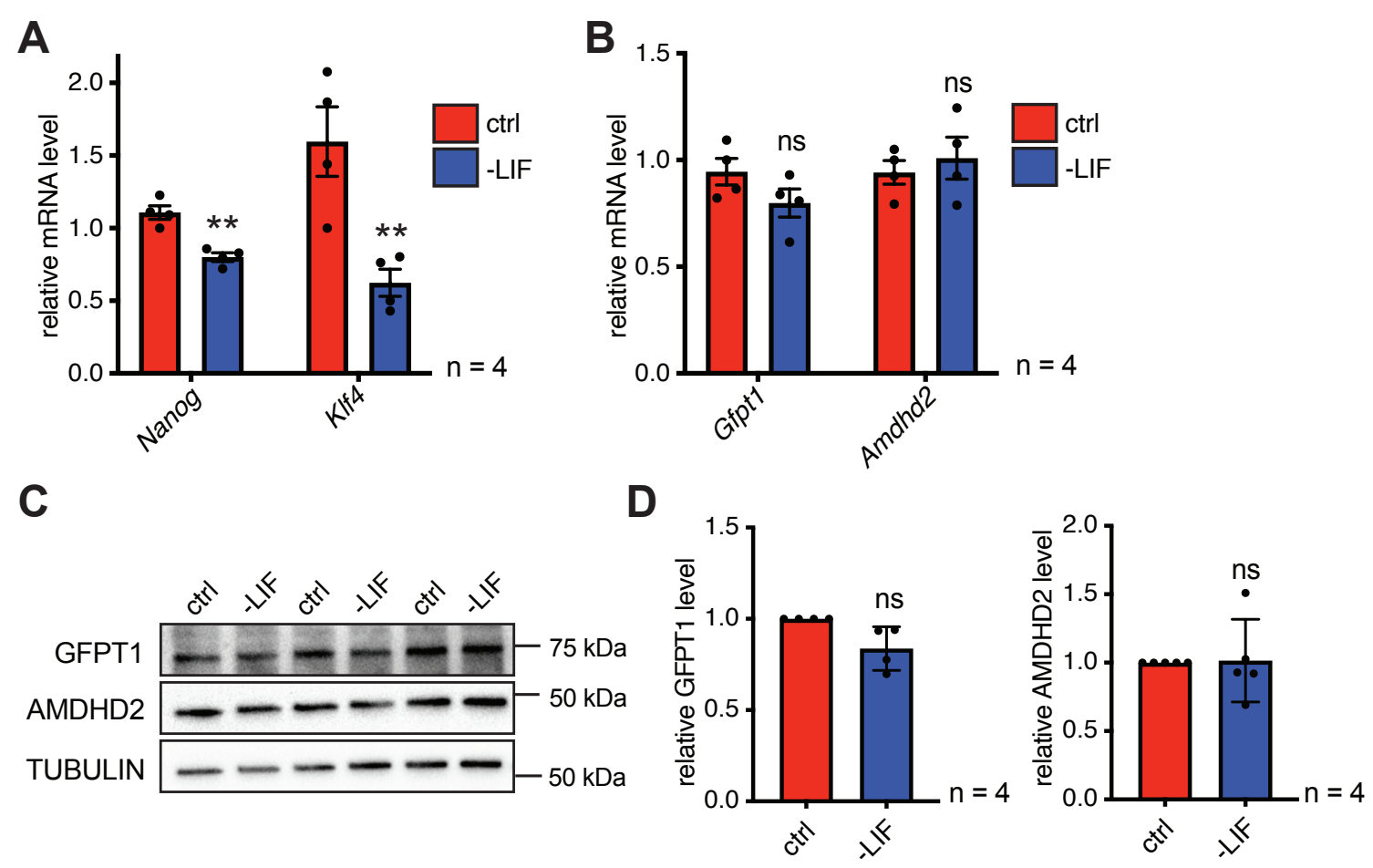